\section{General sessions (1A-01 - 3E-14)}

1A KOBOYASHI, Satoshi ${ }^{1}$, KAWAMOTO, Shyoko ${ }^{1}$ -01 MULJADI, Hendry ${ }^{1}$, ARAKI, Jiro ${ }^{4}$, TANIGUCHI, Takeaki $^{4}$, ITO, Takehiko ${ }^{4}$, MIYAZAKI, Satoru ${ }^{3}$, KUMA, Keiichi ${ }^{2}$, FUJIYAMA, Asao ${ }^{2}$ ('Transdisciplinary Res. Integration Cent., Res. Org. Inform. Systems, ${ }^{2}$ Principles of Inform. Res. Div., Natl. Inst. Inform., ${ }^{3}$ Faclt. Pharm. Sci., Tokyo Univ. Sci., ${ }^{4}$ Res. Cent. Adv. Sci. Tech., Mitsubishi Res. Inst.)

Construction of the web-based comparative genome viewer

In this report, we describe construction and usage of the Comparative Genome Viewer which is provided to the public through Japanese Bio-Portal site, Jabion (URL:http://www. bioportal.jp/). The viewer consisits of interactive interface through which users can retrieve desired data or jump to the original sites. The interface also allow users to use Japanese, although currently in partial, together with the Japanese translation of Entrez gene summary.
1A OSATO, Naoki ${ }^{1}$, GOJOBORI, Takashi ${ }^{1}\left({ }^{1}\right.$ DNA Data -03 Analysis Lab., Cent. Inform. Biol. DNA Data Bank Japan, Natl. Inst. Genet.)

Identification and characterization of human overlapping transcripts that affect their expression

Overlapping transcripts (OTs), which have different mRNAs on both strands of the DNAs at the same locus, have been identified from various species. Some OTs are known to decrease their expression level. However, it is still unclear what kinds of OTs affect their expression. Thus, we examined the expression level of human OTs using public microarray data. As a result, we found that positive correlation of gene expression is stronger in human OTs than randomly selected pairs of human mRNAs. In particular, exon-overlapping transcripts showed stronger correlation than non-exon-overlapping transcripts. These results suggest that interaction between different human OTs affect their expression level.
$1 \mathrm{~A}$ ABE, Takashi ${ }^{1,2}$, KANAYA, Shigehiko ${ }^{3}$, IKEMURA, -02 Toshimichi ${ }^{1}\left({ }^{1}\right.$ Nagahama Inst. Bio-Sci. Tech., ${ }^{2}$ CIBDDBJ Natl. Inst. Genet., ${ }^{3}$ Nara Inst. of Sci. and Tech.)

A Large-scale Batch-learning Self-organizing Map for Function Prediction of Poorly-characterized Proteins Progressively Accumulating in Sequence Databases

Homology searches have been used widely to predict functions of genes and proteins when genomes are newly decoded. As a result of decoding of genome sequences from a wide range of species, a large number of proteins whose function cannot be estimated by the homology search of amino acid sequences is progressively accumulated and remains of no use in science and industry. A method to estimate the protein function that does not depend on the sequence homology search is in urgent need. We previously developed a Batch-Learning SOM (BL-SOM) for genome informatics, which does not depend on the order of data input. The present study focused on BL-SOM analyses on di to tetra continuous amino acid frequencies. Concerning the oligopeptide frequencies in the 110,000 proteins which have been classified into 2,853 function-known COGs (clusters of orthologous groups of proteins), BL-SOMs that faithfully reproduced the COG classifications were obtained. This indicated that proteins, whose functions are presently unknown because of lack of significant homology with function-known proteins, can be related to function-known proteins with the BL-SOM.
1A KAWAI, Yosuke ${ }^{1}$, OOTA, Satoshi ${ }^{2}$, SAITOU, Naruya ${ }^{1}$ -04 ( ${ }^{1}$ Div. Popul. Genet., Natl. Inst. Genet., ${ }^{2}$ RIKEN Biores. Cent.)

Evolutionary dynamics of GC content of human genome

It is unclear how the genomic DNA GC content variation is maintained during mammalian evolution. We therefore inferred the regional equilibrium GC content from both within species (SNPs) and between species (divergence from chimpanzee) data of human and chimpanzee genomes to inquire the influence on the present GC contents. The equilibrium GC contents expected from both polymorphism and divergence data were lower than observed GC contents in many genomic regions, confirming a decline in GC content across the entire genome. However, we also found regions in which the equilibrium GC content expected from divergence data was higher than that expected from polymorphic data. This inconsistency of equilibrium GC content between polymorphism and divergence suggests that there is a weak force of either GC biased gene conversion or natural selection, which raises GC content than expected from mutation pressure. 
1 A SUZUKI, Rumiko ${ }^{1}$, EZAWA, Kiyoshi ${ }^{2}$, SAITOU, -05 Naruya ${ }^{2}$ ( ${ }^{1}$ Dept. Genet., Sch. Life Sci., Grad. Univ. Adv. Stud., ${ }^{2}$ Natl. Inst. Genet.)

Relationship between synonymous substitution and protein domains in mammals, fish, and insects

In order to examine the possibility that evolutionary rate of synonymous substitution, which doesn't alter amino acid sequences, might differ depending on gene characteristics, we examined synonymous substitutions among three pairs of mammalian species (human and rhesus monkey, mouse and rat, cow and dog) and found that genes those include specific protein domains commonly have low synonymous substitutions. We also conducted pairwise comparison between Takihugu and Tetraodon, and between Drosophila melanogaster and D. pseudoobscura. Genes with certain domains showed low $\mathrm{K}_{4}$ values all through the mammals, fish, and flies, while some gene groups showed lineage dependent differences. This result suggests that synonymous sites in protein coding regions are under some extent of selection pressure which is related to GC contents, codon biases, or other factors.

1 A TAKADA, Toyoyuki ${ }^{1,2}$, MITA, Akihiko ${ }^{2}$, MAENO, -06 Akiteru ${ }^{2}$, MORIWAKI, Kazuo ${ }^{3}$, YONEKAWA, Hiromichi ${ }^{4}$, SHIROISHI, Toshihiko ${ }^{2}$ ('Transdisciplinary Res. Integration Cent., Res. Org. Inform. Systems, ${ }^{2}$ Mammalian Genet. Lab., Natl. Inst. Genet., ${ }^{3}$ BioResource Center, RIKEN Tsukuba Inst., ${ }^{4}$ Lab. Animal Sci., The Tokyo Metro. Inst. Med. Sci.)

Genetic dissection of energy-metabolism related traits with Mouse Inter-Subspecific Consomic Strains

B6-ChrN ${ }^{\mathrm{MSM}}$ consomic strains were constructed by substituting every chromosome of a standard laboratory strain C57BL/6J by a chromosome counterpart of MSM/Ms strain derived from Japanese wild mouse. We performed systematic phenotyping of the B6-ChrN ${ }^{\mathrm{MSM}}$ strains and two parental strains C57BL/6J and MSM/Ms, focusing on metabolism-related complex traits. This study successfully detected a large number of significant QTLs for metabolism-related traits. All the results showed that the established inter-subspecific consomic mouse strains would provide a powerful tool to identify latent genetic factors underlying the energy-metabolism related complex traits. Based upon the strain difference, we intend to explore genes underlying the complex obesity traits by using $\mathrm{F} 2$ crosses of $\mathrm{B} 6$ and a relevant consomic strain as well as congenic strains derived from the consomic strain.
$1 \mathrm{~A}$ TANAKA, Shigekazu${ }^{1}$, MIURA, Ikuo ${ }^{2}$, YOSHIKI, -07 Atsushi, KATO, Yoriko ${ }^{3}$, YOKOYAMA, Haruka ${ }^{2}$, SHINOGI, Akiko' ${ }^{2}$ MASUYA, Hiroshi' ${ }^{2}$, WAKANA, Shigeharu $^{2}$, TAMURA, Masaru ${ }^{1}$, SHIROISHI, Toshihiko ${ }^{1}\left({ }^{1}\right.$ Natl. Inst. Genet., Mammalian Genet. Lab., ${ }^{2}$ RIKEN GSC, ${ }^{3}$ RIKEN BRC)

Genetic and functional analysis of mouse Type-I IRS keratin mutations, Re, Re-wavy coat and M100573

Keratins, a family of intermediate filament (IF) proteins. They are involved not only in the mechanical and structural functions, but also in cell growth and differentiation of epithelial tissue. Mutations of several type II inner root sheath (IRS) keratin, such as Caracul $(\mathrm{Ca})$ and its alleles, were reported, whereas no mutation has been reported for the type I IRS keratin. In this study, we demonstrated that two classical mutations, $R e$ and Rewavy coat $\left(R e^{w c}\right)$, and an ENU-induced mutation M100573 have genetic alterations in type I IRS keratin genes. Re and M100573 bear mutation in $K r t 25$, and $R e^{w c}$ bears a mutation in $K r t 27$. These three mutations are located in the helix termination motif of the $2 \mathrm{~B}$ a-helical rod domain of the type I IRS keratin protein. Immunohistological analysis revealed that the IRS of Re/+ mice have abnormal foam-like immunoreactivity with an antibody raised to type II IRS keratin K71. These results suggest that the helix termination motif is essential for the proper assembly of type I and II IRS keratin protein complexes and the formation of keratin intermediate filaments.

1A MASARU, Tamura ${ }^{1}$, TANAKA, Shigekazu ${ }^{1}$, FUJII, -08 Tomoaki ${ }^{1}$, KATO, Yoriko ${ }^{1}$, SHIROISHI, Toshihiko $\left({ }^{1}\right.$ Natl. Inst. Genet., Mammalian Genet. Lab.)

Association of Gasdermin family and human diseases

Gasdermin $(G s d m)$ is a novel gene family consisting of eight structurally related genes in the mouse. One of the members was originally identified as the responsible gene of a dominant mouse skin mutant, Recombination-induced mutation 3 (Rim3), which exhibits mis-differentiation and hyper-proliferation of the epidermis. Based on analysis of Rim3 phenotype and expression patterns of the other Gsdm members, a combination of the family genes may play a key role in differentiation and homeostasis of epithelial cells in mouse skin and gastrointestinal tract. However, function of human GSDM family genes has remained unanswered. To elucidate the function of GSDM family genes in the human, we carried out genome analysis of the GSDM family gene locus. In the human, GSDM family consists of four genes, GSDMA, GSDMB, GSDMC and GSDMD, and these genes are located on the genomic regions closely related to cancer. Further genome analysis suggested that abnormal functions of GSDM family genes may cause cancer development. In addition, we also report results of promoter analysis of the human GSDM family genes. 
$1 \mathrm{~A}$ YEE, Liimien ${ }^{1}$, MATSUOKA, Satoshi ${ }^{2}, \mathrm{ASAI}, \mathrm{Kei}^{1}$, -09 SADAIE, Yoshito ${ }^{1}{ }^{1}$ Grad. Sch. Sci. Eng., Saitama Univ., ${ }^{2}$ Section of Molec. Cell. Biol., Univ. California)

Identification and Analysis of nonA genes, which affect the propagation of Bacteriophage SP10 in Bacillus Subtilis

Simultaneous presence of mutations in nonA and nonB loci is necessary for SP10 phages to propagate in Bacillus Subtilis Marburg strain. Previous study revealed that non $B$ mutation is a nonsense mutation of $B s u \mathrm{M}$, the only restriction and modification system in Bacillus Subtilis, and nonA mutation is the cured state of a prophage SP $\beta$. The objective of this study is to identify the causal gene of nonA mutation, and to reveal its function and the infection mechanism of SP10. We have constructed strains harboring partially deleted SP $\beta$ with nonB background and they were tested for SP10 permissiveness. As the results, yon $O$ and genes in $s s p C \sim y o s T$ region were found to be the causal genes for the nonA mutation. Furthermore, we monitored how those gene products block propagation of the SP10 phage genome.

1 A SHUTO, Satoshi ${ }^{1}$, KUSAKA, Jin ${ }^{1}$, HARA, Hiroshi ${ }^{1}$ -10 MATSUMOTO, Kouji ${ }^{1}\left({ }^{1}\right.$ Dept. Biochem. and Mol. Biol., Grad. Sch. Sci. Eng., Saitama Univ.)

Analysis of the mechanisms that underlie septal localization of phospholipid systhases in Bacillus subtilis.

Cardiolipin (CL) is one of major anionic phospholipids that compose Bacillus subtilis cell membrane. The recent development of specific probe for lipid molecule and of fluorescent protein has revealed that CL is localized at the septum and cell poles and that the major CL synthase, ClsA is also localized in a similar pattern. The mechanisms and the role of the localization are not known. To address the question, we are trying first to determine the region, in the ClsA amino acid sequence, involved in its septal localization and secondly to investigate the relationship between the septal localization and the activity in CL biosynthesis.
1A GE, Liying ${ }^{1}$, HANDA, Naofumi ${ }^{1}$, HIROSE, Aya ${ }^{1}$, -11 KOBAYASHI, Ichizo ${ }^{1}\left({ }^{1}\right.$ Grad. Sch. Front. Sci.s, The Univ. Tokyo)

Use of DNA modification gene as an alternative to antibioticresistance genes for selection of transfer and maintenance of foreign genes

Antibiotic-resistance genes are used in combination with antibiotics for selection of foreign genes during their transfer and maintenance. However, most of the available antibiotics are effective for only a narrow range of bacteria. This forms a technical limit to genetic analysis and manipulation. Moreover, use of antibiotics may promote spread of antibiotic-resistance genes and their carrier bacteria, which poses a serious environmental and public health problem. We found that the DNA modification $(M)$ gene, in the presence of the cognate DNA restriction $(R)$ gene, can serve for gene selection. The principle is simple: Cell that has lost a modification enzyme gene would be forced to death through attack by a restriction enzyme on its chromosome. Our study using EcoRI gene proved that, while expressing the $R$ gene, a plasmid containing $M$ gene could be selected and maintained. Use of DNA modification genes as selection markers would be feasible. 
2A NAKAMURA, Taro ${ }^{1}$, NARITA, Takanori ${ }^{2}$, MORITA, -01 Masayo ${ }^{1}$, YE, Yanfang ${ }^{1}$, YAMAZAKI, Yukiko, KOHARA, Yuji ${ }^{2}$, SHIMODA, Chikashi ${ }^{1}$ ( ${ }^{1}$ Dept. Biol., Grad. Sch. Sci., ${ }^{2}$ Center for Genetic Resource Information, Natl. Inst. Genet.)

A large-scale full length cDNA analysis in fission yeast

We have constructed a full-length cDNA library, which is composed of $1.6 \times 10^{6}$ clones. The 5' and 3' terminal sequences of 22,600 clones were determined and were assembled into about 5,000 clusters. The percentage of full-length cDNAs reaches $86 \%$. The BLAST search indicates that the library covers at least $74 \%$ of the known ORFs annotated by the genome sequencing project. In addition, many novel ORFs and putative RNA products were found. Furthermore, several published ORFs have been corrected by newly found 5' termini and introns. Our large-scale full-length cDNA analysis determined accurate transcriptional start sites and also deduced the 3' terminus of the transcripts. Although the analysis has not been finished yet, the current data reveal the following facts. 1, Roughly half of the transcripts start at less than 150 bp upstream of the ATG initiation codon. 2, A few genes are transcribed from multiple start sites. 3, Overlapping transcription on both strands are found in several genes. This study was supported by the genome analysis program of the National BioResource Project of Japan, NBRP.

2A HANAJIMA, Isao ${ }^{1}$, OHTA, Niji ${ }^{1}\left({ }^{1}\right.$ Dept. Molec. Biol., -02 Faclt. Sci., Saitama Univ.)

Construction of cDNA library of unicellular red alga Cyanidium caldarium RK-1

Cyanidium caldarium is a kind of unicellular red algae and widely distributes acidic hot springs. This alga is thought to highly relate to Cyanidioschizon merolae whose genome is completely sequenced, though there are some difference such as the mode of division or the character of their cell walls.C. caldarium often used for the study of photosynthesys. It will be interesting to investigate the similarity of the genes of $C$. caldarium to those of $C$. merolae and to other species. In this study we constructed the cDNA library of $C$. caldarium and sequenced approximate $600 \mathrm{bp}$ from 5' end, and similarity searches were performed to other sources by using BLASTX program. The results showed approximate $80 \%$ of the genes showed highly similarity tothose of $C$. merolae.
2A FAWCETT, Jeffrey $^{1}$, ROMBAUTS, Stephane ${ }^{1}$, -03 PATTYN, Pedro ${ }^{1}$, STERCK, Lieven ${ }^{1}$, VAN DE PEER, Yves ${ }^{1}$ ( VIB, Dev. Plant Systems Biol., Gent Univ.)

The annotation and analysis of the genome of Arabidopsis lyrata

Sequencing of the whole genome of various species has significantly advanced our understanding of the structure and evolution of genes and genomes. Annotation of the genome is an important aspect of a genome project because most subsequent analyses will heavily rely on that annotation. As an increasing number of genomes are being sequenced, a major challenge lies in providing an efficient and accurate annotation. Our group has been involved in the annotation, gene prediction in particular, of several genomes. Gene prediction in our group is done using a gene prediction program called EuGene, which makes use of sequence homology, and also splice site analysis and probabilistic models. Here, we describe our effort on gene annotation by using the ongoing annotation of the genome of Arabidopsis lyrata as an example. Using our resulting annotation, we also present an overview of the genes and genome of A. lyrata in comparison to $A$. thaliana.

2A YAMAMOTO, Yoshiharu Y. ${ }^{1}$, OBOKATA, Junichi ${ }^{1}$ -04 ( ${ }^{1}$ Cent. Gene Res., Nagoya Univ.)

Development of high density TSS mapping of Arabidopsis and establishment of a plant promoter database

We have developed a novel method for large scale TSS mapping. The method is composed of a combination of Cap Trapper for preparation of 5' end of full-length cDNA, and Massively Parallel Signature Sequencing (MPSS) for high throughput DNA sequencing. Using this novel method, called CT-MPSS, we have prepared large scale TSS information from Arabidopsis. We have previously identified novel core promoter elements from plant promoters, and their relationship to transcriptional characteristics was analyzed using the TSS information. The information of novel core promoter elements and large scale TSS analyses are served by our database. 
2A INAGAKI, Yoshishige ${ }^{1}$, MUTSUKADO, Yukako ${ }^{1}$, -05 TOYODA, Kazuhiro ${ }^{1}$, SHIRAISHI, Tomonori ${ }^{1}$, ICHINOSE, Yuki ${ }^{1}$, OSBOURN, Anne ${ }^{2}\left({ }^{1} \mathrm{Grad}\right.$. Sch. Natural Sci. Tech., Okayama Univ., ${ }^{2}$ Metabolic Biol. Dept., John Innes Centre, Norwich, UK)

Molecular analysis for genome structure and gene expression of Oxidosqualene Cyclase genes in rice seedling

Triterpenoid saponins are suger-modified triterpene derivatives that have various functions, anti-cancer, anti-oxidant, and antimicrobial. Cereals and grasses, like wheat, barley, maize, and rice, are generally deficient in this secondary metabolite with the exception of oats. In oats, this saponin was implicated as determinants of the resistance to the root-infecting fungus Gaeumannomyces graminis. We were not able to detect triterpenoid saponins and intermediate compounds of the metabolite in these metabolite profiles of rice plant using LC/MS and GC/MS. Our final goal is that the anti-microbial saponin is available for the rice plant. Therefore, to be clear this secondary metabolite biosynthesis pathway in rice plant, we are performing molecular analyses. First, we focused one of the pivotal genes, Oxidosqualene cyclase $(\mathrm{OsOSC}$ ), on the sterols/triterpeneoids biosynthesis pathway, and performed gene expression and evolution analyses. In this time, we report that we found eleven OsOSC homologues in the rice genome using the knowledge from oats, and five out of eleven were likely to pseudogenes from the data of genome structures and gene expression analyses.

2A OGIHARA, Yasunari ${ }^{1}$, SAEKI, Asuka ${ }^{2}$, MORITA, -06 Shigeto $^{2}$, MASUMURA, Takehiro ${ }^{2}$, SATOH, Shigeru ${ }^{2}$, KAWAURA, Kanako ${ }^{1}$ ( ${ }^{1}$ Kihara Inst. Biol. Res., Yokohama City Univ., ${ }^{2}$ Grad. Sch. Agr., Kyoto Pref. Univ.)

Silencing of paternally transmitted mitochondrial genes in alloplasmic wheat

Three mitochondrial genes, namely orf25, rps7, atp6 of Aegilops crassa, confer structural alterations around their promoter regions in comparison to those of common wheat (Triticum aestivum cv. Chinese Spring, CS). PCR analysis to detect such structural alterations showed that each of three lines, pure lines and alloplasmic wheat $\{(\mathrm{cr})-\mathrm{CS}\}$ contains both genotypes, although mitochondrial genotypes of CR in CS, those of CS in $\mathrm{CR}$ were still remained as minor fractions. CS mitochondrial gene frequencies in $\{(\mathrm{cr})-\mathrm{CS}\}$ were grown to be ca. $30 \%$. SNPs analysis of these genes indicated that minor types of all mitochondrial genes in alloplasmic wheat were transmitted through pollens. Since the frequencies of paternally transmitted mitochondrial genes in $\mathrm{F}_{1}$ were about $20 \%$, frequencies of paternally transmitted mitochondrial genes were increased by successive back crossing. Expression profiles of those mitochondrial genes were quantitatively analyzed by RT-PCR. Products of paternally transmitted mitochondrial genes were scarcely found. These lines of evidences strongly suggest that paternally transmitted genes/genomes are silenced in the descendants.
2A UEMATSU, Norio ${ }^{1}$, BORDE, Valerie ${ }^{2}$, ROBINE, -07 Nicolas $^{2}$, NICOLAS, Alain ${ }^{2}\left({ }^{1}\right.$ Heavy-Ion Radiobiology Research Group, Research Center for Charged Particle Therapy, National Institue of Radiological Sceiences, Chiba, Japan, ${ }^{2}$ UMR 7147, Institut Curie)

Targeted DSB formation by QQR-Spo11 fusion protein

In meiosis, DNA double strand breaks (DSBs) formation and following recombinational repair are essential for adequate reductional chromosomal segregation. The meiotic DSB sites are not randomly distributed along chromosomes. For example, in budding yeast, the meiotic DSBs are prone to be introduced at some promoter-containing intergenic regions. The precise mechanism how these regions are determined is still elucidated. It has been shown that at least 10 proteins are required for the DSB formation and within, Spo11 is believed to catalyze this process. We show that if fused with DNA binding domain, such as QQR, artificial zinc finger motif, these fusion proteins are able to introduce DSBs near to the binding sites. Moreover, we show that QQR-Spo11 also introduce DSBs at the regions where the binding sequence is missed. The detail data would be shown.

2A HABU, Yoshiki ${ }^{1}$, ANDO, Tsuyu ${ }^{2}$, ITO, Sachie ${ }^{2}$, -08 KISHIMOTO, Naoki ${ }^{1}$, TAGUCHI-SHIOBARA, Fumio $^{1}$, YANO, Masahiro ${ }^{1}\left({ }^{1}\right.$ Div. Plant Sci.s, Natl. Inst. AgroBiol. Sci., ${ }^{2}$ Inst. of Society for TechnoInnovation of Agr., Forestry and Fisheries)

Effect of epigenetic chromatin modification on meiotic recombination and segregation distortion in an inter-subspecific hybrid of rice

In this study, by using a rice inter-subspecific cross (Oryza sativa L. japonica x Oryza sativaa L. indica), we analyzed the effect of epigenetic changes in chromatin modification in the $F_{1}$ hybrid on the pattern of meiotic recombination and segregation distortion. Both of knockdown of the rice DDM1 gene, that is required for maintenance of DNA and histone modification, and inhibition of histone deacetylaces by trichostatin A (TSA) induced DNA demethylation in the centromeric repeats. Genotyping of the whole chromosome 3 of their selfed $\mathrm{F}_{2}$ progenies revealed that DDM1-knockdown and TSA treatment showed similar but not identical alterations of meiotic recombination and segregation distortion. The results suggest that the state of chromatin affects meiotic recombination and segregation of homologous chromosomes. 

Daisuke $^{1}$, KANAZAWA, Akira ${ }^{2}$, SANO, Yoshio ${ }^{1}\left({ }^{1}\right.$ Lab. Plant Breeding, Grad. Sch. Agr., Hokkaido Univ., ${ }^{2}$ Lab. Cell Biol. and Manipulation, Grad. Sch. Agr., Hokkaido Univ.)

Hybrid male sterility induced by $S 13$ found in a distantly related rice species.

The hybrid sterility has been studied in rice to understand the development of reproductive barriers during speciation. We report here a hybrid sterility gene detected from a cross between Asian rice (Oryza sativa) and African wild species (O. longistaminata) with the AA genome. We found that the gene $S 13$ carried by $O$. longistaminata induced abortion of the microspores with the alternative allele $\left(S 13^{a}\right)$ carried by a Japonica strain (T65) only in the heterozygote $\left(S 13 / S 13^{a}\right)$. High-resolution mapping revealed that the $S 13$ locus is located within a chromosomal region of $40 \mathrm{~kb}$ in length. We examined allelic state of 25 lines, including wild and cultivated rice strains. The different responses to the two NILs carrying $S 13$ or $S 13^{a}$ were used to examine the distribution of the alleles. Three Japonica strains gave semi-sterile and fertile hybrids in crosses with NILs having $S 13$ and $S 13^{a}$, respectively, while all the other strains including the wild progenitor gave only fertile hybrids in both crosses. This shows that most of the strains examined carried a neutral allele, $S 13^{n}$. Sequence and gene expression analysis were also carried out to identify the candidate gene(s).

2A MIZUTA, Yoko ${ }^{1,2}$ HARUSHIMA, Yoshiaki ${ }^{2}$, -10 KURATA, Nori ${ }^{1,2}$ ( ${ }^{1}$ Dept. Genet., Sch. Life Sci., Grad. Univ. Adv. Stud., ${ }^{2}$ Natl. Inst. Genet.)

A reproductive barrier caused by interaction of two loci in the hybrid pollen of rice

A reproductive barrier plays an indispensable role in evolution and speciation of organisms. In plants, the reproductive barrier is observed as hybrid incompatibility, hybrid breakdown and hybrid sterility, etc. We developed a method of mapping of reproductive barrier loci on the whole genome in rice, and are developing a method to detect interacting reproductive barrier loci in $\mathrm{F}_{2}$ population by an independence test for segregation. During these studies, a pair of interactive reproductive barrier loci was detected on chromosome 1 (around $45.4 \mathrm{cM}$ ) and chromosome 6 (around $15.8 \mathrm{cM}$ ) in a cross between a japonica cultivar Nipponbare and an indica cultivar Kasalath. Specific elimination of pollens with the Kasalath allele on chromosome 1 and the Nipponbare allele on chromosome 6 was confirmed in reciprocal backcross populations of Nipponbare and their hybrid. These barrier loci were mapped at $45.4 \mathrm{cM}$ spanning $59 \mathrm{~kb}$ on chromosome 1 and mapped at $15.8 \mathrm{cM}$ spanning $95 \mathrm{~kb}$ on chromosome 6.
2A KUBO, Takahiko ${ }^{1}$, YOSHIMURA, Atsushi ${ }^{2}$, KURATA, -11 Nori ${ }^{1}$ ( ${ }^{1}$ Plant Genet. Lab., Natl. Inst. Genet., ${ }^{2}$ Plant Breeding Lab., Faclt. Agr., Kyushu Univ.)

Genetic mechanism of $\mathrm{F}_{2}$ female sterility found in a hybrid progeny of rice

Reproductive barriers often arise in hybrid progeny between two varietal groups of cultivated rice (Oryza sativa L.), Japonica and Indica. $\mathrm{F}_{2}$ sterility showing about $10 \%$ seed fertility was observed in backcrossed progeny derived from a cross between a Japonica variety, Asominori and an Indica variety, IR24. It was found that the $\mathrm{F}_{2}$ sterility was caused by a set of three complementary genes. These complementary genes, named as $h s a 1, h s a 2$ and $h s a 3$, were found to be involved in embryo-sac development. The Indica parent IR24 has a sterile allele $h s a 1^{I R}$, which was located at long arm region of chromosome 12 . Whereas the Japonica parent Asominori has two sterile alleles $h s a 2^{A S}$ on chromosome 8 and $h s a 3^{A S}$ on chromosome 9. Female gametes carrying the $h s a 1^{I R}$, $h s a 2^{A S}$ and $h s a 3^{A S}$ alleles aborted in $h s a 1^{I R}$ homozygous plant, leading to seed sterility and selective elimination of the specific allelic combination. By fine mapping using InDel and SSR markers, the $h s a 1$ and $h s a 2$ genes were shown to be located within $313 \mathrm{~kb}$ and $414 \mathrm{~kb}$ physical intervals, respectively. These genes would reveal their interactive functions in the process of embryo-sac development by molecular cloning.

2A FUJITA, Masahiro ${ }^{1}$, HORIUCHI, Youko $^{1}$, UEDA, -12 Yayoi ${ }^{1}$, MIZUTA, Yoko ${ }^{1}$, KURATA, Nori ${ }^{1}$ ( ${ }^{1}$ Plant Genet. Lab., Natl. Inst. Genet.)

Transcriptome analysis of rice reproductive tissues by microarray

In order to reveal the expression pattern of genes in reproductive stages of rice, we performed microarray analysis. At first, we defined the developmental stages of rice reproductive tissues according to the microscopic observations etc. Tissue samples from panicles and anthers at meiosis or pollen maturation stage, stigmas and/or ovaries at pollination to fertilization stage and ovaries at embryogenesis stage were collected based on our stage definitions. The transcriptomes of each sample were analyzed by triplicate using GeneChip microarrays (Affymetrix). The results showed that the expression patterns of genes were finely correlated with our definition of reproductive stages. We could find the reproductive tissues specific or preferentially expressed genes, and also observe hundreds of genes changed synchronously between stages. Our microarray experiments thus revealed to serve as a platform of gene function analysis in reproductive stages of rice. 
3A HIZUKURI, Yohei ${ }^{1}$, KOJIMA, Seiji ${ }^{1}$, YAKUSHI, -01 Toshiharu1,2, KAWAGISHI, Ikuro ${ }^{1,3}$, HOMMA, Michio ${ }^{1}\left({ }^{1}\right.$ Div. Biol. Sci., Grad. Sch. Sci., Nagoya Univ., ${ }^{2}$ Dept. BioSci. and BioTech., Faclt. Agr., Shinshu Univ., ${ }^{3}$ Dept. Front. BioSci., Faclt. Eng., Hosei Univ.)

Systematic Cys mutagenesis of P-ring component in flagellar motor of E.coli

The $\mathrm{P}$ ring is one of the components of the basal body. It assembles at the peptidoglycan layer, and forms a stiff cylindrical structure to hold the central rod with the L ring, which assembles at the lipopolysaccharide (outer membrane) layer. The $\mathrm{P}$ ring is thought to consist of 26 copies of a single protein FlgI, which is expressed as a precursor form with cleavable N-terminal leader sequence, and exported to the periplasmic space via the Sec apparatus, then assembles into the $P$ ring surrounding the rod. In this work, we generated 32 cysteine-substituted $E$. coli P-ring protein FlgI variants systematically and characterized each FlgI Cys variant. Almost all of the variants showed nearly wild-type functions. To demonstrate which residue of FlgI is exposed to the outer space, we examined a cysteine modification experiment by thiol-specific reagent mPEG-maleimide. Interestingly, the labeled residues of FlgI never overlap with the residues to be important for protein amount or motility presented in this work.

3A IRIEDA, Hiroki ${ }^{1,2}$, OHTA, Noriko ${ }^{1,2}$, BANNO, -02 Satomi ${ }^{1,3}$, HOMMA, Michio ${ }^{2}$, KAWAGISHI, Ikuro ${ }^{1,3}$ $\left({ }^{1}\right.$ Res. Cent. for Micro-Nano Tech., Hosei Univ., ${ }^{2}$ Dept. Biol. Sci., Grad. Sch. Sci., Nagoya Univ., ${ }^{3}$ Dept. Front. BioSci., Faclt. Eng., Hosei Univ.)

Mechanisms underlying signaling thourgh chemoreceptor clustering in Escherichia coli

In the chemotaxis of Escherichia coli, environmental stimuli are sensed by four transmembrane chemoreceptors (MCPs) and an MCP-like transmembrane protein (the redox sensor Aer). Regardless of their signaling states, MCP and Aer exist as homodimers and form a huge cluster at a cell pole. It has been suggested that a trimer of MCP or Aer dimers serves as a building unit of the cluster. We examined the formation of the MCP-Aer cluster by using GFP fusions and in vivo cross-linking. The results suggest that MCP and Aer form a functional mixed cluster, that the clustering ability is affected by a structural change in a part of MCP other than the "trimer contact" site located at the cytoplasmic tip of the highly elongated MCP molecule, and that signals can be transmitted horizontally through interactions between MCP dimers.
3A YANO, Yuikiko ${ }^{1}$, SUGANO, Eriko ${ }^{2}$, TOMITA, -03 Hiroshi ${ }^{2}$, TAMAI, Makoto ${ }^{2}$, YAMAMOTO, Hiroaki ${ }^{1}$ ( ${ }^{1}$ Dept. Dev. Biol. NeuroSci. Grad. Sch. Life Sci., Tohoku Univ., ${ }^{2}$ Biomedical Eng. Res. Org., Tohoku Univ.)

Structual and functional analysis of melanocyte located in choroid: A genetic approach

Choroid that underlies retina has many neural crest derived melanocytes. It has been already reported that mammals with no melanocyte show severe hearing loss, while few studies have been done about the effect on eye structure and visual function.

We start analyzing ultrastructure of eyes in Mitf ${ }^{\text {mibw }} / M_{\text {Miff }}^{\text {mibw }}$ and $W^{v} / W$ mice. It showed the same phenotype (black eye and white coat) but it is caused by different genes, comparing with the wild type C57BL/6J.

Here we discuss how the loss of melanocytes affects choroidal structure, using transmission electron microscopy (TEM). Functional analysis using electroretinography (ERG) is also introduced.

3A MINAMI, Ryunosuke ${ }^{1}$, NAKAMOTO, Masanari ${ }^{1}$ -04 DOTEUTI, Tomoe ${ }^{1}$, YAMAMOTO, Daisuke ${ }^{2}$, NAKAGOSHI, Hideki ${ }^{1}{ }^{1}$ Grad. Sch. Natural Sci. Tech., Okayama Univ., ${ }^{2}$ Grad. Sch. of Life Sci., Tohoku Univ.)

Identification of the neural network that controls sexual differentiation in the Drosophila brain

We generated transgenic flies which express GAL4 under the control of the defective proventriculus (dve) gene enhancer. These dve-GAL4 lines label a subset of neurons in the brain, and we designate these cells as Dve Enhancer-responsive cells (DE cells). The neural activity of DE cells was blocked after puparium formation by using a temperature-sensitive allele of the dynamin gene shibire (shibire ${ }^{t s}$ ). Interestingly, inhibition of neural activity in DE cells caused an abnormal male-male courtship behavior as observed in fluitless (fru) mutants. The male-specific fru gene product $\left(\mathrm{Fru}^{\mathrm{M}}\right)$ is crucial for male behavior. We have shown that a subset of $\mathrm{DE}$ cells coexpresses $\mathrm{Fru}^{\mathrm{M}}$ (DE-Fru ${ }^{\mathrm{M}}$ cells). Furthermore, genetic feminization of $\mathrm{DE}$ cells also exhibited an abnormal male-male courtship behavior. Our results suggest that the male-type specification of DE-Fru ${ }^{\mathrm{M}}$ cells, together with their neuronal activity, is required to suppress homosexual behavior. Further characterization of DE-Fru ${ }^{\mathrm{M}}$ cells provides insight into mechanisms of cell-autonomous sexual differentiation in the brain. 

-05 Ikue ${ }^{1}$ ( ${ }^{1}$ Nagoya Univ.)

G protein-coupled thermosensation by an olfactory neuron in a neural circuit for thermotaxis behaviour of C. elegans

Animals modify their behavioral outputs in response to the environmental stimuli. It is still poorly understood how sensory information is processed at molecular and neural circuit levels. The nematode C. elegans memorizes cultivation temperatures and modulates its migration patterns accordingly on a temperature gradient, which is observed as thermotaxis. We show here that AWC sensory neuron, a well-known olfactory neuron, senses temperature through G protein-coupled signalling and that AWC activity provides a robust influence on a neural circuit for thermotaxis. Abnormal thermotaxis caused by mutation in RGS, a inhibitor of $G$ protein, was suppressed by several mutations in $\mathrm{G}$ protein-coupled olfactory signalling in AWC. The $\mathrm{Ca}^{2+}$ imaging experiments indicate that AWC responds to temperature changes. AWC synapses onto AIY, an essential interneuron in a neural circuit for thermotaxis. We found that the responsiveness to temperature changes was decreased in the AIY interneuron of the RGS mutant. Our results suggest that novel G proteincoupled thermosensory signalling in AWC sensory neuron regulates the neural computation in a neural circuit for thermotaxis.

3A YOKO, $\mathrm{Can}^{1}$, KUHARA, Atsushi ${ }^{1}$, TANIZAWA, -06 Yoshinori ${ }^{2}$, MORI, Ikue ${ }^{1}\left({ }^{1}\right.$ Lab. Mol. Neurobiol., Div., Grad. Sch. Sci., Nagoya Univ., ${ }^{2}$ Div. Cell Biol., MRCLab. Molec. Biol., UK)

Analysis of mechanism underlying synaptic localization in integrating interneuron for $\mathrm{C}$. elegans thermotaxis neural circuit.

Neural function is conquered by complicated neural circuit, in which precise synaptic localization is indispensable. Molecular mechanism underlying synaptic localization is however largely unknown. The RIA, an essential integrating interneuron in the neural circuit for thermotaxis behavior of C. elegans, has a single neural process, where most of presynapses and postsynapses are localized in proximal and distal regions from cell body, respectively. We focused on this characteristic synaptic localization pattern of the RIA neuron in which to address the molecular mechanism of compartmentation between pre- and postsynaptic regions. To identify molecular components underlying synaptic localization, we are analyzing known-mutants defective in a neural circuit for thermotaxis behavior of C. elegans, and performing a genetic screen for novel mutants defective in synaptic localization in RIA by marking synaptic vesicle components EAT-4 and SNB-1 fused to fluorescent proteins. By conducting this analysis, we are hoping to know correlation between synaptic localization and neural function.
3A KIMATA, Tsubasa ${ }^{1}$, KUHARA, Atsushi ${ }^{1}$, TANIZAWA, -07 Yoshinori ${ }^{2}$, MORI, Ikue ${ }^{1}\left({ }^{1}\right.$ Lab. Mol. Neurobiol., Div. Biol. Sci., Grad. Sch. Sci., Nagoya Univ., ${ }^{2}$ Div. Cell Biol., MRC-Lab. Molec. Biol., UK)

Genetical screen for the genes functioning in localization of synapses in C. elegans RIA interneuron

Neural signal is transmitted through synapses in the nervous system, in which localization of synapses at appropriate subcellular position is important for neural function. The molecular mechanism underlying the localization of synapses is however not well known. RIA interneuron essential for thermotaxis behavior in $C$. elegans has a single neurite, where pre and post synaptic regions are clearly divided. We believe that this characteristic localization is a suitable model for the analysis of subcellular localization of synapses. Recent study revealed that mutation in Inositol Monophosphatase encoded by $t t x-7$ gene lead to the defect in thermotaxis behavior caused by abnormal localization of synaptic proteins in RIA. To identify new genes involved in localization of synapses in RIA, we conducted genetic screen for mutations that suppressed the thermotaxis defects of $t t x$ - 7 , since thermotaxis assay enables us to screen more genomes than the direct observation of synapses. Screening about 1,000 genomes, we isolated two suppressers for thermotaxis defects of $t t x-7$. We are now trying to examine the candidates as to whether the localization defect of synaptic proteins are also restored.

3A OKAZAKI, Ayako ${ }^{1}, \mathrm{KUHARA}$, Atsushi ${ }^{1}$, TACHIKAWA, -08 Sayaka ${ }^{1}$, MORI, Ikue ${ }^{1}{ }^{1}$ Laboratory of Molecular Neurobiology, Division of Biological Science, Graduate School of Science, University of Nagoya, Nagoya, Japan)

Genetic analysis of the mutants defective in G proteincoupled thermosensation in C. elegans

Temperature is essential cue for animals. Molecular and neural mechanisms of thermosensation are however not yet well understood. We are using thermotaxis in C. elegans as a model to elucidate thermosebsory mechanism. We currently found that AWC sensory neuron known as olfactory neuron also senses temperature and odorant through $\mathrm{G} \alpha$ ODR-3-coupled signaling. The loss-of-function mutation in negative regulator for $\mathrm{G}$ protein, RGS, encoded by eat-16 gene led to cryophilic defect, which was suppressed by several mutations in $\mathrm{G} \alpha$-coupled signaling in AWC. In order to identify new molecular components involved in $\mathrm{G} \alpha$-coupled thermosensation, we isolated new mutants that suppress cryophilic defects of eat-16 mutants. From about 17600 genomes screening, we isolated 76 suppressors. Of these, eat-16; nj69 mutants showed almost normal thermotaxis and normal responses to AWC-sensed odorants, indicating that $n j 69$ mutation fully suppresses cryophilic defect. nj69 was mapped between -10.69 and -10.57 on chromosome X, which are covered by cosmid F40F4 containing 14 genes. Now we are injecting these genes into eat-16; nj69 mutant to determine responsible gene for nj69 mutation. 
3A SUZUKI, Keita ${ }^{1}$, SASAKURA, Hiroyuki ${ }^{1}$, MORI, -09 Ikue ${ }^{1,2}\left({ }^{1}\right.$ Lab. Molec. NeuroBiol., Div. Biol. Sci., Grad. Sch. Sci., Nagoya Univ., ${ }^{2}$ Inst. Adv. Res., Nagoya Univ.)

Isolation and analysis of thermotaxis defective mutants by using the thermosensory neuron AFD specific GFP marker in C. elegans

The molecular mechanism of thermosensation is not well understood. In order to isolate the genes required for thermosensation, the genetic screening that dose not depend on behavioral responses to temperature was conducted in C.elegans. It was previously reported that the mutants of $c m k-1$ gene encoding calcium/calmodulin-dependent protein kinase I (CMK-1) showed abnormal thermotaxis behavior as well as abnormal downregulation of $H 13$ gene specifically expressed in the AFD neuron. Thus, the maintenance of the expression of $H 13$ gene in AFD by thermal stimulus is likely to be controlled through cGMP-gated cation channels and CMK-1. Using this phenomenon, we conducted the suppressor screening, in which the downregulation of H13promoter:: gfp expression was recovered in $c m k-1$ mutant background. We so far isolated 12 mutant candidates. In this meeting, we report the result of the thermotaxis and chemotaxis behavior analysis and the mapping of suppressor candidates.

3A TAKANO, Ryo ${ }^{1}$ MIYARA, Akiko ${ }^{1}$, KUHARA -10 Atsushi ${ }^{1}$, MORI, Ikue ${ }^{1,2}\left({ }^{1}\right.$ Lab. Molec. NeuroBiol., Div. Biol. Sci., Grad. Sch. Sci., Nagoya Univ., ${ }^{2}$ Inst. Adv. Res., Nagoya Univ.)

A search for molecular pathway involved in TTX-8, a novel protein localized in organelle of neurons.

Many genes required for the nervous system have been identified using different approaches, but most of their molecular natures in vivo are still unknown. We are trying to figure out the molecular mechanisms of neural function by researching the temperature memory-evoked behavior, thermotaxis in C. elegans. TTX-8 is a novel protein required for thermotaxis and seems to localize in organelle of neuron. The abnormal thermotaxis of $t t x-8$ mutants was rescued by the human novel protein FLJ10747, a structural homologue of TTX-8, suggesting that the function of TTX-8 is conserved across the species. To isolate the gene required for the molecular pathway involved in TTX-8, we conducted the yeast two-hybrid screening and identified a novel zinc finger protein. We isolated the deletion mutant of the gene for the zinc finger protein and analyzed the behavior of the mutants in detail. We are in the process of investigating its expression pattern and sub-cellular localization.
3A ANOKYE-DANSO, Frederick ${ }^{1}$, AKWASI, Anyanful ${ }^{2}$, -11 SAKUBE, Yasuji ${ }^{1}$, KAGAWA, Hiroaki ${ }^{1} \quad{ }^{1}$ Div. Bioscience, The Grad. Sch. Natural Sci. Tech., Okayama Univ., ${ }^{2}$ Dept. Path. and Lab. Med., Emory Univ., Atlanta, GA)

GATA/ELT-2, CdxA homolog and fork head/HNF-3/PHA-4 transcription factors restrict the tropomyosin gene expressions in pharynx and gut of Caenorhabditis elegans

Gene regulation during development is an important biological activity that leads to assemble biomolecules at specific location and limited time. The single tropomyosin gene of C. elegans, tmy1/lev-11 produces two groups of transcripts from external and internal promoters. We investigated internal promoter to find out sequences that restrict expression in pharynx and gut. A $100 \mathrm{bp}$ fragment was identified which contained a GATA factor, chicken CdxA homolog and PHA-4 binding sequences. All three factors are essential for the gut expression. ELT-2 and PHA-4 interacted directly with GATA and TGTTTGT sequences respectively. Knockdown of either ELT-2 or PHA-4 abrogated tmy-1::gfp reporter expression in guts demonstrating importance of ELT-2 and PHA-4. Elimination of ELT-2 affected gut expression. Ectopic ELT-2 was sufficient to elicit widespread expression of tmy-1:: lac $Z$. Although we have not isolated the $\mathrm{CdxA}$ homolog, we present a model ELT-2, PHA-4 and CdxA operate to orchestrate pharyngeal and gut expressions from the internal promoter of tmy-1. 
1B IKEGAYA, Yousuke ${ }^{1}$, FUJIHARA, Shinya ${ }^{1}$, -01 MORIGUCHI, Kazuki ${ }^{1}$, TANAKA, Katsuyuki ${ }^{1}$, SUZUKI, Katsunori ${ }^{1}\left({ }^{1}\right.$ Dept. Biol. Sci., Grad. Sch. Sci., Hiroshima Univ.)

A genome-wide screening of yeast mutants with increased efficiency of trans-kingdom conjugation between $E$. coli and $S$. cerevisiae and its application for novel gene introduction method (I).

Trans-kingdom conjugation, a phenomenon of the gene transfer from prokaryotes to eukaryotes by conjugation, has been reported in several organisms. In this study, to establish a direct gene introduction method from $E$. coli to yeast with effortless and high efficiency, we carried out a genome-wide screening for yeast mutants which exhibit an increased efficiency of trans-kingdom conjugation using a $S$. cerevisiae knock-out deletion collection.

As a result of the three-step screening, we successfully isolated 22 increased mutants, which showed more than 16 folds conjugation efficiency than that of the wild type strain. Eight mutants among them showed lack of eight nuclear encoded mitochondrial genes of various functions. In addition, the trans-kingdom conjugation efficiency was successfully increased by treatments with Antimycin A, an inhibitor of electron transport chain, and Erythromycin, an inhibitor of mitochondrial translation, respectively. These facts strongly indicate the possibility that genetic and chemical inhibitions of the mitochondrial function would be an applicable method for gene introduction by trans-kingdom conjugation at least in some fungi.

1B KOJIMA, Kenji ${ }^{1}$, KANEHISA, Minoru ${ }^{2}\left({ }^{1}\right.$ Grad. Sch. -02 BioSci. and BioTech., Tokyo Inst. of Tech., ${ }^{2}$ Inst. Chem. Res., Kyoto Univ.)

Systematic survey for novel types of prokaryotic retroelements based on gene neighborhood and protein architecture

Mobile genetic elements encoding reverse transcriptase are called retroelements. The diverse lifestyles resulted from gene combination are a remarkable feature of eukaryotic retroelements. In contrast to the detailed knowledge of eukaryotic retroelements, prokaryotic retroelements are poorly understood, even though many reverse transcriptase genes have been annotated through genome sequencing. Here we performed systematic survey to find novel types of prokaryotic retroelements based on the gene neighborhood and the protein architecture. We found reverse transcriptase genes associated with DNA polymerase A, which can synthesize second strand cDNA. We also identified reverse transcriptase genes fused with primase genes. They could generate primers for reverse transcription. Furthermore, we found several reverse transcriptase genes are encoded at CRISPR-Cas system loci. CRISPR-Cas system was recently revealed to be a prokaryotic acquired immune system, and it is possible that these reverse transcriptase genes serve immunity against RNA phages.
1B YOKOYAMA, Kohei ${ }^{1}$, NITASAKA, Eiji ${ }^{1}\left({ }^{1}\right.$ Dept. Biol., -03 Grad. Sch. Sci.s, Kyushu Univ.)

A search for autonomous element of Tpn transposon in the Japanese morning glory

In the Japanese morning glory, several responsible genes for unstable mutations were isolated, and all transposable elements inserted in these genes belong to $\mathrm{En} / \mathrm{Spm}$-related element, Tpn1 family. All Tpns identified were non-autonomous elements that truncated transposase gene and captured host gene sequences. The mRNAs for transposase proteins $\operatorname{TNP} \alpha$ and $\operatorname{TNP} \delta$ are expressed by alternative splicing from autonomous Tpn as other $\mathrm{En} / \mathrm{Spm}$-related elements, and they mediate the transposition of non-autonomous elements. TNP $\delta$ has TNPD/TNP2 domains conserved in other En/Spm transposons. On the other hands, $\mathrm{TNP} \alpha$ includes C-terminal sequence showing a homology to cysteine protease domain. This domain was also conserved in MULE and CACTA transposon of other plants. Using TNP $\delta$ sequence as a probe, we screened sufficient number of recombinant clones from a cosmid library, and isolated more 30 candidates of autonomous element, TpnA1 carrying full-length transposase gene is a single copy element in haploid genome. However TpnA1 was thought to be non-autonomous element because it includes substitutions and deletion in exons. Therefore we presume that autonomous element has a special structure.

1B ASAKURA, Nobuaki ${ }^{1}$, MORI, Naoki ${ }^{2}$, YOSHIDA -04 Shinya ${ }^{3}$, OHTSUKA, Ichiro ${ }^{1}$, NAKAMURA, Chiharu ${ }^{2}$ $\left({ }^{1}\right.$ Lab. Biol., Faclt. Eng., Kanagawa Univ., ${ }^{2}$ Faclt. Agr., Grad. Sch. Agr. Sci., Kobe Univ., ${ }^{3}$ Hyogo Pref. Res. Cent. Agr., Forestry and Fisheries)

Possible horizontal transfer of Mutator-like elements within Poaceae

Mutator trait that exhibited high frequency mutations was first identified in maize. Mutator-like elements (MULEs) are widely distributed in plants, and compose a superfamily. MULEs can be divided into several classes based on the comparison of coding sequences for transposases. In Triticum urartu, a wild einkorn wheat, we identified two distinct MULE subclasses belonging to Mutator Class. Similarity of nucleotide sequences between two subclasses was less than $60 \%$, showing their clear differentiation. We aimed to understand MULE dynamics in Poaceae. Distribution of two MULE subclasses, which were identified in $T$. urartu, was investigated within Poaceae by PCR using primer sets corresponding to subclasses. Distribution of both MULE subclasses is patchy. Phylogenetic analysis in each MULE subclass was performed by comparing sequences of PCRamplicons described above. In both subclasses, MULEs that were isolated from distantly related species exhibited remarkably high similarity. Phylogenetic relationship of MULEs in both subclasses was partially inconsistent with the phylogeny of the species. MULEs might have been horizontally transmitted several times within Poaceae. 
1B TSUCHIMOTO, Suguru ${ }^{1}$, HIRAO, Yoshitoshi $^{1}$, -05 OHTSUBO, Eiichi ${ }^{1}$, OHTSUBO, Hisako ${ }^{1}$ ( ${ }^{1}$ Inst. Molec. Cell. BioSci.s, the Univ. Tokyo)

A SINE widely distributed in Poaceae plant species, $O s S N$

We found a new SINE, OsSN (Oryza sativa SINE), in the rice genome. It had no homology to $p-S I N \bar{E}$, a rice $\bar{S} I N E$ identified previously.OsSN was dispersed in the rice genome, and some of the members showed insertion polymorphism between subspecies of $O$. sativa or between $O$. sativa and related wild species. OsSN was divided into five families (OsSN1 OsSN5), which were thought to be generated by domain exchanges. Interestingly, OsSN1 OsSN3 had a stretch of A at the 3' terminus, but OsSN4 and OsSN5 had a stretch of T. Other Poaceae plant species, such as wheat, also had $O s S N$ families. It suggests that $O s S N$ is a SINE widely distributed in Poaceae species.

1B NISHIMURA, Keishiro ${ }^{1}$, TSUCHIMOTO, Suguru ${ }^{2}$, -06 OHTSUBO, Eiichi ${ }^{2}$, OHTSUBO, Hisako ${ }^{2}\left({ }^{1}\right.$ Grad. Sch. Med. and Faclt. Med., Univ. Tokyo, ${ }^{2} \mathrm{IMCB}$, The Univ. Tokyo)

Identification of novel retrotransposons, Ya3 family from Oil Palm plants and their use for the insertion polymorphism analysis

We identified different classes of LTR retrotransposons in oil palm (Elaeis guineensis) plants. Using degenerate primers, reverse transcriptase fragments belonging to a copia-type as well as gypsy type LTR retrotransposons were isolated. Among those, Ya3, a copia-type element, were sequenced by PCR walking, especially by focusing on the regions of both LTRs and their flanking neighboring regions. These elements would be useful for insertion polymorphism analysis.
1B DANJOH, Inaho ${ }^{1}$, SONE, Hiyori ${ }^{1}$, YOSHINO, Kaori ${ }^{1}$, -07 SAIJO, Kaoru ${ }^{1}$, NAGAYOSHI, Mariko ${ }^{1}$, KOZAKO, Tomohiro $^{2}$, TAKEZAKI, Toshiro ${ }^{2}$, ARIMA, Naomichi' ${ }^{2}$, SONODA, Shunro ${ }^{2}$, NAKAMURA, Yukio ${ }^{1}\left({ }^{1}\right.$ Cell Eng. Div., BioResource Center, RIKEN, ${ }^{2}$ Grad. Sch. Med. and Dental Sci., Kogoshima Univ.)

Collection of peripheral blood mononuclear cells obtained from Amerindians and other Mongoloid minority groups

Ancestors of Amerindians migrated from Eurasian continent to North American continent via Bering Strait, then came down to South American continent over 10 thousands years ago. Recently, human geneticists try to find out their origin in Eurasia and to trace their migration path(s) with molecular genetical methods. Professor Shunro Sonoda at Kagoshima University had collected peripheral blood mononuclear cells from over 3,000 individuals in Mongoloid minority groups all over the world, mainly from South America. This valuable collection was transferred from Kagoshima University to RIKEN BioResource Center in 2005. No other resource centers in the world possess such a vast Mongoloid collection.

After material transfer agreement completed, we started establishment of B lymphoblastoid cell lines by Epstein-Barr virus infection, which retain normal karyotypes. We also have organized and upgraded accompanying information for each cell; Tribes and localities from where the samples came, gender, age, and relationship between individuals, as well. We introduce this collection and our approaches with it in this report.

1B MATSUOKA, Yoshihiro ${ }^{1}$, TAKUMI, Shigeo ${ }^{2}$, -08 KAWAHARA, Taihachi ${ }^{3}\left({ }^{1}\right.$ Fukui Pref. Univ., ${ }^{2}$ Grad. Sch. Agr. Sci., Kobe Univ., ${ }^{3}$ Grad. Sch. Agr., Kyoto Univ.)

Flowering time variation in Aegilops tauschii

Aegilops tauschii, the D genome progenitor of bread wheat, is a wild diploid species distributed widely in central Eurasia. To study the species' natural flowering time variation, a common garden experiment was done using 200 accessions that covered the species range. Our main results included that (1) days to flower from germination vary greatly among accessions with a maximum pair-wise difference being more than 30 days; (2) early accessions are frequent in the eastern habitats; and (3) late accessions are frequent in the high latitudinal habitats. We report phylogenetic structure of Ae. tauschii flowering time variation inferred from chloroplast DNA haplotypes analyses. 
1B TSUNEWAKI, Koichiro ${ }^{1}$, YAMAZAKI, Yukiko ${ }^{2}$, -09 MATSUOKA, Yoshihiro ${ }^{3}$, OGIHARA, Yasunari ${ }^{4}$ ( ${ }^{1}$ none, ${ }^{2}$ Natl. Inst. Genet., ${ }^{3}$ Fukui Pref. Univ., ${ }^{4}$ Kihara Biol. Res. Inst., Yokohama City Univ.)

Mitochondrial gene mutations observed between 3 cereals, with special remarks on excess accumulation of C-to-T base change due to $\mathrm{C}$-to-U editing.

Mitochondrial gene mutations, both base changes and indels, occurred during speciation of three cereals, wheat, rice and maize, were studied. In total, 35,965 bp of mitochondrial gene sequences were examined for the base change, finding 806 polymorphic sites. Direction of the base change was determined for all dimorphic sites. Among four transitions, C-to-T showed much higher frequency than three others. Some Cs are known to be edited to $U$ in RNA. If no editing occurs, numbers of both synonymous and non-synonymous mutations caused by C-to-T base change are larger than those of other transitions. By editing, however, the number of non-synonymous mutations was reduced to the same level as in other transitions. This fact suggests that $\mathrm{C}$-to-U editing reduces selection pressure against C-to-T mutations, causing accumulation of this base change in mitochondrial genes. As for indels, 28 insertions, 20 deletions and 7 substitutions were found. Of those, 41 had short direct repeats at their both ends, suggesting involvement of the direct repeats in their production.

1B KAWABE, Akira ${ }^{1,2}$, CHARLESWORTH, Deborah ${ }^{2}$ -10 ( ${ }^{1}$ Div. Popul. Genet., Natl. Inst. Genet., ${ }^{2}$ Inst. Evolutionary Biol., Univ. Edinburgh)

Diversity patterns of the Medea gene in Arabidopsis lyrata.

Molecular imprinting is the differential expression and/or silencing of alleles according to their parent of origin. Conflicts between parents, or parents and offspring, should cause armsraces, with faster evolution of the genes involved in imprinting, compared with other genes. This should be detectable in the evolution of imprinting genes' protein sequences and in the promoter regions of imprinted genes. Previous studies, however, found no evidence of more amino acid substitutions in imprinting genes. We have analysed sequence diversity of the Arabidopsis lyrata MEA gene and divergence from the A. thaliana sequence. The Medea (MEA) gene of A. thaliana is imprinted, being paternally silenced in endosperm cells, and also functions in the imprinting machinery. We find no evidence for adaptive evolution in the coding region of this gene. However, the 5' flanking region diversity patterns, with high diversity and two distinct haplotypes, suggest balancing selection. Because the possible target region of the balancing selection is also the region important for silencing, imprinting status could cause this natural selection.
1B YOSHIDA, Takanori ${ }^{1}$, KAMIYA, Koichi ${ }^{2}$, NAGAI, -11 Hisako $^{1}$, YAHARA, Tetsukazu ${ }^{2}$, TACHIDA, Hidenori ${ }^{2}$ $\left({ }^{1}\right.$ Dept. Biol., Grad. Sch. Sci.s, Kyushu Univ., ${ }^{2}$ Dept. Biol., Faclt. Sci.s, Kyushu Univ.)

Genetic diversity and structure of Japanese prickly ash, Zanthoxylum ailanthoides, a typical pioneer tree

Zanthoxylum ailanthoides is a typical pioneer tree species in Japanese warm-temperate evergreen forests. It has some interesting features such as growth in forest gaps, patchy distribution and maintenance of persistent soil seed banks (a large amount of seeds which exist over long time in the soil). Here we investigate genetic diversity and structure of $Z$. alianthoides by sequencing four nuclear loci, agpSA, agpSB, agpL, and GBSSI, possibly involved in starch synthesis, in over 150 individuals (Tushima, Fukuoka, Kagoshima, Yakushima, over 10 individuals per population). The genetic differentiation between populations is relatively high (mean pairwise $F_{S T}$ ranging from 0.035 to 0.269 ), though some haplotypes are shared by all four populations. These analyses show that the genetic structure of populations in this species is very different from those in the other tree species found in climax forests. This result suggests that the genetic structure of population in this species is shaped not only by past demographic changes but also by the ecological characteristics of the pioneer species.

1B KASUGAYA, Souichirou ${ }^{1}$, KAWATA, Naoko ${ }^{1}$, -12 YAMAGUCHI, Yoshihide ${ }^{1}$, SUN, $\mathrm{Hui}^{2}$, TAKEUCHI, Tetsurou $^{3}$, ASADA, Nobuhiko ${ }^{1}\left({ }^{1}\right.$ Biol. Lab., Faclt. Sci., Okayama Univ. Sci., ${ }^{2}$ Grad. Sch. Life Sci., Northeast Normal Univ., Changchun, China, ${ }^{3}$ Faclt. Humanities, Shujitsu Univ.)

Fine-scale biodiversity of the medaka, Olyzias latipes

The medaka is the minimum freshwater fish native in Japan, and elucidated the phylogenetic relations between the Northern and Southern population. The latter population is varied genetically in visible and molecular phenotype. The first focus is on polygenic polymorphism in the number of anal fin among 9 natural strains: 5 in West Setouchi types and four in San-in types in the Chugoku district, western part of Japan. Distribution of the number of fin examined shows the normal distribution, and the mean value is varied from 16 (HS in San-in) to 19 (K in West Setouchi) meaning the significant difference. Subsequently we examined the polymorphism of the cytochrome b gene between West Setouchi and San-in based on PCR. MtDNA was isolated from a single individual of the medaka in four strains of both types. Band pattern of PCR products are different between both geographic types particularly closely related strains, HK, HM, and HS in San-in type. These genetic differences in the medaka in the Chugoku district are estimated by the origin of genetic drift like the evolution of Olyza sativa. 
2B NOTOHARA, Morihiro ${ }^{1}\left({ }^{1}\right.$ Grad. Sch. Natural Sci., -01 Nagoya City Univ.)

The distribution of the coalescence time and an index describing the population structure

The time for sampled genes from a geographically structured population to get to a common ancestor depends on the population structure and the strength of the migration. I report some applications of three limit theorems of probability theory (the law of large numbers, the central limit theorem and the large deviation principle) to the structured coalescent model. The strong migration limit for the distributions of the coalescence times is derived by means of an application of the law of large numbers to the migration process. The central limit theorem enables us to obtain approximate distributions of the coalescence times in the case of the strong migration. The large deviation principle is concerned with the rate of convergence in the law of large numbers. I report that the rate of convergence can be regarded as an index of the population structure.

2B TANAKA, Kentaro ${ }^{1}$, TAKANO-SHIMIZU, -02 Toshiyuki ${ }^{1,2,3}$, TAKAHASHI, Ryo ${ }^{4}$ ( ${ }^{1}$ The Dept. Genet., SOKENDAI, ${ }^{2}$ The Dept. Popul. Genet., NIG, ${ }^{3}$ The Dept. Biosyst. Sci., SOKENDAI, ${ }^{4}$ RIKEN, GSC)

The fixation probability of a newly arisen gene duplication

Newly arisen duplicated genes can take several different fates during the course of evolution. One copy of the genes may be silenced by degenerate mutation (nonfunctionalization), or both copies may be preserved by fixations of complementary loss-offunction mutations (subfunctionalization) or by gain of a novel function (neofunctionalization). So far, the behavior of a newly arisen duplication in a population have mostly been studied with the double-null recessive model; however, it is known that many lethal mutations are not completely recessive. Here, we studied the fixation probability and fixation time under a partially recessive mutation model and found significant effect of heterozygote fitness effects on the fixation probability in a large population.

\section{B TAKAHASI, K. Ryo ${ }^{1}$ ( ${ }^{1}$ RIKEN GSC)} $-03$

Molecular evolutionary dynamics of a polygenic system under directional selection

To elucidate the effect of directional phenotypic selection on the evolution at the sequence level, we here formulate and investigate a multilocus population genetic model that simulates the stochastic evolution of a polygenic system in a finite population. Assuming the infinite-site model of mutation with gammadistributed phenotypic effects, we study how the evolutionary dynamics of mutation accumulation, as quantified by fixation time and probability, and also by the rate of substitution, are affected by directional phenotypic selection for a moving optimum.

2B NAWA, Nobukazu ${ }^{1}$, TAJIMA, Fumio ${ }^{1}\left({ }^{1}\right.$ Dept. Biol. Sci.s, -04 Grad. Sch. Sci., The Univ. Tokyo)

Analysis of the pattern of DNA polymorphism in human population obtained by SNP data

The pattern of DNA polymorphism is often summarized by Tajima's $D$ statistic or Fu and Li's $D$ statistic, although the pattern can be shown as the allele frequency spectrum. The recent accumulation of SNP data, however, makes us possible to investigate the allele frequency spectrum in detail. Let us define $\theta_{i}$ as $\theta(=4 N \mu)$ estimated by the number of segregating sites whose allele frequency is $i$ / $n$ among $n$ DNA sequences. Results of the coalescent simulation show that the distributions of $\theta_{i}$ in the populations which experienced expansion and reduction are Ushaped and upside-down U-shaped, respectively. In this study, we have analyzed the SNP data of the International HapMap project. We have investigated the allele frequency spectrum except for rare alleles because SNP data has an ascertainment bias. The distribution of $\theta_{i}$ in the YRI population (African) is flat. But the distributions of $\theta_{i}$ in the CEU population (European originated) and in the CHB and JPT population (Asian) are both upside-down U-shaped. From these results, we infer that the CEU population and the CHB and JPT population had experienced the population size reduction in the far past. 
2B INNAN, Hideki ${ }^{1}$, TAKAHASI, Kiyosi ${ }^{2}\left({ }^{1}\right.$ The Graduate -05 Univ. for Advanced Studies, ${ }^{2}$ RIKEN Genomic Sci.s Cent.)

The Direction of Linkage Disequilibrium: a New Measure Based on Ancestral-Derived Status of Segregating Alleles

A new measure of directional linkage disequilibrium is developed for detecting epistatic selection on interacting genes. Simulations show that by orienting the direction of linkage disequilibrium based on ancestral-derived status of alleles, the new measure indeed improves the power to detect a positive fitness interaction between two new mutations.
2B TAKUNO, Shohei ${ }^{1}$, NISHIO, Takeshi ${ }^{1}$, INNAN, -07 Hideki ${ }^{2}\left({ }^{1}\right.$ Grad. Sch. Agr. Sci., Tohoku Univ., ${ }^{2}$ Grad. Univ. Adv. Stud.)

The effect of gene conversion on generating genetic diversity of duplicated genes under multi-allelic balancing selection

Inter-locus gene conversion is considered a crucial mechanism for generating novel combinations of genetic diversity in duplicated genes. The importance of gene conversion between duplicated genes has been recognized in MHC and self-incompatibility, which are likely subject to or multi-allelic balancing selection. To theoretically understand the potential role of gene conversion in such situations, Monte Carlo simulations are performed with a two-locus model. The results show that gene conversion significantly increases the number of haplotypes when selection works on both loci. We find that the tract length of gene conversion plays an important role to determine the efficacy of gene conversion: shorter tract lengths could more effectively generate novel haplotypes given the gene conversion rate per site is the same. Similar results are also obtained when one of duplicated genes is assumed to be a pseudogene. It is suggested that a duplicated gene, even after being silenced, will contribute to increasing the variability in the other locus through gene conversion.

2B OSADA, Naoki ${ }^{1}\left({ }^{1}\right.$ Dept. Biomedical Resources, Natl -08 Inst. Biomedical Innovation)

On the correlation between gene expression pattern and selection intensity in the human genome.

Although mounting evidence suggests the correlation between the gene expression pattern and sequence divergence, little is known about the relationship between the gene expression pattern and polymorphism. Here, I compile the gene expression, polymorphism, and divergence data from the public databases of the human genome. The analysis implies that negative selection is the primary factor affecting expression-dependent gene evolution, and the prevalent but nonuniform distribution of slightly deleterious mutations in the genome. I also estimate the distribution of selection coefficient on amino acid substitutions using the Markov chain Monte Carlo method. While the genes under relaxed negative selection evolved faster than the other genes, these genes are even more liable to slightly deleterious mutations in the population. On the other hand, nonneutral mutations in the highly conservative genes, such as brainexpressed and housekeeping genes, are largely deleterious and eliminated before they enter the population. 
2B KHATAB, Ismael ${ }^{1}$, ISHIYAMA, Hiroko ${ }^{1}$, INOMATA -09 Nobuyuki ${ }^{2}$, SZMIDT, Alfred E. ${ }^{2}{ }^{1}$ Dept. Biol., Grad. Sch. Sci.s, Kyushu Univ., ${ }^{2}$ Dept. Biol., Faclt. Sci.s, Kyushu Univ.)

Demographic history of Larix sibirica and L. sukaczewii inferred from nucleotide variation of nuclear genes

Larix is one of the most important elements of the boreal forest in Russia. Some authors regarded L. sibirica and $L$. sukaczewii as one species, while others considered them as separate species. To clarify patterns of population differentiation, migration history and classification of these two species, we investigated nucleotide variation of the two nuclear gene regions: 4-coumarate coenzyme A ligase (4CL) and coumarate 3- hydroxylase (C3h). We found both high and low population differentiation (Fst) both between and within species. High levels of (Fst) were found among some populations of $L$. sukaczewii and $L$. sibirica which are located near or in refugial areas south of Urals and in southern Siberia. This suggests limited gene flow and independent evolution of some refugial populations. Low levels of population differentiation were found among populations of $L$. sukaczewii from northwestern Russia, which was glaciated during the Pleistocene. We also found clear differences in distribution of haplotypes between L. sibirica and L. sukaczewii, which together with high (Fst) values provides support for their classification as separate species.
2B KIM, Hielim ${ }^{1}$, TAKAHATA, Naoyuki ${ }^{1}$, SATTA, Yoko ${ }^{1}$ -11 ( ${ }^{1}$ The Dept. Biosyst. Sci., Grad. Univ. Adv. Stud.)

Human specific evolution of $A S A H 1$ gene associated with mental activity

To understand the evolution of human mental activity, we performed population genetics analyses of nucleotide sequences $(\sim 11 \mathrm{~kb})$ from a world wide sample of 60 chromosomes for $A S A H 1$. ASAH1 hydrolyzes ceramides which regulate neuronal developments, and its deficiency shows mental retardation. For the region $(\sim 4.4 \mathrm{~kb})$ of this gene, two distinct lineages ( $\mathrm{V}$ and $\mathrm{M})$ have persisted in the human population for $2.4 \pm 0.4 \mathrm{my}$. The persistence is likely due to population structure of humans in Africa. In the $\mathrm{V}$ lineage, however, the haplotypes shows strong linkage disequilibrium, high frequency, and small nucleotide diversity. These features indicate a signature of positive selection for the $\mathrm{V}$ lineage. The computer simulations reveal that an advantageous mutation once fixed in the $\mathrm{V}$ lineage has been positively selected again in the admixture of the $\mathrm{V}$ and $\mathrm{M}$ lineages after out of Africa. In addition, Val at the amino acid 72 is human specific, suggesting that this $\mathrm{Val}$ is the target of positive selection. From the above, we conclude that recent positive selection for the $\mathrm{V}$ lineage consequently results in the rapid expansion of the lineage after the modern human migration from Africa.
2B SHIBATA, Hiroki ${ }^{1}$, TANAKA, Kunika ${ }^{1}$, WATANABE, -10 Kazunori ${ }^{1}$, GOTO, Hiroki ${ }^{1}$, TAKENAKA, Osamu ${ }^{2}$, FUKUMAKI, Yasuyuki ${ }^{1}$ ('1 Med. Inst. Bioregulation, Kyushu Univ., ${ }^{2}$ Primate Res. Inst., Kyoto Univ.)

Molecular evolutionary study of glutamate-receptor gene family as schizophrenia-related genes

Schizophrenia is a common psychiatric disease with relatively strong genetic background $\left(\lambda_{\mathrm{s}}=10\right)$. Typical preadolescent onset characterized by loss of sociality suggests severe reduction of fitness. However, the disease prevalence is highly stable to be $\sim 1 \%$ in any human populations surveyed. We hypothesized that schizophrenia-susceptible alleles are maintained by non-neutral process such as balancing selection. To test the hypothesis, we have been conducting molecular evolutionary analyses on schizophrenia-related genes. In this paper, we report the results of upstream regions of ionotropic glutamate-receptor genes. By resequencing 50 humans and 50 chimpanzees as non-human controls, we collected the complete set of nucleotide variation in 4-5 kb upstream regions of six glutamate-receptor genes: GRIN1, GRIN2A, GRIN2B, GRIN2D, GRIA1 and GRIK1. By window plot analysis, we identified significant positive values of Tajima's $D$ $(+2.16)$ at the $3.0 \mathrm{~kb}$ upstream region of GRIN2B only in humans. Since population contraction is unlikely for humans, this signature suggests human-specific balancing selection possibly associated with schizophrenia. 
3B BANDO, Tetsuya ${ }^{1}$, MAEDA, Yuko ${ }^{2}$, NAKAMURA -01 Taro ${ }^{2}$, MITO, Taro ${ }^{2}$, OHUCHI, Hideyo ${ }^{1,2}$, NOJI, Sumihare $^{1,2}\left({ }^{1}\right.$ Tokushima Intellectual Cluster, ${ }^{2}$ Dept. Life Systems, Inst. Tech. and Sci., The Univ. Tokushima)

Fat and Dachsous protocadherin are required for proper proximodistal and circumferential regeneration of amputated legs in the cricket, Gryllus bimaculatus

In order to elucidate mechanisms in regeneration, we have been working on hemimetabolous insect, cricket Gryllus bimaculatus, which can completely regenerate distal missing part of leg. Since Fat signaling regulates tissue morphogenesis and is evolutionarily conserved from Drosophila to mammals, we speculated that Fat signaling is required for proper regeneration. Gryllus homologues of fat (Gb'ft) and dachsous (Gb'ds) were expressed in developing limb by whole-mount in situ hybridization (ALOKA HS-5100). We performed RNAi to study the functions of Fat signaling in the regeneration process of metathoracic legs. $G b^{\prime} f t^{\mathrm{RNAi}}$ and $G b^{\prime} d s^{\mathrm{RNAi}}$ nymphs recovered lost part, but their regenerated legs were shortened and plump compared with those of the wild type. Intercalary regeneration was occurred between host and grafted tibiae of wild type but was not occurred in $G b^{\prime} f t^{\mathrm{RNAi}}$ and $G b^{\prime} d s^{\mathrm{RNAi}}$ nymphs. Expression of wingless, which is required for regeneration, in $G b^{\prime} f t^{\mathrm{RNAi}}$ and $G b^{\prime} d s^{\mathrm{RNAi}}$ nymphs were similar to that in wild type. These results suggest that Fat signaling is essential for proper proximodistal and circumferential regeneration of the leg.

3B MAEDA, Yuko ${ }^{1}$, BANDO, Tetsuya ${ }^{2}$, NAKAMURA, -02 Taro ${ }^{1}$, MITO, Taro ${ }^{1}$, OHUCHI, Hideyo ${ }^{1,2}$, NOJI, Sumihare ${ }^{1,2}\left({ }^{1}\right.$ Dept. Biol. Sci. Tech., Faclt. Eng., Univ. Tokushima, ${ }^{2}$ Tokushima Intellectual Cluster)

Warts, Expanded and Dachs are required for proper regeneration of amputated legs in the cricket, Gryllus bimaculatus

To elucidate mechanisms of regeneration, we have been working on a hemimetabolous insect, Gryllus bimaculatus, which can completely regenerate a missing part of leg. Since the Fat signaling regulates PCP, proximodistal patterning and cell proliferation, which is evolutionarily conserved, we speculated that the Fat signaling is required for proper regeneration. Recently, it was reported that cell proliferation is regulated by the Fat signaling through the Warts (Wts) , Expanded (Ex) and Dachs (D). Thus, we analyzed functions of Gryllus homologues of $w t s, e x$ and $d$ in the leg regeneration. At the 4th instar, in both $G b^{\prime} w t s^{\mathrm{RNAi}}$ and $G b^{\prime} e x^{\mathrm{RNAi}}$ nymphs, the tibiae were enlarged, similar to $G b^{\prime} f t^{\mathrm{RNAi}}$. BrdU staining revealed that the overgrowth was due to excess cell proliferation. The tibia of $G b^{\prime} d^{\mathrm{RNAi}}$ was shorter and the tibia of $G b^{\prime} x^{\mathrm{RNAi}}$ was longer than that of wild type. These results suggest that Wts and Ex are required for proper cell proliferation in leg regeneration; the enlargement of the tibia observed in Gb'wts ${ }^{\mathrm{NAi}}$ and Gb'ex ${ }^{\mathrm{RNAi}}$ depends on cell proliferation through the Warts, but the shortening of the tibia observed in $G b^{\prime} f t^{\mathrm{RNAi}}$ and $G b^{\prime} d^{\mathrm{RNAi}}$ is independent on the Warts kinase.
3B MATSUMURA, Hiroyuki $^{1}$, TADA, Masako ${ }^{1,2}$, -03 NAKATSUJI, Norio ${ }^{3}$, TADA, Takashi ${ }^{1,4}$ (' ${ }^{1}$ Stem Cell Eng., Inst. Front. Med. Sci., Kyoto Univ., ${ }^{2}$ ReproCELL Incorporated, ${ }^{3}$ Dev. Diff., Inst. Frontier Kyoto Univ., ${ }^{4}$ JST CREST)

MHC-personalized ES-somatic hybrid cells generated by targeted chromosome elimination

Nuclear reprogramming activity for the restoration of pluripotency to specialized somatic cells is a unique property of embryonic stem cells (ESCs) as shown by cell fusion in humans and mice. To enable the generation of personalized pluripotential stem cells, a new chromosome elimination technology has recently been developed. Here, to generate major histocompatibility complex (MHC)-personalized hybrid cells, we selectively eliminated ESC-derived Chromosome 17s (Ch17s) from mouse ES-somatic hybrid cells. The MHC type of Ch17-eliminated (Ch17 (-/-)) hybrid cells completely matched that of the somatic donor. Ch17(-/-) hybrid cell-derivatives successfully escaped from immuno-rejection, as shown by formation of teratomas without strong inflammatory reactions and by cytotoxic T-lymphocyte assays. These findings provide a strong basis for efforts to develop MHC personalization technology for generating immunologically semi-syngeneic pluripotential stem cells from an individual's own somatic cells in humans.

3B AMAKAWA, Yuko ${ }^{1,2}$, HOKI, Yuko ${ }^{1}$, SASAKI, -04 Hiroyuki ${ }^{1,2}$, SADO, Takashi ${ }^{1,2}\left({ }^{1}\right.$ Dept. Human Genet., Natl. Inst. Genet., ${ }^{2}$ Dept. Genet., Grad. Sch. Life Sci., Grad. Univ. Adv. Stud.)

Inhibition of $\mathrm{X}$ chromosome reactivaton in mouse inner cell mass

Non-coding Xist RNA encoded on an X chromosome is essential for mammalian $\mathrm{X}$ chromosome inactivation. At the early stage of mouse development, one of the two $\mathrm{X}$ chromosomes becomes inactivated in females, and the inactivated $\mathrm{X}$ chromosome is stably maintained in successive cell divisions. However, it is known that Xist expression ceases in cells that have contributed to the inner cell mass (ICM) and primordial germ cells, and subsequently the inactive $\mathrm{X}$ chromosome becomes reactivated by unknown mechanisms. To address the biological significance of this reactivation, we attempted to prevent the reactivation by introducing a constitutively active allele of Xist $\left(X i s t^{\mathrm{CAG}}\right)$ into mice. We will report the evaluation of the Xist ${ }^{\mathrm{CAG}}$ allele and its effects on $\mathrm{X}$ chromosome reactivation in ICM and subsequent development. 
3B SATO, Yasunari ${ }^{1}$, ISHIDA, Ryutaro ${ }^{1}$, INADA, Eriko ${ }^{1}$, -05 TANAKA, Shigekazu ${ }^{2}$, TAMURA, Masaru ${ }^{2}$, MASUYA, Hiroshi $^{3}$, WAKANA, Shigeharu ${ }^{3}$, SHIROISHI, Toshihiko $^{2,3}$, WAKAMATSU, Kazumasa ${ }^{4}$ ITO, Shosuke ${ }^{4}$, YAMAMOTO, Hiroaki ${ }^{1}{ }^{1}$ Dept. Dev. Biol. Neurosci. Grad. Sch. Life Sci., Tohoku Univ., ${ }^{2}$ Mammalian Genet. Lab., Natl. Inst. Genet. Lab., Natl. Inst. Genet., ${ }^{3}$ Mouse Functional Genomics Res. Group, RIKEN GSC, ${ }^{4}$ Faclt. Health Tech., Fujita Health Univ. Sch. Health Sci)

Analysis of a new coat color mutant mouse strain along with aging

We have previously shown that a mutant mouse line generated from ENU-mutagenesis changes its coat color from black to brown along with aging. This mutant line shows not only a decrease in the expression level of melanization genes but also some pleiotropism, for example, thickened skin epidermis and enlarged sebaceous gland. This time, analyzing from a same coat color changing mutant, we found that the decrease in melanogenesis in early stage of anagen makes its hair brown. So we focused on this stage and analyzed the expression of melanization genes, the number of melanocytes and ultrastrucuture of these cells. Thickened epidermis is also shown in this mutant. Therefore we focused on the relationship between proliferation activity in epidermis and their hair cycle. From these results, we will report the characterization of this new mutant.

3B SUZAKI, Takuya ${ }^{1}$, HIRANO, Hiro-yuki ${ }^{1}\left({ }^{1}\right.$ Grad. Sch. -06 Sci., Univ. Tokyo)

Functional analyses of a suppressor of fon 2 mutation, which is involved in the regulation of meristem maintenance in rice

Plant architecture and formation of lateral organs depend on the activity of the meristem. In Arabidopsis, it is well known that the size of meristem is regulated by CLAVATA (CLV) signaling pathway. On the other hand, the genetic mechanisms of such regulation are poorly understood in other plants. We have been studying the function of FLORAL ORGAN NUMBER1 (FON1) and FON2 genes that regulate the size of floral meristem in rice. Our previous findings indicated that the FON1-FON2 system in rice corresponds to the CLV signaling system in Arabidopsis and suggested that the negative regulation of stem cell identity by these systems may be principally conserved in a wide range of plants within the Angiosperms. To elucidate the mechanism of meristem maintenance further, it is essential to identify other genes that regulate meristem size. Here, we report the isolation of a gene that suppresses the fon 2 mutation and its function. Our results strongly suggest an existence of an extra signaling pathway independent that of FON2-FON1 to regulate maintenance of the aerial meristems in rice.
3B YOSHIDA, Akiko ${ }^{1}$, SUZAKI, Takuya ${ }^{1}$, HIRANO, -07 Hiro-yuki ${ }^{1}$ ( ${ }^{1}$ The Dept. Biol. Sci.s, Grad. Sch. Sci., Univ. Tokyo)

Analysis of a gene that controls the development of the spikelets in rice

For the comprehensive understanding of the evolution of plant flowers, it is important to study the development of monocot flowers as well as that of eudicot flowers. In grasses, the inflorescences comprise of unique structural units, spikelets and florets. The rice spikelet has one floret, which are subtended by two tiny glumes, called empty glumes or sterile lemma. The empty glume is thought to be a rudimentary organ of two lateral florets, which have been degenerated during rice evolution. To reveal the developmental mechanism of the empty glume and to elucidate the evolutionary importance of it, we analyzed the morphological features of the rice $\mathrm{g} 1$ mutant, the empty glumes of which are longer and larger than those of wild type. In addition, we have tried to isolate the $G 1$ gene by positional cloning. Here, we will report the results of these experiments and discuss the evolution of rice spikelets.

3B TSUDA, Katsutoshi ${ }^{1}$, ITO, Yukihiro ${ }^{2}$, KURATA, Nori $^{1}$ -08 ( ${ }^{1}$ Plant Genet. Lab., Natl. Inst. Genet., Dept. Genet., Grad. Sch. Life Sci., Grad. Univ. Adv. Stud., ${ }^{2}$ Lab. Env. BioTech., Grad. Sch. Agr. Sci., Tohoku Univ.)

Analysis of the regulatory system of a rice KNOX gene, OSH1

$K N O X$ genes are expressed specifically in the shoot apex to develop and maintain the shoot apical meristem, and are downregulated in leaves. Because their ectopic expressions in leaves lead abnormal leaf morphology, the regulation of $K N O X$ gene expression is crucial for plant development.

To elucidate the regulatory mechanism of KNOX gene expression in rice, we identified mutant lines that ectopically express one of the rice $K N O X$ gene, $O S H 1$ in leaves. And we report a reporter system being developed now for the $O S H 1$ cis element analysis. 
3B MURAI, Koji ${ }^{1}$, SHITSUKAWA, Naoki ${ }^{1}$, TAKUMI, -09 Shigeo ${ }^{2}$, MOCHIDA, Keiichi ${ }^{3}$, KAWAURA, Kanako ${ }^{4}$, OGIHARA, Yasunari ${ }^{4}\left({ }^{1}\right.$ Dept. BioSci., Fukui Pref. Univ., ${ }^{2}$ Grad. Sch. Agr. Sci., Kobe Univ., ${ }^{3}$ RIKEN Plant Sci. Cent., ${ }^{4}$ Kihara Inst. Biol. Res., Yokohama City Univ.)

Genetic and epigenetic alteration among three homoeologous genes of a MADS-box gene in hexaploid wheat

Bread wheat (Triticum aestivum L.) is a hexaploid species with A, $\mathrm{B}$ and $\mathrm{D}$ ancestral genomes. Most bread wheat genes are present in the genome as triplicated homoeologous genes (homoeologs) derived from the ancestral species. Two class E MADS-box genes are identified in wheat, WSEP (wheat SEPALLATA) and WLHS1 (wheat Leafy Hull Sterile 1), which are homologs of OsMADS45 and $O s M A D S 1$ in rice, respectively. The three wheat homoeologs of WSEP showed similar genomic structures and expression profiles. In contrast, the three homoeologs of WLHS1 showed genetic and epigenetic alterations. The A genome WLHS1 homoeolog (WLHS1-A) had a structural alteration that contained a large novel sequence in place of the $\mathrm{K}$ domain sequence. Phylogenetic analysis indicated that the variant WLHS1-A appeared in domesticated tetraploid species. A yeast two-hybrid analysis and a transgenic study demonstrated that the WLHS1-A protein had no apparent function. The B and D genome homoeologs, WLHS1-B and WLHS1-D respectively, had an intact MADSbox gene structure, but WLHS1-B was predominantly silenced by cytosine methylation. Of the three WLHS1 homoeologs, only WLHS1-D functions in hexaploid wheat.

3B KUROKI, Rie ${ }^{1}$, NITASAKA, Eiji ${ }^{1}\left({ }^{1}\right.$ Dept. Biol., Grad. -10 Sch. Sci., Kyusyu Univ.)

Identification of the responsible gene for slender mutant delicate in the Japanese morning glory

In the Japanese morning glory (Ipomoea nil), there are various mutants not only in flower colors, but also in morphology of lateral organs. A classic morphological mutant, delicate $(d l)$ has narrow leaves and separated flowers. We succeeded to isolate the responsible gene $D L$ using STD (simplified transposon display) method. The $D L$ encodes the ortholog of FILAMENTOUS FLOWER (FIL) in Arabidopsis and GLAMINIFOLIA (GRAM) in Antirrhinum. These genes are a member of $Y A B B Y$ family transcription factor expressing in the abaxial side of lateral organs and specify the abaxial identity. In $d l$ mutant, Tpn138 was inserted in the third intron of $D L$ gene, and $D L$ transcripts were reduced. This partial loss-of-abaxial identity in $d l$ mutant causes narrow laminae and petals. FEATHERED $(F E)$ is ortholog of KANADI1 involved in abaxial identity, and fe mutation enhances the $d l$ phenotype. There are morphological mutants such as crumpled ( $\mathrm{cm}$ ) or crepe ( $\mathrm{cp}$ ) that enhance the phenotype of $d l$ mutant, thus, responsible genes for these mutations also thought to control adaxial/abaxial polarity.
3B UEDA, Nanae ${ }^{1}$, FUJITA, Takashi ${ }^{1}$, NAKAHORI, -11 Kiyoshi ${ }^{1}$, KAMADA, Takashi ${ }^{1}\left({ }^{1}\right.$ Grad. Sch. Natural Sci. Tech., Okayama Univ.)

Molecular analysis of the gravitropism defective mutant, B199, of Coprinus cinereus

We performed genetic and molecular studies on the REMI mutant strain of Coprinus cinereus, B199, which is defective in negative gravitropic response of the stipe during fruiting-body development. After a plasmid rescue, the grv1 gene responsible for the mutation was cloned as a DNA fragment that rescues the mutation. Sequencing of the genomic DNA, together with RACE experiments, identified an ORF enconding a protein of 517 amino acids. Pfam motif-finding software indicated that Grv1 is a member of the major facilitator superfamily. grv1 was also shown to be specifically transcribed in the stipe tissue by northern analysis.

3B ISHIJIMA, Junko ${ }^{1}$, IWABE, Naoyuki ${ }^{2}$, MASUDA -12 Yoshiki $^{3}$, WATANABE, Yoko, MATSUDA, Yoichi ${ }^{1}$ $\left({ }^{1}\right.$ Lab. Animal Cytogenetics, Creative Res. Initiative "Sousei", Hokkaido Univ., ${ }^{2}$ Dept. Biophysics, Grad. Sch. Sci., Kyoto Univ., ${ }^{3}$ Dept. Biol., Kawasaki Med. Sch.)

A genetic and cytological study of sexual differentiation in the freshwater sponge Ephydatia muelleri

Porifera (sponges) are the most basal phylum of extant metazoans, and are thought to possess primitive characteristics for multicellular organisms. Without formation of gonadal tissue, gametes develop in the mesohyl at a specific season of the year. There is little information concerning with factors that influence sex determination and the onset of the reproduction period. In a field study of Ephydatia muelleri at Tsukisamu-gawa in Hokkaido, we observed that sexual reproduction occurred for a short time in early summer, from June to July. Their oocytes and spermatocytes were found in separate individuals as well as other gonochoric freshwater sponges. We cloned a marker gene (E448) expressed differentially in early oogenesis using differential display method. The genetic polymorphism of the sequence detected by PCR amplification was clearly associated with the female (oocyte producing) phenotype. This suggests a possibility that sexual differentiation is controlled genetically in the population. We will also report the cytological characteristics and highly conserved karyotypes of freshwater sponge species. 
1C IWASE, Mineyo ${ }^{1}$, SATTA, Yoko ${ }^{1}$, TAKAHATA, -01 Naoyuki ${ }^{1}$ ( ${ }^{1}$ Department of Biosystems Science, The Graduate University for Advanced Studies (Sokendai), Hayama, Japan)

Ectopic sequence exchanges from $V C X / V C Y$ to $K A L X / K A L Y$ gene region on primate sex chromosomes.

The sequence comparison of the distal half of the human $\mathrm{X}$ short arm with the $\mathrm{Y}$ counterpart shows that the per-site sequence differences (p) are ca. 10\% on average. Despite this rather high extent of sex chromosomal differentiation, a 100-kb contiguous region including $K A L X / Y$ and $V C X / Y$ shows a significantly low p-value (1-5\%), suggesting frequent occurrence of conversion between $\mathrm{X}$ and $\mathrm{Y}$ chromosome. The comparisons of primate sequences reveal the presence of palindromic structures in the telomeric boundary of the region and several large repetitive elements at the centromeric end in both sex chromosomes. These structures have most likely been responsible for the conversion events in the primate sex chromosomal evolution.
1C SAITO, Shigeru ${ }^{1,2}$, SAITO, Claire ${ }^{1,2}$, SHINGAI, -02 Ryuzo ${ }^{1,2}\left({ }^{1}\right.$ Dept. Welfare Eng., Faclt. Eng., Iwate Univ., ${ }^{2}$ Iwate Univ. 21st COE Program)

Adaptive evolution of uncoupling protein-1 conferred novel nonshivering thermogenesis on ancestral eutherian mammals

Under cold conditions, eutherian mammals upregulate heat production in brown adipose tissue (BAT), and uncoupling protein (UCP)-1 is an essential factor in BAT thermogenesis. However, when and how the thermogenic function of UCP1 has been acquired remain unknown. Here we show that UCP1 evolved rapidly by positive Darwinian selection in the common ancestor of eutherians, although this gene arose in the ancestral vertebrates, since the orthologous genes were shared among most of the vertebrate species. Adaptive evolution occurred after the divergence between eutherians and marsupials, which is consistent with the fact that BAT has been found only in eutherians. Our findings demonstrate that UCP1 mediated BAT thermogenesis was acquired in primitive eutherians and conferred an efficient mechanism for body temperature regulation. Phylogenetic reconstruction of UCP1 with two paralogs (UCP2 and UCP3) among vertebrate species revealed that the gene duplication events which produced these three genes occurred in the common ancestor of vertebrates much earlier than the emergence of eutherians. Our data demonstrate that novel gene function can evolve without de novo gene duplication event.
1C KANEKO, Satoko ${ }^{1}$, TAKAHATA, Naoyuki ${ }^{1}$, SATTA, -03 Yoko ${ }^{2}\left({ }^{1}\right.$ Hayama Center for Adv. Stud., Grad. Univ. Adv. Stud., ${ }^{2}$ Dept. Biosyst. Sci., Grad. Univ. Adv. Stud.)

Evolutionary dynamics of 'functional' processed pseudogenes that stabilize Makorin1 mRNAs in mammals

The transcribed processed pseudogene Makorin1-p1 in mice is shown to stabilize Makorin1 mRNAs. We examined the presence or absence of Makorin1-derived processed pseudogenes in mice, rats, primates and some other mammals. Makorin1-p1 is specific to subgenus Mus and emerged 4.5mya. In Mus caroli, both Makorin1-p1 and another older Makorin1-derived processed pseudogene are transcribed, demostrating the rapid generation and turnover. In Catarrhini, we found two processed pseudogenes, MKRN4 and MKRNP1, which possess the conserved 'functional' the B region. These pseudogenes are transcribed in humans. For MKRN4, conservation of the B region is limited in the comparison between humans and chimpanzees. For MKRNP1, the $\mathrm{B}$ region is commonly conserved among primates. We concluded that the evolutionary dynamics of Makorin1derived processed pseudogenes in other mammals depends on how frequently processed pseudogenes occurred. When they frequently occurred as in rodents, even the region responsible for stability evolved in a neutral fashion. On the other hand, when they rarely occurred as in primates, they are subjected to negative selection, suggesting the functional role.

\section{C KUREMIYA, Eri ${ }^{1}$, SHIMADA, Mitsuyo ${ }^{1}$, -04 HUKUMOTO, Saiko ${ }^{1}$, KONDO, Rumi ${ }^{1}$ ( ${ }^{1}$ Dept. Molec. Biol. and Biochem., Ochanomizu Univ.)}

Evolutionary analysis of olfactory receptor gene family in Drosophila species

The olfactory receptor (OR) gene families encode a diverse group of 7 transmembrane proteins, G protein coupled of receptors (GPCRs), that bind diverse volatile chemicals from the environment. OR is activated by a specific set of odors and each odor activates a combination of ORs, a process known as combinational coding. To study the evolution of such OR genes, we conducted molecular evolutionary analysis on all 59 OR genes from 12 Drosophila species. We found that the rate of evolution varies extensively among ORs. Characteristics of evolutionary rates for different domains (transmembrane domains, extracellular domains and cytoplasmic domains) also differed from other GPCRs. 
1C HAMADA, Junya ${ }^{1}$, MARUKI, Takahiro ${ }^{2}$, SHIMIZU, -05 Tsunenori ${ }^{3}$, TAMURA, Koichiro ${ }^{1,2,3}\left({ }^{1}\right.$ Dept. Biol. Sci.s, Grad. Sch. Sci. Eng., Tokyo Metro. Univ., ${ }^{2}$ Dept. Biol., Faclt. Sci.s, Tokyo Metro. Univ., ${ }^{3}$ Dept. Biol. Sci.s, Grad. Sch. Sci.s, Tokyo Metro. Univ.)

Molecular evolution of nuclear mitochondrial DNA in the Drosophila nasuta subgroup

Nuclear mitochondrial DNA (numt) describes any mitochondrial DNA (mtDNA) sequences transferred from the mitochondrial genome sequence into the nuclear genome sequence. In recent years, numt has been recognized in a variety of animal and plant species. In the Drosophila melanogaster genome, several copies of numt have been found as well. In this research, we initially found a COX1 gene homologue in several species belonging to the $D$. nasuta subgroup. Genetic analyses showed that the COX1 gene homologue follows Mendelian inheritance, suggesting it was a numt carried by the nuclear genome rather than maternally inherited mtDNA. In phylogenetic analyses, the numt sequences obtained from different species were not monophyletically clustered. This addresses possibilities of more than a single origin or/and conversion events afterwards. We are testing these possibilities by examining the distribution of the numt on larval salivary gland polytene chromosomes using the in situ hybridization technique. We would like to discuss about the evolution of the numt and mtDNA in the $D$. nasuta subgroup.

$1 \mathrm{C}$

SAKATE, Ryuichi ${ }^{1,2}$, SATO, Yoshiharu ${ }^{1,2}$, MATSUYA, -06 Akihiro ${ }^{3}$, ITO, Takeshi ${ }^{2,4}$, GOJOBORI, Takashi ${ }^{2,5}$, IMANISHI, Tadashi ${ }^{2}$ ('Japan Biol. Inform. Res. Cent., Japan Biol. Inform. Consortium, ${ }^{2}$ Biol. Inform. Res. Cent., Natl. Inst. Adv. Industr. Sci. Tech., ${ }^{3}$ Life Sci. Group, Hitachi, Ltd, ${ }^{4}$ Genome Res. Dept., Natl. Inst. AgroBiol. Sci., ${ }^{5}$ Cent. Inform. Biol. DNA Data Bank Japan, Natl. Inst. Genet.)

Investigation of human-specific duplicate genes in H-InvDB Evola

Evola is a sub-database of H-InvDB, an integrated database of human transcriptome (http://h-invitational.jp/), and contains human orthologs for 11 model vertebrates including chimpanzee, mouse, cow, chicken, fugu, etc.. Orthologs are a pair of genes in different species that evolved from a common ancestral gene by speciation. Orthologous relationships are not only one-to-one but also many-to-one, one-to-many and many-to-many between two species. Most of these multi-gene relationships are thought to be results of gene duplication after speciation. How duplications have occurred is one of the most actively pursued issues in current genomics. By investigating original pipelines, we detected $29.8 \%$ of human genes have multi-gene orthologous relationships to mouse, and $23.0 \%$ to chimpanzee. Gene structure and evolutionary conservation among these duplicate genes will be discussed.
1C NISHIOKA, Tasuku ${ }^{1,2}$, KAMRUZZAMAN, -07 Muhammad $^{2}$, ABE, Kenich ${ }^{1}$, SATTA, Yoko ${ }^{1}$, NISHIBUCHI, Mitsuaki ${ }^{3}$ ( ${ }^{1}$ Department of Biosystems Science, The Graduate University for Advanced Studies (Sokendai), Kanagawa, Japan, ${ }^{2}$ Grad. Sch. Med., Kyoto Univ., ${ }^{3}$ Center for Southeast Asian Studies, Kyoto Univ.)

Revealing the history of pandemicity of Vibrio parahaemolyticus by the nucleotide sequence analysis of 11 genes

Vibrio parahaemolyticus is marine bacterium that causes seafood-borne infections. The infection by pandemic strains (a newly emerged O3:K6 clone and its serotype variants) has been spreading over the world from Southeast Asia since 1995. To understand genetic changes in V. parahaemolyticus responsible for this pandemicity, we sequenced 11 genes of 61 strains, both pandemic/non-pandemic, isolated from 11 Asian countries during the time from 1980 to 2002 . The sequenced segment is $8055 \mathrm{bp}$ in total and covered $0.16 \%$ of the entire genome, $\sim 5 \mathrm{Mb}$. The analysis of genetic diversity within and between pandemic/nonpandemic strains showed that the pandemic strains were derived from a single non-pandemic lineage and recently expanded. Furthermore, the phylogenetic analysis revealed that genetic exchanges have occurred in seven genes whereas the remaining four genes are tightly linked with each other. The tree based on these linked sequences shows that before $1995 \mathrm{~V}$. parahaemolyticus acquired unique insertion sequences that result in environmental adaptation of $V$. parahaemoluticus. This acquisition is probably responsible for the post 1995-pandemicity.

1C SUZUKI, Yoshiyuki ${ }^{1}\left({ }^{1}\right.$ Cent. Inform. Biol. DNA Data -08 Bank Japan, Natl. Inst. Genet.)

Multiple transmissions of tick-borne encephalitis virus between Japan and Russia

Tick-borne encephalitis (TBE) is a zoonotic disease causing meningitis, encephalitis, and meningoencephalitis. Tick-borne encephalitis virus (TBEV) is an etiological agent of TBE. From an analysis of five distinct sequences of Japanese TBEV, it has been proposed that Japanese TBEV was transmitted from Russia to Japan on just a single occasion $260-430$ years ago. Here thirteen distinct nucleotide sequences encoding the entire region of the envelope protein for Japanese TBEV were analyzed. It is shown, from the phylogenetic analysis, that Japanese TBEV belongs to the Far Eastern subtype, which is known to be highly pathogenic. Japanese TBEV was divided into three groups, and TBEV was inferred to have been transmitted between Japan and Russia at least three times, which were estimated to have occurred several hundred years ago. These results indicate that TBEV has not only been endemic but also transmitted multiple times to Japan. 
1C NAMBU, Takayuki ${ }^{1} \quad{ }^{1}$ Dept. BioSci., Nagahama -09 Institute of BioSci. and Tech.)

Evolution of proteobacterial flagellar genes sharing paralogous relationships

Many bacteria, including Salmonella enterica and Escherichia coli $\mathrm{K} 12$, have a single set of flagellar genes. However, an increasing number of bacterial species have been shown to possess two sets of flagellar genes, each of which is involved in either of the two distinct flagellar systems, polar and lateral flagella. They include some Vibrio and Aeromonas species. In order to gain an insight into the mechanism underlying acquisition of two flagellar gene sets in a single genome by these bacterial species, I conducted molecular data analyses with PSIBLAST against the RefSeq database. As the result, I identified 31 proteobacterial species (43 strains) whose genomes contain multiple copies of flagellar genes. On the basis of their phylogenetic relationships, I provide evidence that multiple horizontal transfers, duplications, and losses of flagellar gene clusters may have occurred in some lineages. A model for the evolution of proteobacterial flagellar gene sets sharing paralogous relationships is proposed.

1C SAWAI, Hiromi ${ }^{1}$, OTANI, Hiroto ${ }^{1}$, TANABE, -10 Kazuyuki ${ }^{1}$ ( ${ }^{1}$ Lab. Malariology, Res. Inst. Microb. Dis., Osaka Univ.)

Natural selection on the merozoite surface protein 1 gene (msp 1) of human malaria parasites

Malaria, caused by malaria parasites the genus Plasmodium, affects $300-500$ million people annually with over one million deaths. The Plasmodium merozoite surface protein 1 (MSP-1) is a promising malaria vaccine candidate. However, the highly polymorphic nature of the gene encoding this protein - $m s p 1$ presents a potential obstacle for effective vaccine development. Here, we investigate the evolutionary history of $m s p 1$ of Plasmodium vivax and construct phylogenetic trees of $m s p 1$ from $P$. vivax and seven $P$. vivax-related monkey malaria parasite species. All $P$. vivax $m s p 1$ alleles cluster in the $P$. vivax lineage and are not distributed among other species. Similarly, all $m s p 1$ alleles of the related species cluster in the their lineages. These suggest that in contrast to presumed ancient origin of $m s p 1$ polymorphism of $P$. falciparum, the origin of $P$. vivax $m s p 1$ polymorphism is relatively recent. We observed positive selection in the $P$. vivax lineage. Notably, positive selection acts on different regions of $m s p 1$ in $P$. vivax and $P$. falciparum. This study indicate that the evolutionary history of $m s p 1$ and selective pressure from host immunity differ greatly among parasite lineages.
1C TAKUMI, Shigeo ${ }^{1}$, HIROSE, Shizuko ${ }^{1}$, MATSUOKA, -11 Yoshihiro ${ }^{2}{ }^{1}$ Grad. Sch. Agr. Sci., Kobe Univ., ${ }^{2}$ Dept. BioSci., Fukui Pref. Univ.)

Molecular population genetic analysis of a wheat $\mathrm{D}$ genomespecific gene WCBF2 encoding a cold-responsive CBF transcription factor

Cold acclimation process in higher plants is partly regulated through the signal transduction pathways that lead to the induction and enhancement of expression of different sets of Cor/Lea genes. CBF/DREB transcription factor genes play important roles in development of freezing tolerance through positive regulation of the Cor / Lea gene expression. In wheat and barley, a cluster of the $C B F$ genes is assigned to a QTL of freezing tolerance $(F r-2)$ on the long arms of group 5 homoeologous chromosomes. We identified a wheat $C B F$ gene, $W C B F 2$, as a D genome-specific copy of the $C B F$ cluster and analyzed the evolutionary feature of the WCBF2 locus using the D-genome progenitor Aegilops tauschii. Our results using transgenic tobacco expressing WCBF2 strongly indicated that WCBF2 functions as a transcription factor to develop of freezing tolerance in common wheat. In contrast to the cases of non-D-genomespecific $C B F$ loci, our tests detected no signature of purifying selection at the $W C B F 2$ locus.

1C OHSHIMA, Kazuhiko ${ }^{1}$, IGARASHI, Kumiko ${ }^{1}$, -12 BABUSHOK, Daria ${ }^{2}$, KAZAZIAN, Haig ${ }^{2}\left({ }^{1}\right.$ Nagahama Inst. Bio-Sci. Tech., ${ }^{2}$ Dept. Genet., Univ. Pennsylvania)

Polymorphism of a novel exon-shuffled gene in human population

We report a unique mechanism of gene creation, whereby new combinations of functional domains are assembled at the RNA level from distinct genes and the resulting chimera is then reverse transcribed and integrated into the genome by the L1 retrotransposon. We characterized a novel gene (S5aL) created by this mechanism from an intergenic transcript between the phosphatidylinositol-4-phosphate 5-kinase (PIP5K1A) and the $26 \mathrm{~S}$ proteasome subunit (S5a) genes in a hominoid ancestor. S5aL is transcribed specifically in the testis. The S5aL gene encodes a chimeric protein combining the lipid kinase domain of PIP5K1A and the ubiquitin-binding motifs of S5a. Strong positive selection on S5aL led to its rapid divergence from the parental genes PIP5K1A and S5a, forming a chimeric protein with a distinct cellular localization, minimal lipid kinase activity, but significant affinity for cellular ubiquitinated proteins. We will describe the polymorphism of S5aL gene in human population. 
2C SATO, Jun ${ }^{1}$, UETA, Junpei ${ }^{1}$, SUZUKI, Hitoshi ${ }^{2}$, -01 TAKAHATA, Naoyuki ${ }^{3}$, MEKADA, Kazuyuki ${ }^{4}$, MORIWAKI, Kazuo ${ }^{4}$, YAMAGUCHI, Yasunori ${ }^{1}$ $\left({ }^{1}\right.$ Dept. BioTech., Faclt. Life Sci. and Tech., ${ }^{2}$ Grad. Sch. Environ. Sci., Hokkaido Univ., ${ }^{3}$ Dept. Biosyst. Sci., The Grad. Univ. Adv. Stud., ${ }^{4}$ RIKEN BRC)

The origin of Mus musculus in Japan suggested from the recombination between Hemoglobin beta adult genes.

Many individuals of the wild derived house mouse, Mus musculus, in East Asia have been examined with morphometric, chromosomal, biochemical, and genetic data. Several variants of the hemoglobin beta chain ( $\mathrm{Hbb}$ ) have also been characterized by polymorphisms of the protein electrophoresis and nucleotide sequences. There are five Hbb haplotypes, s, d, p, w1, and w2 in the wild populations of the house mouse. It has been suggested that the $p$ haplotype is the recombinant carrying the b1 gene of the $d$ haplotype and the $b 2$ gene of the w1 haplotype, and the w2 haplotype is likewise the recombinant between the w1 and unknown haplotypes. In this study, for clarifying the origin of the Japanese house mice, nucleotide sequences of the b1 and b2 genes were determined for the wild mice collected from East Asia, including Japan, China, and Russia. House mice in Japan were consequently shown to possess d-like b1 gene and w1-like b2 gene, suggesting that house mice inhabiting the most of the Japanese islands are descendants of the recombinant produced by the hybridization between different subspecies groups, castaneus and musculus, in the Eurasian continent.

2C OKAMOTO, Yuki $^{1}$, KITAMURA, Tomoko ${ }^{1}$, NOMURA, -02 Taiji ${ }^{1}$, ENDO, Takashi R. ${ }^{1}$, MIYASHITA, Naohiko T. ${ }^{1}$, NASUDA, Shuhei ${ }^{1}\left({ }^{1} \mathrm{Grad}\right.$. Sch. Agri. Kyoto Univ.)

Phylogenetic relationships of Triticum species inferred from nucleotide sequence variations in the flanking regions of a Ty1/copia-type retrotransposon located on the chromosome $5 \mathrm{~A}$ of wheat

There is a Ty1/copia-type retrotransposon in a flanking region of the $T a B x 3 A$ gene on chromosome $5 \mathrm{~A}$ of common wheat. Plylogenetic analysis of the 5' upstream region of this retrotransposon revealed that eight common wheat accessions were classified into two main clusters. This result supported the hypothesis that hexaploid wheat originated diphyletically. In order to reveal the origin of the variation found in common wheat, we studied sequence variations in flanking regions of the retrotransposon and the $T a B x 3 A$ gene among diploid, tetraploid, and hexaploid wheats. Phylogenetic analysis revealed that the nucleotide sequences were classified into two groups; one consisted of diploid wheat, and another consisted of tetraploid and hexaploid wheats. This result suggested that the sequences diverged in tetraploid wheats and that hexaploid wheat inherited the divergence.
2C OHMICHI, Yoshiaki ${ }^{1}$, ISHII, Takashige ${ }^{2}$, -03 NAKAMURA, Chiharu ${ }^{1}$, MORI, Naoki ${ }^{1}{ }^{1}$ Lab. Plant Genet., Grad. Sch. Agr. Sci., Kobe Univ., ${ }^{2}$ Lab. Plant Breeding, Grad. Sch. Agr. Sci., Kobe Univ.)

Mitochondrial microsatellite variability in the ancestral species of wheat (Aegilops speltoides Tausch.)

The genus Triticum consists of a polyploid series and is classified into four groups, einkorn (genome: AA, $2 \mathrm{n}=14$ ), emmer (AABB, $2 \mathrm{n}=28$ ), timopheevi (AAGG, $2 \mathrm{n}=28$ ) and common wheat (AABBDD, $2 \mathrm{n}=42$ ). Polyploid species in Triticum and its closely related genus, Aegilops, originated through the allopolyploidization process. The $\mathrm{A}$ and $\mathrm{D}$ genomes of common wheat originated from einkorn wheat and Ae. tauschii, respectively. Although the origin of B and G genomes has been debated, it is generally accepted that both emmer and timopheevi groups originated by amphidiploidization of the hybrid between wild einkorn wheat and most provably Ae. speltoides $(2 \mathrm{n}=14, \mathrm{SS})$. In order to reveal the origin of tetraploid wheat, molecular variation at 10 mitochondrial microsatellite loci was examined using 88 accessions of Ae. speltoides collected in the natural distribution area. Based on the results, intraspecific variation in the mitochondrial genome of Ae. speltoides is evaluated, and the origin of $\mathrm{B}$ and $\mathrm{G}$ genomes is discussed.

2C TAKEZAKI, Naoko ${ }^{1}$, NEI, Masatoshi ${ }^{2}$ ( ${ }^{1}$ The Life Sci. -04 Res. Cent., Kagawa Univ., ${ }^{2}$ Pennsylvania State Univ.)

Empirical Tests of the Reliability of Phylogenetic Trees Constructed with Microsatellite DNA

Microsatellite DNA loci or short tandem repeats (STRs) are abundant in eukaryotes and are often used for constructing the phylogenetic trees of closely related populations or species. These phylogenetic trees are usually constructed by using some genetic distance measures based on allele frequency data, and there are many distance measures that have been proposed for this purpose. In the past the efficiencies of these distance measures in constructing phylogenetic trees have been studied mathematically or by computer simulations. Recently, however, 783 STR loci have been compiled from various human populations. We have therefore investigated the relative efficiencies of different distance measures such as $D_{A}$, standard genetic distance $D_{S}$, $\mathrm{F}_{\mathrm{ST}}{ }^{*}, \mathrm{~F}_{\mathrm{ST}} /\left(1-\mathrm{F}_{\mathrm{ST}}\right)$ and $(\delta \mu)^{2}$, in constructing phylogenetic trees, as well as the effect on P1s of loci of different nucleotide repeat sizes, using these data. 
2C WATADA, Masayoshi ${ }^{1}$, MIYAKE, Hitoshi ${ }^{1}\left({ }^{1}\right.$ Dept. -05 Biol., Faclt. Sci., Ehime Univ.)

Molecular phylogenetic study of the Drosophila montium species subgroup inferred from mitochondrial DNA sequences

The Drosophila montium species subgroup is the largest in the melanogaster species group. The Oriental region is the richest in species, followed by the Afrotropical, Australian and the east Palearctic regions. We studied the phylogenetic relationships among the forty species of the montium species subgroup using the DNA sequences of mitochondrial COI and COII of these species. Phylogenetic trees based on both $C O I$ and $C O I I$ data reveal that 40 species of the subgroup make four clusters and 11 ungrouped species. The first cluster is the auraria species complex in Palearctic region and the second is most of the kikkawai species complex in the Oriental region. The third cluster consists of four species complexes that distribute in the Afrotropical and Indian regions. The fourth cluster is some of the kikkawai species complex and D. birchii in the Australian region. These results differed from the previous reports on the morphological characters and polytene chromosomes, suggesting the importance of reconstruction of the species complex of the montium species subgroup.
2C ISHIWATA, Keisuke ${ }^{1}$, SASAKI, Go ${ }^{2}$, MIYATA, -06 Takashi ${ }^{1,2}$, SU, Zhi-hui ${ }^{1,2}$ ( ${ }^{1}$ Dept. Biol. Sci.s, Grad. Sch. Sci., Osaka Univ., ${ }^{2}$ JT Biohistory Res. Hall)

Phylogeny of holometabolous insects based on nuclear genes.

Insecta (Hexapoda) consists of five orders of wingless incects (apterygota) and many orders of winged insects (pterygota). Pterygota comprises two major grorps, Palaeoptera and Neoptera, the latter includes Paraneoptera, Polyneoptera and Holometabola. It has been considered that Holometabola diverged from the insect belonging to Paraneoptera or Polyneoptera. Holometabolous insects are the most diverse insect group which accounts for more than $80 \%$ of all insect species. The phylogenetic relationships of holometabolous insects have been analyzed by morphological and molecular evidence such as $18 \mathrm{~S}$ rRNA gene. However, it is still unsolved. In this study, therefore, we used several nuclear genes coding amino acid sequence to analyze the phylogenetic relationships of holometabolous insects. The results revealed that Holometabola is separated into three main lineages: Hymenoptera, (Neuroptera + Strepsiptera + Coleoptera) and (Lepidoptera + Trichoptera + Mecoptera + Siphonaptera + Diptera), and Hymenoptera is the sister group of other two lineages. The phylogenetic relationships among holometabolous orders are also resolved completely.
2C SASAKI, Go ${ }^{1}$, ISHIWATA, Keisuke ${ }^{2}$, MIYATA, -07 Takashi ${ }^{1,2}$, SU, Zhi-hui ${ }^{1,2}$ ('JT Biohistory Res. Hall, ${ }^{2}$ Grad. Sch. Sci., Osaka Univ.)

Origin of Hexapoda analysed by multiple nuclear-DNA coded proteins

It has been thought that Hexapoda is monophyletic and closely related with Myriapoda. Recently, ecular phylogenetic analyses revealed that Hexapoda and Crustacea form a cluster, Pancrustacea. thermore, phylogenetic analysis with mitochondrial proteins by Nardi et al. (2003) suggests a basal position of Collembola (Entognatha) within Pancrustacea. This is inconsistent with monophyly of apoda. Overall, however, the phylogenetic relationships within Pancrustacea and the origin of oda remain to be resolved. To clarify these problems, we have sequenced multiple nuclear DNA-coded proteins from hexapods and other arthropods. Together with these sequences, we this time analysed ore taxa and gene data. Here we report the result of phylogenetic analysis based on the maximum elihood (ML) method.

2C KATOH, Kazutaka ${ }^{1}$, TOH, Hiroyuki ${ }^{2}$ ( ${ }^{1}$ Digital Med -08 Initiative, Kyushu Univ., ${ }^{2}$ Med. Inst. Bioregulation, Kyushu Univ.)

PartTree: an algorithm to build an approximate tree from a large number of unaligned sequences

To construct a multiple sequence alignment (MSA) of a large number (greater than approx. 10,000) of sequences, the calculation of a guide tree with a complexity of $O\left(N^{2}\right)$ to $O\left(N^{3}\right)$, where $N$ is the number of sequences, is the most time-consuming process. To overcome this limitation, we have developed an approximate algorithm, PartTree, to construct a guide tree with an average time complexity of $O(N \log N)$. The new MSA method with the PartTree algorithm can align approximately 60,000 sequences in several minutes on a standard desktop computer. The loss of accuracy in MSA caused by this approximation was estimated to be several percent in benchmark tests using Pfam. The present algorithm has been implemented in the MAFFT sequence alignment package (http://align.bmr.kyushu-u.ac.jp/ mafft/software/). 
2C AKAGI, Kazutaka ${ }^{1}$, SARHAN, Moustafa ${ }^{1}$, UEDA, -09 Hitoshi, ( ${ }^{1}$ Grad. Sch. Natural Sci. Tech., Okayama Univ., ${ }^{2}$ Dept. Biol., Faclt. Sci., Okayama Univ.)

Determination mechanism of pupation timing by unstable transcription factor Blimp-1 in Drosophila

We have recently found that Blimp-1, which induced directly by ecdysone plays important roles in determining the precise timing of FTZ-F1 expression and the timing of pupation by working as a transcriptional repressor in D. melanogaster. Analysis of regulation mechanism of Blimp-1 expression reveals that the blimp-1 gene products are only present at high ecdysone titer period because of their instability. We also obtained results to show that proline rich region of Blimp-1 carry a degradation signal for rapid turnover and this signal plays an important role to determine the timing of pupation. To evaluate the region more, we are planning to analyze related Drosophila species, which show different pupation timing.
2C YORIMITSU, Takeshi ${ }^{1}$, KIRITOOSHI, Naruto ${ }^{1}$, -11 SHIRAI, Tetsuya ${ }^{1,2}$, NAKAGOSHI, Hideki ${ }^{1}$ ( ${ }^{1}$ Natural ScGrad. Sch. Natural Sci. Tech., Univ. Okayama, ${ }^{2}$ Inst. Res. in Humanities, Univ. Kyoto)

Functional analysis of the Drosophila dve gene during ocelli formation

The Drosophila homeobox gene defective proventriculus (dve) is required for morphogenesis and functional specification of various types of cell. Adult head is derived from two eye-antennal discs, and Dve is expressed in a restricted region of eye disc where ocelli will be formed. To investigate $d v e$ function, we generated dve mutant mosaic clones in adult heads. In dve mutant heads, the number of ocelli was greatly reduced. Two homeobox genes, orthodenticle (otd) and engrailed (en), are involved in ocelli formation. So, we examined a genetic hierarchy of these genes. In otd mutants $\left(o c^{1}\right)$, En was not expressed in a presumptive ocellar region, but Dve expression was not affected in this mutants. In consistent with this observation, dve mutation also did not affect En expression. These results indicate that Dve and Otd-En pathways are both required for ocelli formation, whereas these two pathways function in paralle.

2C LIU, Qing-xin ${ }^{1}$, IKEO, Kazuho ${ }^{1}$, HIROMI, Yasushi ${ }^{2}$, -12 HIROSE, Susumu ${ }^{3}$, GOJOBORI, Takashi ${ }^{1}\left({ }^{1}\right.$ Lab. for DNA Analysis, Natl. Inst. Genet., ${ }^{2}$ Dept. Dev. Genet., Natl. Inst. Genet., ${ }^{3}$ Dept. Dev. Genet., Natl. Inst. Genet.)

Functional analysis of Drosophila TDF during the eye development

In Drosophila, the tracheas defective ( $t d f$ ) gene encodes a bZIP protein that required for the development of trachea, heart, head and neural system. TDF is highly expressed in the cells of the morphogenetic furrow (MF) region. Loss of TDF function causes defects in the eye development. Overexpression of TDF in the eye disc induced abnormal eyes. The targets of $t d f$ responsible for these responses have not been identified. To identify $t d f$ downstream genes in a comprehensive manner, we used genome-wide oligonucleotide arrays and analyzed differential gene expression in wild-type embryos versus $t d f$ mutant embryos. Upon knockout of $t d f$ function, expression of 340 genes decreased and 338 genes increased. Many of these genes can be assigned to specific aspects of the tracheal and neural system development. We also discovered $t d f$ target genes that are likely to play specific roles in eye morphogenesis. 
3C MATSUMOTO, Yoshifumi ${ }^{1}$, OZAWA, Norihiro ${ }^{1}$, -01 HIRAMATSU, Chihiro ${ }^{1}$, OKABE, Yugo ${ }^{1}$, KAWAMURA, Shoji ${ }^{1}\left({ }^{1}\right.$ Dept. Integr. BioSci.s, Grad. Sch. Front. Sci.s, Univ. Tokyo)

Spectral differentiation and molecular evolution of L/M opsin alleles in family Atelidae

The color vision of New World monkeys (platyrrhines) is unique among animals in that it is highly polymorphic. Males are dichromatic and females are either dichromatic or trichromatic. This phenotypic variation results from an allelic polymorphism of the single-locus $\mathrm{L} / \mathrm{M}$ cone opsin gene residing on the $\mathrm{X}$ chromosome. We previously identified two alleles of L/M opsin genes from a social group of black-handed spider monkeys (Ateles geoffiroyi) in Costa Rica based on the amino acid compositions at three critical sites for spectral tuning (three-site rule) and showed that the observed absorption spectra by photopigment reconstitution were very different from the predicted ones from the rule. In this study we included another atelid species, common woolly monkey (Lagothrix lagotricha), and conducted site-directed mutagenesis. We analyzed amino acid substitutions responsible for the deviation from the three-site rule and located these mutations in the phylogenetic tree of atelid monkeys.
3C HIWATASHI, Tomohide ${ }^{1}$ ( ${ }^{1}$ The Univ. Tokyo, Grad. -02 Sch. Front. Sci.s, Dept. Integr. BioSci.s)

Test of balancing selection hypothesis on the L/M opsin polymorphism in natural populations of New World monkeys by their nucleotide variation

Color vision polymorphism of New World monkeys is due to allelic variation of the single locus $\mathrm{L} / \mathrm{M}$ opsin gene residing on the $\mathrm{X}$ chromosome. This allelic polymorphism is trans specific, and has been regarded as being maintained by some form of balancing selection. However, selective advantage of trichromats, who are heterozygous on the $\mathrm{L} / \mathrm{M}$ opsin gene, has been controversial. Effective population size, central to estimate the persistence duration of a neutral variation in a population, has remained uncovered for New World monkeys. Effect of genetic drift and population size fluctuation has also not been evaluated at social group level. In this study, we examined nucleotide variation in a social group of capuchin monkeys Cebus capucinus and in that of spider monkeys Ateles geoffroyi of the L/M opsin gene and of several neutral reference regions. Our coalescence simulation revealed that in both populations the nucleotide diversity and Tajima,s D value of the L/M opsin were significantly larger than those of neutral expectations. These results indicate that balancing selection, but not demographic effects nor genetic drift, is responsible for the color vision polymorphism.
3C SUZUKI, Hitoshi ${ }^{1}$, ISHIMORI, Chicako ${ }^{1}$, NUNOME, -03 Mitsuo $^{1}$, TSUCHIYA, Kimiyuki ${ }^{2}$, YONEKAWA Hiromichi $^{3}$, MORIWAKI, Kazuo ${ }^{4}$, APLIN, Ken ${ }^{5}$ ( ${ }^{1}$ Faculuty of Env. Earth Sci., Hokkaido Univ., ${ }^{2}$ Lab. of Biores., Appl. Biol. Co., Ltd., ${ }^{3}$ RIKEN, Biores. Cent., ${ }^{4}$ Tokyo Metro. Inst. Med. Sci., ${ }^{5}$ Community Ecology Group, CSIRO Sustainable Ecosystems, Australia)

Haplotype assessment in six tightly linked gene sequences revealed multiple dispersal events of the house mouse Mus musculus from the north, central and south to Japan

We conducted phylogeographic inference on the Japanese wild mouse Mus musculus, where secondary contact with north Eurasian subspecies group (SG) of $M$. m. musculus and Southeast Asian SG of M. m. castaneus is though to have mingled. In order to assess the status of the genetic hybridization, we examined haplotype structuring in a $150-\mathrm{kb}$ stretch on Chromosome 8, determining six short segments (ca. 300-510 bp) of Fanca, Spire2, Mc1r, Tubb3, Def8, and Afgl31, which are intermittently arranged in this order. Linkage analysis for alleles of the six genes by a parsimonious method revealed a complicate state in the haplotype structures in individuals from northern Japan; alleles of the west European SG of $M$. m. domesticus were denoted in Def8 and Afg311, with high association with castaneus alleles at the neighboring genes of Spire 2 and Tubb3. Since the castaneus and domesticus elements are absent in the northern and southern parts of eastern Eurasia, respectively, it is possible that the two lineages were migrated from the south and north, respectively, and mingled in the Japanese Islands, prior to the introduction of musculus from the Korean Peninsula.

3C KIMURA, Ryosuke ${ }^{1,2}$, OHASHI, Jun ${ }^{2}$, MATSUMURA, -04 Yasuhiro $^{3}$, NAKAZAWA, Minato ${ }^{4}$, INAOKA, Tsukasa ${ }^{5}$, OHTSUKA, Ryutaro ${ }^{6}$, TOKUNAGA, Katsushi ${ }^{2}\left({ }^{1}\right.$ Dept. Forensic Med., Tokai Univ. Sch. Med., ${ }^{2}$ Dept. Human Genet., Grad. Sch. Med., The Univ. Tokyo, ${ }^{3}$ Div. Health Inform. and Education, Natl. Inst. Health and Nutrition, ${ }^{4}$ Socio-Env. Health Sci., Grad. Sch. Med., Gunma Univ., ${ }^{5}$ Dept. Env. Sociology, Faclt. Agr., Saga Univ., ${ }^{6}$ Natl. Inst. Env. Studies)

Population structure and natural selection in Oceanic human populations

A genome-wide SNP typing on an indigenous New Guinean population, Gidra, and a Polynesian population, Tongans, was carried out by using Affymetrix 500K Assay. The SNP data were analyzed together with the data of HapMap samples (YRI, CEU, CHB, JPT) provided by Affymetrix. In agreement with previous studies, our phylogenetic analysis suggested that indigenous New Guineans are closer to Asian populations than to African and European populations. A population structure analysis revealed that genetic contribution to the Tongan population is $70 \%$ Mongoloid and 30\% Australoid. A high degree of linkage disequilibrium observed in the Gidra and Tongans implies that these populations have experienced population bottlenecks. We performed a scan for natural selection by examining haplotypic variation and identified candidates of locally selected loci, which may include "thrifty genes" in Oceania. Such an approach based on evolutionary medicine, providing a clue to understand how human beings have been adapted to our environments and lifestyles, must also be contribute to revealing gene functions if it is employed together with association analyses and following functional analyses. 
3C TAKAHASHI, Aya ${ }^{1,2}$, ITOH, Masanobu ${ }^{3,4}$, KONDO, -05 Rumi ${ }^{5}$, INOMATA, Nobuyuki ${ }^{6}$, TAKANO-SHIMIZU, Toshiyuki ${ }^{1,2,7}\left({ }^{1}\right.$ Dept. Popul. Genet., Natl. Inst. Genet., ${ }^{2}$ Department of Genetics, Graduate University for Advanced Studies (SOKENDAI), Mishima, Japan, ${ }^{3}$ Dept. Appl. Biol., Grad. Sch. Sci. and Tech., Kyoto Inst. of Tech., ${ }^{4}$ Insect Biomedical Res. Cent., Kyoto Inst. of Tech., ${ }^{5}$ Dept. Biol., Ochanomizu Univ., ${ }^{6}$ Dept. Biol., Grad. Sch. Sci.s, Kyushu Univ., ${ }^{7}$ Department of Biosystems Science, Graduate University for Advanced Studies (SOKENDAI), Hayama, Japan)

Natural variants of a pigmentation-controlling gene that affects mate preference in Drosophila melanogaster

Variation in the pattern and intensity of pigmentation exists widely in diverse insect taxa. Polymorphism in thoracic trident pigmentation intensity in $D$. melanogaster is a suitable material to study the genetic basis of its natural variation. Two representative inbred lines of different geographic origins were subjected to a systematic mapping of this phenotype. The constructed recombinant lines allowed us to genetically map this phenotypic variation to a $\sim 75 \mathrm{~kb}$ region, which included a candidate gene, ebony. Further analyses by complementation test, RNAi knockdown and qRT-PCR confirmed that this locus is controlling the thoracic pigmentation pattern in these lines. This gene is also known to have pleiotropic effects on behavior. Indeed, a certain level of assortative mating between trident pigmented group and non-pigmented group was detected in a population from Iriomote, Japan. We found that a short ( 250bp) upstream region of this gene had strong association with the phenotype in this population sample. The pattern of sequence variation further provided evidence for assortative mating in a natural population.

3C INOMATA, Nobuyuki ${ }^{1}$, NAKASHIMA, Shuichi ${ }^{1}\left({ }^{1}\right.$ Dept. -06 Biol., Grad. Sch. Sci.s, Kyushu Univ.)

Short 5'-flanking regions of the Amy gene of Drosophila affect amylase gene expression and respond to food environments

Molecular population genetic studies on the duplicated amylase genes of Drosophila species have suggested that their 5'-flanking regions play an important role in evolution. Thus, we studied their functions of the Amy1 gene of Drosophila kikkawai using in vitro deletion mutagenesis followed by $P$-element-mediated germline transformation. We found two cis-regulatory elements increasing larval amylase activity on starch food, and a larval cisregulatory element responding to different foods. The presence of biological functions in the 5' -flanking region suggests that it can be subject to natural selection. When the position of an insert in the genome is a major source of between-transgenic line variation in gene expression, we should expect positive correlation in amylase activity between glucose and starch foods. In most cases, highly significant correlation was found in adults, but not in larvae. This result suggests that the position effects are environment-dependent. This implies that the fate of a new copy following gene duplication could be affected by environments as well as its genomic location when the copy involves environmentresponse cis-regulatory elements.
3C TAKAHASHI, Kazuo ${ }^{1}$, TAKANO-SHIMIZU, -07 Toshiyuki ${ }^{1,2,3}$ ( ${ }^{1}$ Div. Popul. Genet., Natl. Inst. Genet., ${ }^{2}$ Dept. Genet., Grad. Univ. Adv. Stud., ${ }^{3}$ Dept. Biosyst. Sci., Grad. Univ. Adv. Stud.)

Developmental buffering of Hsp70 under environmental stresses

Heat shock proteins (HSP), a sort of molecular chaperon, are thought to buffer development against environmental perturbations and to act as an evolutionary capacitor. HSPs constitute a small multigene family and each of HSPs in a genome has the potential to buffer environmental and genetic variation on the developmental process. In fact, Hsp70 is induced by various environmental stresses such as high/low temperature and poor nutrient. In this study, using fluctuating asymmetry of morphological traits as an index, we investigated the interaction between Hsp70A and Hsp70Ba under different environmental stresses such as high temperature and poor nutrition.

3C YUKUHIRO, Kenji ${ }^{1}$, KOMOTO, Natuo ${ }^{1}$, MITA, -08 Kazuei ${ }^{1}\left({ }^{1}\right.$ Natl. Inst. AgroBiol. Sci.)

Two types of class 2 transposable element in Bombyx mori and B. mandarina show different features in their copy numbers and target site preference.

A class 2 transposable element, 028 , which is about $280 \mathrm{bp}$ in size, was confirmed to insert at vicinity of putative transcription start site of Bombyx mandarina og gene but not to disturb the expression of og gene. To examine a distribution of 0.28 along B. mori genome, we conducted KAIKO blast search using 0.28 nucleotide sequence as query. As result, we detected about 3,000 copies. Using a part of these sequences, we carried out phylogenetic analysis and found that several sequences occurred multiplicatively, strongly suggesting that 0.28 still actively transpose in $B$. mori genome. Furthermore, we confirmed that 0.28 induced $4 \mathrm{bp}$-duplication at the insertion site. The consensus sequence of the target site duplication was AWWT. To compare the copy number of MITE-like element Organdy, which is likely to an active transposable element in $B$. mori with that of 0.28 , we conducted KAIKO-bast search using Organdy nucleotide sequence as query. Contrast to that of 0.28 , the copy number of non truncated Organdy elements was less than 20. 
3C LI, Zidong ${ }^{1}$, KUSUMI, Junko ${ }^{3}, \mathrm{KADO}$, Tomoyuki ${ }^{2}$, -09 TSUMURA, Yoshihiko ${ }^{2}$, MIDDLETON. A, Beth ${ }^{4}$, TACHIDA, Hidenori ${ }^{3}$ ( ${ }^{1}$ Dept. Biol., Faclt. Sci.s, Kyushu Univ., ${ }^{2}$ Forestry Forest Products Res. Inst., ${ }^{3}$ Dept. Biol., Faclt. Sci.s, Kyushu Univ., ${ }^{4}$ National Wetlands Res. Cent., U.S. Geological Survey, LA)

Multilocus patterns of nucleotide polymorphism and past population structure in Taxodium distichum.

We studied the nucleotide polymorphism of Taxodium distichum using samples from the Mississippi Alluvial Valley. The average value of silent site polymorphisms over 10 loci is significantly higher than that of its close relative, Cryptomeria japonica. In addition, all loci show negative Tajima's $D$, indicating excesses of rare-frequency variants compared to the expectation from the standard neutral model. This result suggests that $T$. distichum has experienced a recent population expansion. A maximum likelihood analysis confirms a rapid population expansion of $T$. distichum, which is in striking contrast to the slow population reduction of $C$. japonica. Next we investigated genetic differentiation between two varieties of $T$. distichum, bald cypress (var. distichum) and pond cypress (var. imbricarium). Three out of 10 loci show significant genetic differentiation between varieties, and especially at Acaulis5 (Acl5) and ammonium transporter $(A M T)$ loci, the $F_{\mathrm{ST}}$-values are remarkably high. However, the remaining 7 loci do not show significant genetic differentiation and their average of the $F_{\mathrm{ST}}$-value is very low, suggesting substantial gene flow still occurs between the varieties.

3C MANSAI, Sayaka ${ }^{1}$, TAMURA, Miho ${ }^{1}$, SASAKI, -10 Manami ${ }^{1}$, FUTAMURA, Norihiro ${ }^{3}$, SHINOHARA, Kenji $^{3}$, TSUMURA, Yoshihiko ${ }^{3}$, KUSUMI, Junko ${ }^{2}$, TACHIDA, Hidenori ${ }^{2}\left({ }^{1}\right.$ Dept. Biol., Grad. Sch. Sci.s, Kyushu Univ., ${ }^{2}$ Dept. Biol., Faclt. Sic., Kyushu Univ., ${ }^{3}$ Forestry Forest Products Res. Inst.)

Diversifying selection in a resistance gene family of Cryptomeria japonica

In plants, $R$-genes play an important role to recognize foreign pathogens. By analyzing genetic variation of $R$-genes, we can infer the evolutionary history of host-pathogen interaction. For herbaceous model plants, previous studies have revealed various types of natural selection acting on $R$-genes. However, natural selection in tree species is still unknown. These species may have a unique system to resist against pathogens because of long-lived perennials. Therefore, we determined nucleotide sequences of a $R$-gene (CD657) in the populations of a conifer, Cryptomeria japonica, and its close relative, Taxodium distichum. The result shows that this gene constitutes a small multigene family whose members have high similarity to each other. Interestingly, many tracts of sequence exchanges between members of the gene family are detected. Moreover, the rate $\left(d_{N}\right)$ of nonsynonymous substitutions exceeds that $\left(d_{S}\right)$ of synonymous substitutions. This $\left(d_{N} / d_{S}>1\right)$ suggests action of positive selection on amino acid substitutions in this multigene family. Based on these results, we discuss how the genetic diversity of this multigene family has been maintained in natural populations.
3C HARUSHIMA, Yoshiaki ${ }^{1,2}$, KURIKI, Satoshi, -11 MIZUTA, Youko ${ }^{1,4}$, FUJISAWA, Hironori ${ }^{3,4}$, KURATA, Nori ${ }^{1,4}$ (' ${ }^{1}$ lant Genet. lab., Natl. Inst. Genet., ${ }^{2}$ Transdisciplinary Research Integration Center, Res. Org. Inform. Systems, ${ }^{3}$ The Inst. Statistical Mathematics, ${ }^{4}$ Grad. Univ. Adv. Stud.)

Detection of interactive reproductive barriers in F2 population

Reproductive isolation is genetic mechanism to isolate species. Reproductive barriers between japonica and indica cultivars can be detected and mapped by distorted marker segregation in their $\mathrm{F}_{2}$ population. Reproductive isolation occurs by a complex interaction of factors. We will introduce a trial to detect a pair of interactive barrier loci within a gametophyte or a zygote by independence tests of marker segregations in $\mathrm{F}_{2}$ population. Since independence tests for all marker combinations covering a whole genome were serious multiple tests, statistically significant threshold were adjusted considering marker linkage. All peak values of independence tests were under the threshold. To detect false negative interactions, we partitioned a statistical value, $\kappa^{2}$ with four degree of freedom, into four independent components with a single degree freedom. Genetic models of interacting pair loci were constructed for 5 gametophytic cases and 20 zygotic ones, and $\kappa^{2}$, each component, each allele frequency and apparent viability were estimated for each model. True interactive peaks of $\kappa^{2}$ were extrapolated considering the models.

3C MIYAKE, Takashi ${ }^{1}$, TAKEBAYASHI, Naoki ${ }^{1}$, -12 SALTER, Dane ${ }^{1}$, WOLF, Diana, E. ${ }^{1}{ }^{1}$ Inst. Arctic Biol., Univ. Alaska Fairbanks)

Natural selection on imprinted genes in outcrossing Arabidopsis lyrata and self-fertilizing A. thaliana

A primary hypothesis for the evolution of genomic imprinting in genes controlling offspring growth is a conflict of interest between maternally- and paternally-inherited genes. Genomic conflict may be expected to create an arms race among maternallysilenced, growth-enhancing genes and paternally-silenced, growth-suppressing genes, resulting in rapid evolution of gene regulatory regions and/or amino acid sequences. This conflict is expected to occur in polygamous species (multiple sires/dam), but not in monogamous or self-fertilizing species. We examined sequence diversity in the regulatory regions and coding regions of two imprinted Arabidopsis genes (FWA and MEA). Molecular population genetic analysis suggests positive selection in these genes in outcrossing, polygamous Arabidopsis lyrata, but not in self-fertilizing A. thaliana. 
1D SANDA, Eri ${ }^{1,2}$, SHINOHARA, Akira ${ }^{1,2}$, SHINOHARA -01 Miki ${ }^{1}$ ( ${ }^{1}$ Inst. Prot. Res., Osaka Univ., GenomeChromosome Functions, ${ }^{2}$ Grad. Sch. Sci., Osaka Univ.)

The role of the CSM2 gene in recombination during meiosis of S. cerevisiae

The CSM2 gene of S. cerevisae is required for DNA repair in mitosis, and in chromosome segregation during meiosis. However, molecular functions of the Csm2 in homologous recombination are largely unknown. To know function of CSM2 in meiotic recombination, we characterized meiotic phenotypes of a csm2 deletion mutant. The mutant shows a delay in the repair of double-strand breaks, as a result, in formation of crossing-over. In the csm 2 mutant, coordinated action of Rad51 and Dmc1, RecA homologs required for strand exchange, is disrupted; Dmc1-focus formation is normal, but Rad51-foucs formation is partially impaired. These results suggest that $\mathrm{Csm} 2$ play a role in homology search/strand exchange steps by helping the assembly of Rad51 complexes on DNA.

1D OHYA, Tomoko ${ }^{1}$, HISHIDA, Takashi ${ }^{1}\left({ }^{1}\right.$ Res. Inst. -02 Microb. Dis., Osaka Univ.)

Regulation of the replication bypass pathways at stalled replication forks in Saccharomyces cerevisiae

Progression of replication forks is often hindered by various kinds of DNA damage, which result in increased genomic instability. In Saccharomyces cerevisiae, DNA homologous recombination (RAD52 pathway) and DNA damage tolerance ( $R A D 6$ pathway) pathways play an important role in the resumption of stalled replication fork. The $S$. cerevisiae $\mathrm{Mgs} 1$ belongs to the $\mathrm{AAA}^{+} \mathrm{AT}$ Pase family and is conserved from bacteria to humans. Current our studies have shown that an mgs1 mutation is synthetic lethal with mutations of $R A D 6$ and $R A D 18$, respectively, which are members of the RAD6 pathway and that Mgs1 negatively regulate the $R A D 6$ pathway possibly through the interaction with PCNA. These results suggest that Mgs1 act to prevent the attendant risk of increased genome instability caused by inappropriate $R A D 6$-dependent ubiquitination of PCNA. In this study, we will show the mechanisms that control access of either the $R A D 6$ or $R A D 52$ pathways to the stalled replication forks.
1D MURAYAMA, Yasuto ${ }^{1}$, KUROKAWA, Yumiko ${ }^{1}$, -03 HARUTA, Nami ${ }^{2}$, IWASAKI, Hiroshi ${ }^{1}\left({ }^{1}\right.$ Internatl. Grad. School of Arts and Sci.s Supramolecular Biol., Yokohama city Univ., ${ }^{2}$ Res. Inst. Microb. Dis., Osaka Univ.)

Molecular analysis of activation of Rhp51-dependent DNA strand exchange by the Swi5-Sfr1 complex

The fission yeast Swi5-Sfr1 complex functions as a recombinase mediator in Rhp51-dependent recombination and recmobinational repair. The complex stimulates the in vitro Rhp51dependent DNA strand exchange reaction that requires ATP hydrolysis. The Swi5-Sfr1 mediator enhances the single-stranded DNA-dependent ATPase activity of Rhp51 and thus this enhancement of ATPase should be closely related to the stimulation of strand exchange. In this meeting, we will report our on-going analysis of the functional relationships between the ATPase and strand exchange activities and will discuss about activation mechanism of presynaptic filaments made of Rhp51.

1D UENO, Masaru ${ }^{1}, \mathrm{KIBE}$, Tatsuya $^{2}$, IMANO, Ryouta ${ }^{1}$, -04 TANAKA, Genki ${ }^{1}$, KAWABATA, Naoki ${ }^{1}\left({ }^{1}\right.$ Grad. Sch. Adv. Sci. of Matter, Hiroshima Univ., ${ }^{2}$ Fuculty of Sci., Shizuoka Univ.)

Telomere loss in fission yeast pot1 disruptant is suppressed by deletion of RecQ helicase

The stalling of replication forks occurs naturally in the telomere repeats. Human RecQ helicase WRN binds to telomere and is thought to be required for inhibition of the stalling of replication forks in the telomere repeats. Pot1 specifically binds to the singlestranded telomere DNA. Deletion of S. pombe pot1 causes rapid telomere loss. However, the mechanism of the rapid telomere loss in the pot1 disruptant remains unclear. Here, we found that the telomere loss in the pot1 disruptant was suppressed by additional deletion of RecQ helicase rqh1. Moreover, the telomeres in the pot1 rqh1 double mutant were maintained by recombination. I will present details of the phenotypes of the pot 1 rqh1 double mutant and discuss possible new roles of the Pot1 and Rqh1 at telomeres. We are also investigating if DNA replication is involved in the rapid telomere loss in the pot1 disruptant. 
1D SAKAGUCHI, Chikako ${ }^{1}$, HISHIDA, Takashi ${ }^{1}\left({ }^{1}\right.$ Res. -05 Inst. Microb. Dis., Osaka Univ.)

Functional analysis of bacterial SMC-like protein, RecN in DNA bouble strand break repair.

Escherichia coli recN is a member of SMC family and has been implicated in DSB repair. Previous genetic studies have shown that RecN is required for both RecBCD- and RecF-dependent repair of DSBs. Our previous study has shown that GFP-RecN forms both nucleoid-associated and cytoplasmic foci in response to DNA damage. Cytoplasmic GFP-RecN foci are non-specific RecN aggregates, which are therefore rapidly degraded by the ClpXP protease. We also have shown that proteolytic removal of cytoplasmic RecN aggregates plays an important role in efficient recovery after release from DNA damage. In this study, to examine the role of RecN in DSB repair, we screened for recN mutants deficient in DNA damage repair. These mutants with impaired DNA repair activity were subsequently tested for the subcellular localization in response to DNA DSBs. Consequently, we have isolated several recN mutants that are not only deficient in DNA repair, but also affect nucleoid-associated focus formation, suggest the importance of RecN focus formation on nucleoid for DNA DSB repair. Future characterization of these recN mutants will define mechanisms of dynamic RecN assembly on DSB site.
1D NAKAMURA, Kenta ${ }^{1}$, SU'ETSUGU, Masayuki ${ }^{1}$, -07 KATAYAMA, Tsutomu ${ }^{1}$ ('The Dept. Molec. Biol., Grad. Sch. Pharm. Sci., Kyushu Univ.)

Transcriptional modes of the $h d a$ gene, a negative regulator for the initiation of chromosomal replication in Escherichia coli

In Escherichia coli, the nucleotide-bound forms of DnaA are important for regulation of the initiation of chromosomal replication. ATP-bound form of DnaA is active for initiation, whereas ADP-bound DnaA is not. Hydrolysis of DnaA-bound ATP is promoted in a manner depending on the Hda protein and the $\beta$ clamp (a replicase subunit). This system is called RIDA (Regulatory Inactivation of DnaA). Cellular contents of ATPDnaA rapidly decrease after initiation. This result indicates that RIDA is regulated during the cell cycle. Here, we analyzed expression pattern of Hda in the cell. Northern blot analyses revealed that $h d a g e n e$ was transcribed solely or co-transcribed with the upstream genes of $u r a A$ and $u p p$. The amounts of the $h d a$ transcripts and Hda protein were not largely changed during the cell cycle. The transcriptional level of $h d a$ increased in the exponential growth phase, which is similar to that of dnaA. In rapidly growing cells, increase in the transcription of $h d a$ might be regulated for efficient inactivating of DnaA.
1D OHSHIKA, Yasuna ${ }^{1}$, UHIDA, Kaori $^{1}$, FURUKOHRI, -06 Asako ${ }^{1}$, SHINOZAKI, Yutaka ${ }^{1}$, ISHIKAWA, Shu ${ }^{2}$, OGASAWARA, Naotake ${ }^{2}$, NOHMI, Takehiko ${ }^{3}$, MAKI, Hisaji ${ }^{1}$, AKIYAMA, Masahiro ${ }^{1}\left({ }^{1}\right.$ Dept. Biol. Sci.s, Nara Inst. of Sci. and Tech., ${ }^{2}$ Dept. Inform. Sci., Nara Inst. of Sci. and Tech., ${ }^{3}$ Div. Genet. and Mutagenesis, Natl. Inst. Health)

\section{Inhibition of DNA replication by DNA polymerase DinB}

$E$. coli DinB belongs to a member of the Y-family DNA polymerases and functions to restore progression of replication-fork stalled by DNA damage, so called bypass DNA synthesis (or translesin DNA synthesis). It has been also known that the cellular content of DinB is increased by SOS induction. We examined if increased expression of $\operatorname{din} B$ in $E$. coli produces any cellular effects. By its overproduction, cellular DNA synthesis was immediately stopped. In the cells, the nucleoid was elongated, and double strand brakes were accumulated. Using DNA synthesis assays in vitro, replicative DNA polymerase III in synthesizing DNA was inhibited by DinB. These suggest that DinB may have a role in modulating progression of DNA replication fork in vivo. We are currently investigating if the inhibitory function of $\operatorname{din} B$ in replication is evolutionally conserved using $B$. subtilis.
1D OZAKI, Shogo ${ }^{1}$, KAWAKAMI, Hironori ${ }^{1,5}$ -08 NAKAMURA, Kenta ${ }^{1}$, FUJIKAWA, Norie ${ }^{2}$ KAGAWA, Wataru' ${ }^{2}$ YOKOYAMA, Shigeyuki ${ }^{2,3}$, KURUMIZAKA, Hitoshi ${ }^{2,4}$, KATAYAMA, Tsutomu ${ }^{1}$ ( ${ }^{1}$ Dept. Molec. Biol., Grad. Sch. Pharm. Sci., Kyushu Univ., ${ }^{2}$ RIKEN Genomic Sci. Cent., ${ }^{3}$ Dept. Biophysics and Biochem., Grad. Sch. Sci., Univ. Tokyo, ${ }^{4}$ Grad. Sch. Sci. Eng., Waseda Univ., ${ }^{5}$ Cold Spring Harbor Lab., Cold Spring Harbor)

Analysis on a novel functional structure in DnaA for regulating the duplex unwinding of chromosomal replication origin

$E$. coli DnaA, a member of AAA+ family, binds ATP or ADP, and forms a multimeric complex with the replication origin (oriC). ATP-DnaA, but not ADP-DnaA, causes site-specific duplex DNA unwinding within oriC. Despite of the importance of origin unwinding for the initiation process, structural and molecular basis of oriC unwinding remains unclear. Some AAA+ proteins have been reported to form ring-like multimers and the functional central pores. We thus hypothesized that DnaA multimers formed on oriC carry a pore-like structure which has a specific function in oriC unwinding. Using a homology model of a DnaA multimer, we selected candidates for the crucial residues on the pore surface and constructed a series of mutant DnaA proteins that carry an alanine-substitution for each candidate residue. Using in vitro reconstituted systems, we found that some of these mutant DnaA proteins were specifically defective in oriC unwinding. Footprint analysis indicated that like the wild-type DnaA, these proteins formed specific multimers on oriC. These and other results indicate that these residues play a specific role in duplex unwinding within the oriC region. 
1D FURUYA, Nobuhisa ${ }^{1}$, KOMANO, Teruya ${ }^{1} \quad{ }^{1}$ Dept. -09 Biol. Sci.s, Tokyo Metro. Univ.)

Analysis of specific DNA binding of NikA protein to the origin of transfer of conjugative plasnid R64

Conjugative DNA transfer of bacterial plasmid such as F, R64 and RP4 is initiated by site- and strand-specific cleavage (nicking) into the origin of transfer, oriT. At the oriT site, protein-DNA complex called relaxosome is formed within bacterial cells. NikA is a DNA-binding protein required for the relaxosome formation at the R64 site. NMR analysis has revealed that a dimer of $\mathrm{N}$-terminal half of NikA, $\mathrm{NikA}^{1-51}$ forms a ribbonhelix-helix (RHH)-fold, that belongs to the Arc repressor-type DNA-binding protein family. In the case of Arc, two dimers binds to symmetric sequences of the target DNA as a tetramer. Although the NikA-binding sequence within R64 oriT was identified as a $17 \mathrm{bp}$ sequence (named repeat A), notable symmetric structure were not found. As the RHH structure of NikA was estimated to recognize "ACGGTA" sequence within one-half of the repeat A sequence, binding of $\mathrm{NikA}^{1-51}$ to synthetic probes containing two "ACGGTA" sequence was tested. Among those probes, one that have two directly located "ACGGTA" 5 bpapart was found to bind two NikA ${ }^{1-51}$ dimers, suggesting only one dimer of full-length NikA is bound to the repeat A sequence.

1D TAKEUCHI, Ari ${ }^{1}$, TONE, Takahiro ${ }^{1}$, MAKINO, -10 Osamu ${ }^{1}{ }^{1}$ Dept. Genet., Life Sci. Inst., Sophia Univ.)

Subcellular localization of the early mRNA of Bacillus subtilis phage $\phi 29$ depending on its replication protein, gp1

The gene 1 product (gp1) of $\phi 29$ localizes at cell membrane and has the ability to bind the early mRNA of $\phi 29$ replication genes in vitro. Here, we report the results of in situ hybridization analyses of the $\phi 29$ early mRNA in infected cells. The early mRNA was shown to localize mainly at cell poles, septal regions, and sometimes at sites scattered along the cell membrane. In contrast, the localization of the mRNA at cell poles and septal regions diminished when gp1 was not produced due to the nonsense mutation in gene 1. Furthermore, functional fusions of gp1 with GFP showed similar localization as that of $\phi 29$ early mRNA (i.e. cell poles and etc) when induced in infected or uninfected cells. These results suggested that gp1 tethers $\phi 29$ early mRNA at specific sites within a cell. $\phi 29$ early mRNA is the first example of an intracellularly localized RNA visualized in prokaryotes. Possible roles of the RNA localization during the $\phi 29$ DNA replication will be discussed.
1D TONE, Takahiro $^{1}$, TAKEUCHI, Ari ${ }^{1}$, MAKINO, -11 Osamu ${ }^{1}$ ( ${ }^{1}$ Dept. Genet., Life Sci. Inst., Sophia Univ.)

Involvement of self-association property of gene 1 product (gp1) in DNA replication of $B$. subtilis phage $\phi 29$

Gene 1 product (gp1) of $B$. subtilis phage $\phi 29$ is a replication protein, and its self-associated product has been proposed to act as the scaffold for the assembly of $\phi 29$ DNA replication machinery. To investigate this model in infected cells, we constructed nine $\phi 29$ mutants each bearing a different mutation in which a single amino acid of gp1 was substituted. Among them, DNA replication was inhibited for three mutants which had a substitution at coiled-coil region or hydrophobic region; these regions were reported to be important for the self-association of gp1 in vitro. As the results of in vivo chemical cross-linking assay, the self-association property of gp1 of the three mutants in infected cells was drastically reduced as compared to that of wild type or other mutants which replicated normally. These results suggested that the ability of gp1 to self-associate was important for $\phi 29$ DNA replication. To investigate the role(s) of the selfassociated gp1, we are searching for factors which interact with gp1 in vivo. 
2D IWAMA, Hisakazu ${ }^{1}$, MASAKI, Tsutomu ${ }^{2}\left({ }^{1}\right.$ Life Sci. -01 Res. Cent., Kagawa Univ., ${ }^{2}$ Dept. Gastroenterology and Neurology, Faclt. Med., Kagawa Univ.)

An Analysis on Influence of Selective Avoidance by Exhaustive Survey of Occurrences of microRNA Target Motifs in UTRs of 20,527 Human Genes

Selective avoidance is known as a mechanism by which genes preferentially expressed at the same time and place as a miRNA have evolved to selectively avoid miRNA target sites.

In the present study, we aimed to estimate the extent of the influence of selective avoidance on miRNA regulatory networks. We specifically posed a hypothesis that if selective avoidance is a ubiquitous or major mechanism, the miRNA target motifs in 3' UTRs would be decreased as a whole. To test this hypothesis, we made a non-redundant set of miRNA 7-nt core motifs (including seed sequences), and then examined their occurrences within the 3 ' and 5' UTRs of 20,527 human protein-coding genes and the entire genome as well.

The results revealed that miRNA target motifs appeared much more frequently than non-target motifs and were enriched in the 3' UTRs. Although this enrichment was relatively reduced in a set of 2,525 genes coexpressed with miR-124a in the prefrontal cortex, it still remained at a high level. These results suggest that miRNA target motifs are fostered by some other factors that surpass the influence of selective avoidance.

2D NAKAGAWA, So ${ }^{1}$, NIIMURA, Yoshihito ${ }^{2}$ -02 GOJOBORI, Takashi ${ }^{3}$, TANAKA, Hiroshi ${ }^{1,2}$, MIURA, Kin-ichiro ${ }^{4}\left({ }^{1}\right.$ Dept. Systems Biol., Sch. Biomedical Sci., Tokyo Med. and Dental Univ., ${ }^{2}$ Dept. Bioinform., Med. Res. Inst., Tokyo Med. and Dental Univ., ${ }^{3}$ Cent. Inform. Biol. DNA Data Bank Japan, Natl. Inst. Genet., ${ }^{4}$ Dept. Medical Genome Sci., Grad. Sch. Front. Sci., Univ. Tokyo)

Comparative genomic analysis of the nucleotide biases for translation initiation among 285 prokaryotes

Recent studies have revealed that the mechanisms of translation initiation in prokaryotes are diverse. To obtain some insight into the diversity of the nucleotide biases for translation initiation in prokaryotes, we conducted comparative analyses by using the genomes of 285 prokaryotes species. Previously we have invented a method to represent the statistical biases in nucleotide appearance at each position and evaluate the similarities of them. In this analysis, we applied this method to each species of 5' untranslated regions (5' UTRs). We then found that the ShineDalgarno (SD) sequence, a purine-rich region located upstream of the initiation codon existed among most of the species examined. The frequency patterns of the SD sequence vary depending on the taxonomy of species. However, the SD sequence did not appear among some species. The leaderless mRNA which has the initiation codon immediately at the 5' terminus was major among them. Additionally, some species show the mixed signals of them. These observations suggest that the diversity of the mechanisms of translation initiation in prokaryotes is related with sequence of the 3' end of 16S rRNA.
2D SUGIURA, Masahiro ${ }^{1,2}$, NAKAMURA, Masayuki ${ }^{1}$ -03 ( ${ }^{1}$ Grad. Sch. Natural Sci., Nagoya City Univ., ${ }^{2}$ Sugiyam a Human Res. Cent., Sugiyam Jogakuen Univ.)

Translation efficiencies of synonymous codons in chloroplasts

The 20 common amino acids, except for methionine and tryptophan, are coded for by 2 to 6 synonymous codons. Codon usage of synonymous codons is different by different organisms. The so-called codon optimization based on codon usage is often applied to improve the expression of foreign genes in host cells. However, codon usage is distinct from the translation efficiency of individual codons. We have developed an in vitro translation system from tobacco chloroplasts, which allows us to determine translation rates of chloroplast mRNAs. Using this system, we devised an in vitro assay for translation efficiencies of synonymous codons. We found that translation efficiencies of synonymous tyrosine and phenylalanine codons are opposite to their codon usage in chloroplasts. This raises an important issue for foreign gene expression in other cells.

2D CHADANI, Yuuhei $^{1}$, ONO, Katsuhiko ${ }^{1}$, ABO -04 Tatsuhiko ${ }^{1}\left({ }^{1}\right.$ Grad. Sch. Natural Sci. Tech., Okayama Univ.)

Analysis of $E$. coli mutant which requires SsrA RNA for growth

In bacteria, unusual mRNA (e.g. mRNA lacking stop codon) causes incomplete polypeptide synthesis and captures ribosome in unproductive complex at its 3' terminus. Bacterial cells deal with such a case by trans-translation system in which SsrA RNA, also known as tmRNA, binds to stalled ribosome, releases ribosome from defective mRNA, and then add peptide tag to Cterminus of nascent polypeptide for subsequent proteolysis. Because $E$. coli do not require SsrA for growth, it is desirable to obtain the $E$. coli mutant which require SsrA for growth to investigate the biological significance of trans-translation. Recently we have reported that temperature-sensitive phenotype of $\operatorname{deg} P$-deficient $E$. coli is enhanced in the absence of SsrA. Here we report another mutant which requires SsrA for growth irrespective of the temperature. The mutant has base-substitution mutation in $y h d L$ ORF, which renders Alanine at position 18 to Threonine in putative gene product YhdL. Disruption of $y h d L$ also caused the same phenotype, indicating that A18T mutation in YhdL is loss-of-function mutation and $\Delta y h d L$ and $\Delta s s r A$ are synthetically lethal. 
2D MAEHATA, Yuuki ${ }^{1}$, TOMINAGA, Akira ${ }^{1}\left({ }^{1}\right.$ Natural -05 ScGrad. Sch. Natural Sci. Tech., Univ. Okayama)

Analysis of flagellin genes in three Escherichia strains

We have analysed the nucleotide sequences of flagellin genes in three Escherichia strains (E. fergusonii, E. vulneris, E. hermanii). In the 5' and 3' -constant regions of the flagellin genes $(\mathrm{C} 1$ and $\mathrm{C} 2$ ), fli $_{\mathrm{f}}$ gene of $E$. fergusonii and $f l i C_{\mathrm{v}}$ gene of $E$. vulneris showed relatively high homology with the $f l i C_{11}$ gene of $E$. coli (H11 type strain) $(\mathrm{C} 1: 87.3 \%, \mathrm{C} 2: 89.3 \%)$ and the $f l i C_{\mathrm{Y}}$ gene of $Y$. enterocolitica ( $\mathrm{C} 1: 80.7 \%$ and $\mathrm{C} 2: 78.3 \%)$. In $E$. hermanii, two flagellin genes $\left(f l i C_{\mathrm{h}}\right.$ and $\left.f l j B_{\mathrm{h}}\right)$ were shown to be present and were highly homologous to $f l i C_{\mathrm{f}}$ and $f l i C_{11}$ gene. The $f l j A_{\mathrm{h}}$ gene, which is homologous to the fljA gene of Salmonella enterica serovar Typhimurium, was located in the downstream region of $f l j B_{\mathrm{h}}$. Moreover, 5'-UTR region of the $f l i C_{\mathrm{h}}$ gene was identical to that of the fliC(i) gene of $S$. enterica except for two bp mismatches. These results suggest that the expression of the $f l i C_{\mathrm{h}}$ gene is controlled by the $\mathrm{Flj}_{\mathrm{h}}$ repressor. The promoter region of the $f l j B_{\mathrm{h}}$ gene was also resemble to that of $f l j B(1,2)$ gene of $S$. enterica but not contained a sequence corresponding to the inverted repeat of the $\mathrm{H}$ segment that controls the alternative expression of the $f l j B(1,2)$ gene.
2D MURAKAMI, Kana ${ }^{1}$, NATORI, Yousuke ${ }^{1}$, NANAMIYA -07 Hideaki ${ }^{2}$, TOZAWA, Yuzuru ${ }^{2}$, KAWAMURA, Fujio ${ }^{1}$ $\left({ }^{1}\right.$ Dept. Life Sci., Coll. Sci., Rikkyo Univ., ${ }^{2}$ Cell-Free Sci. Tech. Res. Cent., Ehime Univ.)

Regulation of transcription of an rrn operon by relA, yjbM and ywaC in Bacillus subtilis.

Bacterial cells exert stringent response in which the RelA protein plays a key role under various environmental conditions such as amino acid starvation. We found that the relA disrupted mutant grew more slowly than the wild-type cell, and showed that transcription of the rRNA operon from its P1 promoter was greatly reduced in the relA disrupted mutant. Moreover, we found that growth arrest was observed in the relA mutant under amino acid starvation. It is thus suggested that there are some gene(s), other than relA, which are able to initiate the stringent response in B.subtilis. We successfully isolated two types of suppressor mutants from the relA disrupted mutant. The suppressor mutations were mapped in two different genes, $y j b M$ and $y w a C$, which are assigned to encode a novel type of (p)ppGpp synthetase. We next constructed double disrupted mutants (relA $y j b M$, relA $y w a C$ ) and a triple disrupted mutant (relA yjbM $y w a C$ ), and found that growth rate as well as transcription activity of the rRNA operon from its P1 promoter were almost completely restored in the triple mutant. In addition, the triple disrupted mutant cells showed a 'relaxed phenotype' under amino acid starvation.

2D SATO, Makiko ${ }^{1}$, NATORI, Yousuke ${ }^{1}$, AKANUMA -08 Genki ${ }^{1}$, NANAMIYA, Hideaki ${ }^{2}$, KAWAMURA, Fujio ${ }^{1}$ $\left({ }^{1}\right.$ Dept. Life Sci., Coll. Sci., Rikkyo Univ., ${ }^{2}$ Cell-Free Sci. Tech. Res. Cent., Ehime Univ.)

A study of novel mutants carrying a single copy of rRNA operon and its suppressor mutants in Bacillus subtilis

Bacillus subtilis has 10 copies of the rRNA operon coding for $16 \mathrm{~S}$, 23S, and 5S rRNA ( $r r n O, A, J, W, I, H, G, E, D, B)$. To find a unique function of each rRNA operon in $B$. subtilis, we constructed 7 mutants with a single copy of the $r r n$ operon and designated them as ' $r r n X^{+}$. Compared with wild-type strain, all $r r n X^{+}$strains have apparent defects in growth and competence as well as sporulation, although levels of the defects in these mutants were different from each other. It is thus likely that $B$. subtilis cells increased the copy number of rrn operons during evolution to cope with environmental changes. We also report some genetic data and growth characteristics of the suppressor mutants isolated from $r r n O^{+}, A^{+}, I^{+}, D^{+}$, and $B^{+}$. 
TANIGAWA, Osamu ${ }^{1}$, NATORI, Youske ${ }^{1}$, AKANUMA, -09 Genki ${ }^{1}$, FUKUDA, Takahito ${ }^{1}$, NANAMIYA, Hideaki ${ }^{2}$, KAWAMURA, Fujio ${ }^{1}\left(^{1}\right.$ Laboratory of Molecular Genetics and Research Information Center for Extremophile, College of Science, Rikkyo University, ${ }^{2}$ Cell-Free Sci. Tech. Res. Cent. , Ehime Univ.)

A study of a temperature sensitive mutant of $r p l B$ gene, coding for L2 ribosomal protein, and its suppressor mutants in Bacillus subtilis

To clarify the individual function of the ribosomal proteins, we tried to isolate temperature-sensitive mutants carrying point mutations in ribosomal protein genes by introducing PCR error in Bacillus subtilis. One temperature-sensitive mutant, carrying a mutation in the $r p l B$ gene which encodes the L2 ribosomal protein, was obtained. Moreover, we successfully isolated a suppressor mutant (srb-1: suppressor of $r p l B$ mutation) from this mutant. srb1 was found to be located in the promoter region of the functionally unknown gene yaaA, and enhanced the transcription of $y a a A$ gene as well as its downstream genes, $r e c F, y a a B$, and gyrAB.
2D NATORI, Yousuke ${ }^{1}$, KAWAMURA, Fujio $^{1}\left({ }^{1}\right.$ Dept. Life -10 Sci., Coll. Sci., Rikkyo Univ.)

Isolation of drug resistance mutants carrying mutations within 16S or 23S rRNA gene in Bacillus subtilis.

Bacillus subtilis, one of the best characterized gram-positive bacterium, has 10 rRNA operons in the genome. We have been interested in determining whether the function of all the rRNA operons is equivalent or not. To address this question, we successfully constructed the strains carrying only one of the rRNA operons (either $r r n O, A, J, I, E, D$ or $B$ ) in its genome. From these strains, we successfully isolated spectinomycin or erythromycin resistance mutants carrying mutations within the $16 \mathrm{~S}$ or 23S rRNA gene. We found that the phenotype of this mutation within the $16 \mathrm{~S}$ or $23 \mathrm{~S}$ rRNA gene did not appear in wild type cells since they contain 10 copies of rRNA operon.
2D KANAZAWA, Akira ${ }^{1}$, ISHII, Shiho ${ }^{1}\left({ }^{1}\right.$ Research Faclt -11 Agr., Hokkaido Univ.)

Induction of post-transcriptional gene silencing by overexpression of the CHS-A gene and a reversion of the state through epigenetic transcriptional repression in petunia

Transformation of petunia plants with the chalcone synthase-A (CHS-A) cDNA controlled by the cauliflower mosaic virus 35S promoter sometimes causes homology-dependent gene silencing. This silencing is observed as changes in flower-color because CHS-A catalyzes an essential step in the biosynthesis of anthocyanin pigments. Transcription run-on assays have confirmed that the production of white flower is due to posttranscriptional gene silencing (PTGS), and indicated that transcription of the transgene at a high rate induces PTGS. In the present study, we confirmed this observation using an experimental system that involves an induction of overexpression of the $C H S$ - $A$ gene by sugars in seedlings. We have also found that transgene transcription is repressed in a revertant line that was derived from a plant exhibiting CHS-A PTGS. We analyzed methylation status of the transgene promoter, and found that it is highly methylated in the revertant line. The expression was restored by treatment with either 5-azacytidine or trichostatin A. These results demonstrate that epigenetic inactivation of the $C H S-A$ transgene led to a reversion of the PTGS phenotype.

2D FUJIMOTO, Ryo ${ }^{1}$, KAWABE, Akira $^{2}$, KINOSHITA -12 Yuki $^{1}$, TAKASHIMA, Kazuya ${ }^{1}$, KINOSHITA, Tetsu ${ }^{1}$ MIURA, Asuka ${ }^{1}$, KAKUTANI, Tetsuji ${ }^{1}$ ( ${ }^{1}$ Dept. Integrated Genetics, Natl. Inst. Genet., ${ }^{2}$ Dept. Popul. Genet., Natl. Inst. Genet.)

Evolution of imprinted FWA gene in Arabidopsis

FWA gene in Arabidopsis thaliana is expressed specifically in endosperm. In addition, this expression is imprinted (maternalorigin-specific). Silencing in embryonic lineage and silencing of paternal copy depend on DNA methylation in the promoter region. The promoter sequence is similar to SINE and this region contains two pairs of tandem repeats, short (38-bp) and long (198bp). As the mechanism for control by methylation in FWA gene, two possibilities have been proposed: (1) SINE-like sequence is targeted for methylation, or (2) structure of tandem repeat is important. In this study, to learn the role of tandem repeat during the evolution of the transcriptional control of FWA gene, we examined the polymorphism of the $F W A$ gene and $F W A$ transcription using natural strains of Arabidopsis thaliana and related Arabidopsis species. 
3D HASUNUMA, Kohji ${ }^{1}$, YOSHIDA, Yusuke ${ }^{1,2}$, WANG, -01 Niyan ${ }^{1}\left({ }^{1}\right.$ Kihara Inst. Biol. Res., Grad. Sch. Internatl. Integrated Sci., Yokohama City Univ., ${ }^{2}$ Kishi Initiative Res. Unit RIKEN)

Functional analysis of catalase- 1 and nucleoside diphosphate kinase- 1 on the tolerance to singlet oxygen including light in Neurospora crassa

We reported that Catalase-1 (CAT-1) played an important role in protecting conidial viability in Neurospora crassa, and interacted with a light signal transducer, nucleoside diphosphate kinase-1 (NDK-1). To disclose the functional interaction between CAT-1 and NDK-1 at the genetic level, we created CAT-1 and NDK-1 double mutants by crossing single mutants of cat $-1^{R I P}$ and $n d k$ $1^{P 72 H}$. $n d k-1^{P 72 H}$ and the double mutants were more sensitive to riboflavin than the wild type and cat-1 $1^{R I P}$ under strong light. The pull down experiment suggests that His-tagged NDK-1 is bound to radioactive NADH. However, his-tagged NDK-1 ${ }^{\text {P72H }}$ was not. The double mutants showed much lower conidial viability and lost all conidial germination ability much more $c a t-1^{R I P}$, when they were cultured under continuous light. These results indicate that the interaction of CAT- 1 with NDK-1 plays an important role in supporting the survival of conidia under oxidative and lightinduced stress including singlet oxygen, and confirm our former conclusion that reactive oxygen species play an important role in light signal transduction via NDK-1 at the genetic level.
3D KISHI, Tsutomu ${ }^{1}$, IKEDA, Akemi ${ }^{1}$, NAGAO, Rina ${ }^{1}$ -03 KOYAMA, Noriko ${ }^{1}$ ( ${ }^{1}$ Kishi Initiative Res. Unit, RIKEN)

The $\mathrm{SCF}^{\mathrm{Cdc4}}$ ubiquitin ligase regulates calcineurin signaling through degradation of phosphorylated Ren 1 , an inhibitor of calcineurin

Calcineurin is the serine/threonine protein phosphatase that is required for the expression of genes involved in $\mathrm{Ca}^{2+}$-dependent processes. Calcineurin activity is regulated by the highly conserved RCN family of proteins. However, regulation of calcineurin by RCNs appears contradictory: RCNs function as autoregulatory negative feedback inhibitors of calcineurin, whereas their phosphorylation stimulates calcineurin. Here we show that phosphorylation of yeast RCN, Ren1, triggers degradation through the $\mathrm{SCF}^{\mathrm{Cdc} 4}$ ubiquitin ligase. Such degradation relieved the inhibitory effect of Rcn 1 on calcineurin signaling, thereby activating calcineurin in response to $\mathrm{Ca}^{2+}$ as well as reactivating calcineurin in response to changes in $\mathrm{Ca}^{2+}$ concentration. Phosphorylation of Rcn1 by Mck1 (a member of GSK3 family of protein kinases) triggered the degradation of Ren1 through the $\mathrm{SCF}^{\mathrm{Cdc} 4}$ ubiquitin ligase, and was stimulated by $\mathrm{Ca}^{2+}$. On the other hand, calcineurin-dependent dephosphorylation of Rcn 1 counteracted the degradation of Rcn 1 . Based on these results, we propose a model how calcineurin activity is fine-tuned to $\mathrm{Ca}^{2+}$ signals.
3D MOIZUMI, Kouta ${ }^{1}$, MURAYAMA, Tadako ${ }^{1} \quad{ }^{1}$ The -02 Dept. Appl. Material and Life Sci., Univ. Kanto Gakuin)

A novel gene which is concerned with cAMP signal transduction pathway in Neurospora crassa

In filamentous fungi, the signal transduction mediated by cyclic AMP (cAMP) is required for both hyphal development and virulence of pathogenic fungi. However, the cAMP-signal pathways in filamentous fungi remain poorly understood. Not only to control the fungal pathogenesis, but also to develop fungal application to medicine, fermentation and environmental control, analyses of the genes included in cAMP-signal pathways in filamentous fungi are indispensable. A morphological mutant of Neurospora $c r-1$ has defect in adenylyl cyclase gene. Cyclic AMP content of $c r-1$ was lower than that of the wild type. The $c r-1$ mutant grew to be colonial in contrast to the wild type which grew to be filamentous. The $\mathrm{cr}-1$ mutant recovered filamentous growth by a spontaneous suppressor mutation $w h$. The $w h$ was thought to be a mutation of the gene closely linked with eas on the left arm of the second chromosome which may be concerned with the cAMP signal transduction patway. We are trying to isolate the clone of the $W H$ gene.
3D ASAI, Kei ${ }^{1}$, MATUSZAKI, Kunihiko ${ }^{1}$, SADAIE, -04 Yoshito ${ }^{1}\left({ }^{1}\right.$ Grad. Sch. Sci. Eng., Saitama Univ.)

\section{Regulatory network of sigma factors in Bacillus subtilis}

The eighteen sigma factors are encoded on Bacillus subtilis genomic DNA. One indispensable sigma factor, five sigma factors necessary for sporulation, and a lot of sigma factors assumed to be related to an environmental stress response are included. The soil bacterium, B. subtilis, not only divides in a calm environment but also resists various environmental stresses, forming the spore under extreme nutritional stress. Many of genes that hold these activities are regulated through the mechanism of so-called network control consist of two or more transcriptional and sigma factors. In order to study this regulation, we have made the multiple disruptions of the sigma factors. Some interesting changes in phenotype were observed in this study. 
3D HASHIMOTO, Michihiro ${ }^{1}$, HARA, Hiroshi ${ }^{1}$, ASAI, -05 Kei ${ }^{1}$, SADAIE, Yoshito ${ }^{1}$, MATSUMOTO, Kouji ${ }^{1}$ ( ${ }^{1}$ Dept. Biochem. and Mol. Biol., Grad. Sch. Sci. Eng., Saitama Univ.)

Activation of extracytoplasmic sigma factors in Bacillus subtilis cells with reduced phosphatidylglycerol content

Phosphatidylglycerol (PG) is the essential phospholipid in Bacillus subtilis. Reduction of PG content in the membranes stops cell growth and eventually causes cell lysis. We have assumed that some of extracytoplasmic function (ECF) sigma factors, which are regulated directly by respective cognate transmembrane anti-sigma factors, may sense the condition of the membranes with reduced PG content. We thus examined possible inductions of two stress sigma factors and seven ECF sigma factors after the repression of the $p g s A$ gene encoding a key enzyme for PG synthesis by using specific reporter genes. We observed a remarkable induction of SigM, though many of others were not induced. Based on the results, we will discuss what kind of stress is generated in the condition of the membranes with reduced $\mathrm{PG}$.

3D YAMANOI, Rei ${ }^{1}$, NAKADATE, Hisasi ${ }^{1}$, FUKUI, -06 Reiko ${ }^{1}$, ASAI, Kei ${ }^{1}$, SADAIE, Yosito ${ }^{1}$ ( ${ }^{1}$ Area of Biochem. and Molec. Biol., Div. Life Sci., Grad. Sch. Sci. Eng., Saitama Univ.)

Analysis of repressor protein of Glucomannan utilization Operon in Bacillus subtilis

Bacillus subtilis which is a soil bacterium secretes extra celler enzymes in the response to nutrient starvation. One of these enzymes is mannanase, encoded by ydhT gene. In Glucomannan Utilization Operon(ydhMNOPQRST), it was suggested from ydhQ::lacZ reporter assay that a protein YdhQ repressed this operon. To investigate further, we constructed E. coli-B. subtilis shuttle vector carrying IPTG inducible ydhQ gene, and showed that overexpressed YdhQ works in vivo in B. subtilis. We currently study to analyze operator structure and binding condition of YdhQ in vitro.
3D FUKUI, Reiko ${ }^{1}$, ITO, Hiroto ${ }^{1}$, SHIMURA, Daisuke ${ }^{1}$, -07 ASAI, Kei ${ }^{1}$, SADAIE, Yoshito ${ }^{1}$ ( ${ }^{1}$ The Dept. Biochem. and Molec. Biol., Faclt. Sci., Sitama Univ.)

Analysis of operon structures of the regulon candidate genes of yesM / yesN two-component system in Bacillus subtilis

There are a lot of two-component systems in Bacillus subtilis. However, most of the functions of these systems are unknown. As one end of the functional analysis of these systems, DNA microarray analysis revealed the regulon candidate genes that were activated for transcription under overexpression of the response regulators.

In this study, we attempted to determine the operon structures of the regulon candidate genes of yesM / yesN two-component system by lac $Z$ assay and Nothern blot analysis. Moreover, to promote more accurate selection of regulon candidate genes, we tried to identify transcriptional activator. The results of this study suggested that regulon candidate genes of yes $M$ / yes $N$ twocomponent system were involved in metabolism of rhamnogalacturonan.

3D YANO, Koichi ${ }^{1}$, ASAI, Kei ${ }^{1}$, SADAIE, Yoshito ${ }^{1}\left({ }^{1} \mathrm{Grad}\right.$. -08 Sch. Sci. Eng., Saitama Univ.)

An in vitro transcription system using fluorescence-labeled RNA and its application in Bacillus subtilis.

There are $\sigma^{\mathrm{B}}$, seven ECF sigma factors and newly identified $\sigma^{\mathrm{I}}$, that respond to environmental stress in Bacillus subtilis. Because promoter regions where these sigma factors recognize resemble each other, it is necessary to carry out experiments to analyze ability of each sigma factors to recognize promoter sequence precisely. We established an in vitro transcription system using digoxigenin-labeled UTP. At first we used RNA polymerase holo enzyme containing $\sigma^{\mathrm{A}}$ of Bacillus subtilis and promoter DNA. Furthermore, we describe an experiment using RNA polymerase holo enzyme containing $\sigma^{\mathrm{I}}$. 
3D YOSHIMOCHI, Takeshi ${ }^{1}$, KIBA, Akinori $^{2}$, HIKICHI, -09 Yasuhumi ${ }^{2}$, OONISHI, Kouhei ${ }^{3}$ ( ${ }^{1}$ The United Grad. Sch. Agr. Sci.s, Univ. Ehime, ${ }^{2}$ Dept. Biores.-Sci., Univ. Kochi, ${ }^{3}$ Res. Inst. Molec. Genet., Univ. Kochi)

Analysis of regulation mechanism of $h r p$ regulon expression depending on culture condition in Ralstonia solanacearum

In Ralstonia solanacearum, expression of the hrp regulon, encoding type III secretion system, is induced by co-cultivation with plants and repressed when incubated in a rich medium in vitro. We have demonstrated that the hrp regulon is negatively regulated with a pleiotropic transcriptional regulator $\mathrm{PhcA}$ in a cell density-dependent manner. However, the regulation mechanism of the hrp regulon expression in response to culture condition remains to be revealed. An AraC-type transcriptional regulator, $\mathrm{HrpB}$, regulates the overall expression of the $h r p$ regulon. A component of the plant signal-dependent regulatory cascade, HrpG, is just upstream of $h r p B$. In this study, we analyzed the expression of genes that are located in the regulatory cascade. As a result, the expression of all genes including $h r p G$ in the cascade were found to be very high even in the rich media condition. On the other hand, the $h r p B$ expression was repressed at low level. Because HrpG is an orphan response regulator of a two-component system, we speculate that unidentified sensor kinase(s) might involve in HrpG phosphorylation depending on culture condition and phosphorylated HrpG regulates the $h r p B$ expression.

3D WADA, Takeo ${ }^{1}$, MORIZANE, Tomoe ${ }^{1}$, KUTSUKAKE, $^{2}$ -10 Kazuhiro ${ }^{1}\left({ }^{1}\right.$ Grad. Sch. Natural Sci. Tech., Okayama Univ.)

A novel regulatory protein involved in the activity control of the master regulator of the flagellar regulon in Salmonella

Flagellar operons are divided into three classes with respect to their transcriptional hierarchy in Salmonella. The flhDC operon is the sole one belonging to class 1 , whose products assemble into an $\mathrm{FlhD}_{4} \mathrm{C}_{2}$ heterohexamer acting as the flagellar master regulator. On the other hand, the flagellar gene expression is known to be affected by various environmental cues as well as many global regulators. For example, cells grown in the minimal medium show much reduced transcriptional activity in many flagellar genes as compared with those grown in the rich medium. In this study, we showed that this effect is due to the reduced transcription of the class 2 operons in the poor medium. This repression was found to be relieved by mutations in either one of the two non-flagellar genes $c l p P$ and $y d i V$. The $c l p P$ gene is known to encode a protease responsible for degradation of FlhD and FlhC. Consistent with this, the $c l p P$ mutation resulted in stabilization of FlhC. In contrast, the $y d i V$ mutation did not affect its stability. Purified YdiV protein was shown to bind to $\mathrm{FlhD}_{4} \mathrm{C}_{2}$ through interaction with the FlhD subunit. These results suggest that YdiV acts as an anti-FlhD $\mathrm{D}_{2}$ factor.
3D MAKINO, Kozo ${ }^{1}$, OYAMADA, Tomoya ${ }^{1}$, YOSHIDA, -11 Yusuke $^{1}$, YOKOYAMA, Katsushi ${ }^{2,3}$ ( ${ }^{1}$ Dept. Appl. Chem., Natl. Defense Acad. of Japan, ${ }^{2}$ National Institute of Advanced Industrial Science and Technology (AIST), ${ }^{3}$ Japan Science and Technology Agency (JST))

Molecular analysis of the novel two component regulatory systems that are present in enterohemorrhagic $E$. coli O157: $\mathrm{H} 7$

We identified novel two sets of two-component regulatory systems that consisted of response regulator and sensor kinase genes by comparison of two Escherichia coli genomes, the enterohemorrhagic E. coli (EHEC) O157:H7 strain RIMD 0509952 and the $E$. coli laboratory strain K-12. To search promoter regions regulated by these response regulators, the O157 DNA fragments were randomly cloned into a plasmid containing the promoterless $l a c Z$ gene as a reporter gene. Overproduction of these response regulators positively regulated transcription initiation of the operons that are present in the O157 specific regions. We also discovered that expression of one of these response regulators was positively regulated by CRPcAMP that is one of global metabolic transcriptional regulators.

3D OYAMADA, Tomoya ${ }^{1}$, YOKOYAMA, Katsushi ${ }^{2,3}$ -12 YOSHIDA, Yusuke ${ }^{1}$, MAKINO, Kozo ${ }^{1}$ ( ${ }^{1}$ Dept. Appl. Chem., Natl. Defense Acad. of Japan, ${ }^{2}$ National Institute of Advanced Industrial Science and Technology (AIST), ${ }^{3}$ Japan Science and Technology Agency (JST))

Molecular analysis of CRP-cAMP dependent promoters in enterohemorrhagic $E$. coli O157 genome

We have previously cloned CRP-cAMP dependent promoters from enterohemorrhagic $E$. coli $\mathrm{O} 157: \mathrm{H} 7$ genome by the whole genome shotgun system that is composed of lac-deletion strains and the low copy-number plasmid pMW222 carrying a promoter-less reporter gene, lacZ. We have identified many known and novel CRP-cAMP dependent promoters. For the purpose to identify CRP-cAMP binding sites within the promoter regions, we performed footprinting assays with the DNA fragments containing the novel CRP-cAMP dependent promoter region and the CRP-cAMP complex. The result showed that the identified CRPcAMP binding sites were located within the promoter regions. 
3D YOSHIDA, Yusuke ${ }^{1}$, OYAMADA, Tomoya ${ }^{1}$, -13 YOKOYAMA, Katsushi ${ }^{2,3}$, SUZUKI, Masashi ${ }^{2}$, MAKINO, Kozo ${ }^{1}\left({ }^{1}\right.$ Dept. Appl. Chem., Natl. Defense Acad. of Japan, ${ }^{2}$ National Institute of Advanced Industrial Science and Technology (AIST), '3apan Science and Technology Agency (JST))

Molecular analysis of the Lrp family transcriptional regulators

In the $E$. coli gemome, the Lrp-like transcriptional regulators are known as Lrp (leucine-responsive regulatory protein), AsnC (asparagine synthase $\mathrm{C}$ regulatory protein) and $\mathrm{YbaO}$ (unknown function). These proteins contain similar amino-acid composition. The N-terminal portions of these proteins are considered as DNA binding function and the C-terminal regions are considered as multimerization function. To elucidate the functions of these transcriptional regulators, we made the deletion strains, overproducing strains and etc. Moreover, we tested protein-protein interactions between these proteins by using a two-hybrid system.
1E UEHARA, Hiroshi ${ }^{1}$, ABE, Takashi ${ }^{1}$, TANAHASHI, -01 Kayo ${ }^{1}$, NAKAHARA, Taku ${ }^{1}$, OHSHIMA, Kazuhiko ${ }^{1}$, IKEMURA, Toshimichi ${ }^{1}$ ( ${ }^{1}$ Nagahama Inst. Bio-Sci. Tech.)

Database for Genes Contributing Sustainable World Constructed by Undergraduate Students

Metagenome analyses of mixed genomes of uncultured microorganisms derived from various environmental samples have been progressively developed, and two million or more of gene candidates are registered in the international DNA databanks without information of their gene functions.

As a bioinformatics exercise in Nagahama Institute of BioScience and Technology, a database for genes that may contribute achievement of the environmentally sustainable world in a broad sense are constructed. Students independently set and search for, on their own motivation, such genes that may contribute environmental cleanup and detoxification from a huge number of gene candidates obtained by metagenome analyses but left of no use because of lack of annotation concerning their functions. Genes newly annotated by students have been registered in the "Database for Genes Contributing Sustainable World" constructed by our group and publicized with students names. Many gene candidates that are thought to have the potentiality in the heavy metal removal, the degradation of agrichemicals, $\mathrm{PCB}$, or environmental hormones, and the bio-fuel production have been found.

The exercise text is available by requests.

1 E SANBONMATSU, Ryoko ${ }^{1,2}$, SHIMADA, Makoto ${ }^{1,2}$, -02 YAMASAKI, Chisato ${ }^{1,2}$, YAMAGUCHI-KABATA, Yumi $^{2}$, GOJOBORI, Takashi ${ }^{2,3}$, IMANISHI, Tadashi ${ }^{2}$ ( ${ }^{1}$ Japan Biol. Inform. Res. Cent., Japan Biol. Inform. Consortium, ${ }^{2}$ Biol. Inform. Res. Cent., Natl. Inst. Adv. Industr. Sci. Tech., ${ }^{3}$ Cent. Inform. Biol. DNA Data Bank Japan, Natl. Inst. Genet.)

Identification of polymorphic microsatellites on all human genes and their effects on human proteome

Microsatellites or short tandem repeats (STRs) are highly polymorphic and sometimes found on human genes. Recent studies have shown that STRs play important roles in altering protein function and causing genetic diseases. In this study, we detected STRs of 2-5 bp units and single amino acid repeats in CDS regions of all human genes extracted from comprehensive human gene catalogs including H-InvDB. In addition, we examined the repeat polymorphism by using sequence comparisons and public databases. As a result, 860 polymorphic STRs were identified from the transcript alignments of human genes. Furthermore, 549 and 565 polymorphic STRs were identified respectively on human genes by matching with dbSNP and $\mathrm{H}-$ GOLD polymorphism databases. Therefore, a total of 1,292 human genes have polymorphic STRs. Because many of those polymorphic STRs existed in CDS regions, we conclude that STRs are diversifying human protein structure and function. 
1E UEHARA, Shigeyuki ${ }^{1}$, IZUMI, Yoshiko ${ }^{1}$, KUBO, -03 Yuko ${ }^{1}$, WANG, Chi Chiu ${ }^{2}$, MINETA, Katsuhiko ${ }^{3}$, IKEO, Kazuho ${ }^{4}$, GOJOBORI, Takashi ${ }^{4}$, TACHIBANA, Masayoshi $^{5}$, SHIROISHI, Toshihiko ${ }^{6,7}$, YAMAMOTO, Hiroaki ${ }^{1}{ }^{1}$ Dept. Dev. Biol. NeuroSci. Grad. Sch. Life Sci., Tohoku Univ., ${ }^{2} \mathrm{Li}$ Ka Shing Inst. Health Sci. and Dept. Obstetrics and Gynaecology, Prince of Wales Hospital, The Chinese Univ. Hong Kong, ${ }^{3}$ Dept. Bioengineering and Bioinformatics, Grad. Sch. Inform. Sci. Tech., Hokkaido Univ., ${ }^{4}$ Cent. Inform. Biol. DNA Data Bank Japan, Natl. Inst. Genet., ${ }^{5}$ Genome Sci. Branch, Center for Bioresource-based Researches, Brain Res. Inst., Niigata Univ., ${ }^{6}$ Mouse Functional Genomics Res. Group, RIKEN GSC, ${ }^{7}$ Mammalian Genet. Lab., Genetic Strains Res. Cent., Natl. Inst. Genet.)

Analysis of the relationship between the mouse inner ear melanocytes, essential for hearing acuity, and anti-oxidant responses

Melanocytes, pigmented cells of mammals originating from the neural crests are distributed throughout the body surface to determine the coat/skin color. Also, they migrate to the stria vascularis in the inner ear cochlea. Loss of them results in loss of auditory sense, that is, the melanocytes in this region are essential for the maintenance of hearing acuity. We previously reported that Gsta4, which encodes one of anti-oxidant enzyme, was specifically expressed in the strial melanocytes of wild-type mice, and that this expression was lost in those of Mitf $f^{m i-b w}$ / Mitf ${ }^{i-b w}$ mice, having no melanocytes and are genetically deaf. Here, we report the analysis of expressions of other genes encoding anti-oxidant enzymes in the inner ear, as the first step to survey the relationship between the strial melanocytes and anti-oxidant responses.

$1 E$ NAKAMURA, Junko ${ }^{1}$, KANG, Dongchon ${ }^{2}$, -04 MATSUURA, Etsuko ${ }^{3}$ ( ${ }^{1}$ Dept. Molec. Biol. and Biochem., Ochanomizu Univ., ${ }^{2}$ Dept. Basic Med., Kyushu Univ., ${ }^{3}$ Dept. Biol., Ochanomizu Univ.)

Ultrastructure of mitochondria in D. melanogaster overexpressing mitochondrial transcription factor A

Mitochondrial transcription factor A (TFAM) is the primary component necessary for transcription initiation of mitochondrial DNA (mtDNA). TFAM has been recently shown to package mtDNA without sequence specificity and to be essential for mtDNA maintenance. In D. melanogaster, we have shown that flies overexpressing TFAM become lethal or their lifespan is significantly shortened. To further investigate this phenomenon, we analyzed ultrastructure of mitochondria in adult flies with Drosophila TFAM- $\triangle C$ gene expressed using GAL4/UAS system. The TFAM- $\triangle C$ lacks the sequences for C-terminal 25 amino acids necessary for the transcription initiation and it was expressed in all cells by the $h s-N 630-G A L 4$ driver at $30^{\circ} \mathrm{C}$. Thoraxes were sampled for observation every three days. By the 6th day after eclosion, the ultrastructure of mitochondria of flies overexpressing TFAM- $\triangle C$ was not different from those of controls. However, disorders in cristae were obvious on the 9th day and thereafter, and the changes such as sparse cristae and decreases in the electron density in matrix were observed with aging. Shortened lifespan might be related to such changes in mitochondria.

\section{$1 \mathrm{E}$ KIKUNO, Yuji ${ }^{1}\left({ }^{1}\right.$ Grad. Sch. Sci. Eng., Univ. Saitama) $-05$}

\section{Analysis of apoptotic gene in Neurospora crassa}

Apoptosis has crucial roles for the life cycle of higher eukaryotes, and it was shown that yeast has the same apoptotic mechanism. In analyzing of a Neurospora genome database, it has 2 casapases and an apaf-1-like homologue gene. In our laboratory, to reveal apoptotic activity in response to DNA damage in Neurospora, we established disrupted mutants of caspases, aif-1 and apaf-1. We report here that single mutants of each caspase show significant tolerance to hydrogen peroxide, and double mutant become more resistant than each single mutants. Now, we are examining characters of these mutants in several points including a relationship with cell cycle checkpoint.

\section{E KAWASHIMA, Kunitaka ${ }^{1}$, MURAYAMA, Tadako ${ }^{1}$ -06 ( ${ }^{1}$ The Dept. Appl. Material and Life Sci. in Univ. Kanto Gakuin)}

Genetic Analysis oh the gene resistant to an antifungal sabstance in Neurospora crassa

It has been described that $80 \%$ of plant deseases are caused by filamentous fungi. A soil bacterium which belongs to the genus Bacillus and secretes antifungal substance for the representative pathogenic fungus Rosellinia necatrix has been isolated in our laboratory. The antifungal substance secreted was highly stable to the heat-treatment of 120 degrees celsius for 20 minutes, and inhibited the growth of almost all filamentous fungi including a model fungus Neurospora. LS-MS analysis suggested that the antifungal substance is a cyclic peptide belonging to the Iturin group. We have isolated several Neurospora mutants resistant to the antifungal substance and genetically analysed in order to know the mechanism with which the antifungal substance inhibits the growth of the filamentous fungi. It may be possible to arrive at the gene by chromosome walking from the nearest gene because the Neurospora whole-genome has been sequenced and the sequence data are released. 
$1 \mathrm{E}$ NISHIHARA, Kiyoshi ${ }^{1}$, KAZAMA, Yusuke ${ }^{2}$, FUJIWARA -07 Makoto $^{2}$, KOIZUMI, Ayako ${ }^{1}$, YAMANAKA, Kahori ${ }^{1}$, ABE, Tomoko ${ }^{2}$, KAWANO, Shigeyuki ${ }^{1}\left({ }^{1}\right.$ Dept. Integr. BioSci.s, Grad. Sch. Front. Sci.s, The Univ. Tokyo, ${ }^{2}$ RIKEN Nishina Center)

Expression and function of SlWUS, a WUS homologue linked to the X-chromosome in the dioecious plant Silene latifolia

Although the dioecious plant Silene latifolia has the XY sex determination system, either the gene determining sex or the detailed process of sexual differentiation have not been unraveled yet. We isolated two copies of WUSCHEL (WUS) homologue and demonstrated the linkage of SlWUS1 to the X-chromosome and SlWUS2 to autosome. WUS is also involved in the demarcation of whorl 4, where a gynoecium differentiates, so it is expected to be a key of the female differentiation. The result of RT-PCR applied to F1 progeny by inter-strain crossing revealed that the female express both SlWUS1 of two X-chromosomes. The inactivation of SlWUS1 would be not caused either on the two X chromosomes. This suggests that the expression level of SlWUS1 is different between the male and the female.

1E MATSUKI, Kanako ${ }^{1}$, AMANO, Satoko ${ }^{1}$, HIMI, Eiko ${ }^{2}$, -08 NODA, Kazuhiko ${ }^{2}$, TAKEDA, Kazuyoshi ${ }^{2}$, TAKETA, Shin ${ }^{1}\left({ }^{1}\right.$ Faclt. Agr., Kagawa Univ., ${ }^{2}$ Res. Inst. Biores., Okayama Univ.)

Isolation and structural analyses of seed-specific polyphenol oxidase genes in barley

In barley, polyphenol oxidase (PPO) is considered a cause of browning of barley flour products, which impairs their appearance quality. To clone barley PPO genes that are specifically expressed in seeds, we tried PCR amplification of barley homologues using a primer pair designed in the conserved regions of polyploid wheat PPO genes. In the PCR experiment using barley genomic DNA as the template, two bands were amplified. We focused on the stronger band, named PPO-1, and performed its intensive analyses. Using this PCR band as a probe, a PPO-1 hitting BAC clone gene was selected. Moreover, mRNA was isolated from young caryopses and hulls and used for RT-PCR experiments. On the basis of available results, amino acid sequence for the barley PPO-1 gene was deduced. Genetic polymorphism in the PPO-1 gene was analyzed in 52 phenol insensitive barley accessions. We identified various kinds of nonsynonymous substitutions, and the 52 accessions were classified into 5 major types. Linkage analysis confirmed an exact correspondence between the PPO-1 gene polymorphism and the phenol reaction phenotype of awns.
1E OKAMOTO, Kazuhisa ${ }^{1}$, ONAI, Kiyoshi ${ }^{1}$, NISHIOKA -09 Ryo ${ }^{2}$, TOMIOKA, Satoshi ${ }^{2}$, ISHIURA, Masahiro ${ }^{1}$ $\left({ }^{1}\right.$ Cent. Gene Res., Nagoya Univ., ${ }^{2}$ Product Marketing Dept., TAITEC CORPORATION)

Development of a new shaking closed culture system with automatic cell density monitoring in real-time

Many researchers grow bacterial cells using shaking closed cultures, and measure the cell density of the culture by taking out a part of culture. But, such a sampling of the culture affected cell growth by stop the shake culture and decreasing culture volume. Especially, if infectious disease causing bacteria were used as an experimental material, such a procedure has the risk of contamination and infection. To solve these problems, we developed a monitoring system of cell density for shaking culture. The system allows easy and safety monitoring of cell density in shaking culture.

$1 \mathrm{E}$ ONAI, Kiyoshi ${ }^{1}$, MORISHITA, Megumi ${ }^{1}$, ISHIURA, -11 Masahiro ${ }^{1}\left({ }^{1}\right.$ Cent. Gene Res., Nagoya Univ.)

Comparative analysis of the cyanobacterial circadian clock genes kaiABC.

Circadian rhythms are endogenous daily cycles in physiological activities observed in cyanobacteria to human and are generated by the circadian clock. The kaiABC cluster is a clock oscillator gene set in Synechococcus sp. strain PCC 7942. kaiA and kaiBC mRNAs are transcribed separately, and their transcriptions are regulated by the clock. KaiA protein enhances the activity of kaiBC promoter $\left(\mathrm{P}_{k a i B C}\right)$ whereas KaiC represses the activity. These positive and negative feedback regulations of the $\mathrm{P}_{k a i B C}$ generate the circadian oscillation (Ishiura et al., Science 281:7680). We will report the results of comparative analysis of the $k a i A B C$ gene set in three cyanobacterial strains. 
1E AOKI, Setsuyuki ${ }^{1}$, OKADA, Ryo ${ }^{1}$, TEZUKA, Yuki ${ }^{1}$, -12 ICHIKAWA, Kazuhiro ${ }^{1}$, SANTOSH, Satbhai ${ }^{1}\left({ }^{1} \mathrm{Grad}\right.$. Sch. Inform. Sci., Nagoya Univ.)

Circadian clock-related genes in the moss Physcomitrella patens

Physcomitrella patens is an important model for the study of the evolution of plants because; 1) a highly efficient gene targeting is applicable to this plant and; 2) it is classified into bryophytes which diverged from angiosperms more than 400 million years ago. We are using $P$. patens to understand the evolution of the circadian clocks in plants. Recently, the draft genome sequence of $P$. patens has been revealed, making this plant more valuable model system than ever. Here we report the recent progress on the analyses of the moss structural homologs of the $A$. thaliana circadian clock (-related) genes.
2E FURUKOHRI, Asako ${ }^{1}$, KATAYAMA, Tsutomu ${ }^{2}$, -01 GOODMAN, F., Myron ${ }^{3}$, MAKI, Hisaji ${ }^{1}\left({ }^{1}\right.$ Grad. Sch. Biol. Sci., Nara Inst. of Sci. and Tech., ${ }^{2}$ Dept. Molec. Biol., Grad. Sch. Pharm. Sci., Kyushu Univ., ${ }^{3}$ Dept. of Biol. Sci and Chem., Univ. Southern California)

In vitro analysis of polymerase switch using E. coli DNA polymerases : A novel effect of translesion polymerase Pol IV on replicative polymerase Pol III HE

DNA lesions that block a replicative DNA polymerase are bypassed by specialized DNA polymerases. This process needs a polymerase exchange events at the primer-template junction, so called polymerase switch. Here, we studied the dynamics of polymerase during polymerase switch in vitro using proteins purified from $E$. coli, DNA poymerase III holoenzyme (Pol III HE) and DNA polymerase IV (Pol IV). Pol IV is Y-family specialized polymerase encoded by $\operatorname{din} B$ gene, which upregulated by the SOS response. We observed that Pol IV is able to take over the primertemplate from Pol III initiation complex formed on the primed circular ssDNA under the nucleotide omission, and start DNA synthesis with the $\beta$ clamp instead of Pol III*. Moreover, we show that Pol III* detached from the $\beta$ clamp immediately after the addition of Pol IV. We therefore conclude that Pol IV has a novel activity to obstruct the interaction between Pol III core and the $\beta$ clamp when it gains the primer during polymerase switch.

2E ENDO, Kingo ${ }^{1,2,3}$, TAGO, Yu-ichiro ${ }^{3}$, DAIGAKU, -02 Yasukazu ${ }^{3}$, YAMAMOTO, Kazuo ${ }^{3}$ ( ${ }^{1}$ Dept. Molec. Genet., Inst. Dev., Aging and Cancer, Tohoku Univ., ${ }^{2}$ Cent. Res. Strategy and Support, Tohoku Univ., ${ }^{3}$ Grad. Sch. life Sci., Tohoku Univ.)

The role of $R A D 30$ on repair of spontaneous DNA lesion in Saccharomyces cerevisiae.

Saccharomyces cerevisiae $R A D 30$ is a gene coding for DNA polymerase eta (Pol eta) that belongs to the Y-family polymerase. Pol eta bypasses DNA lesions including UV photoproducts, acetylaminofluorene, cisplatin-induced DNA crosslink, 8-oxoguanine, O6-methylguanine, benzo[a]pyrene adducts and abasic sites, during DNA polymerization, called translesion synthesis (TLS). Previously using haploid and diploid yeast strains, we argued that both homologous recombination (HR) pathway mediated by RAD52 and TLS pathway mediated by REV3 competed each other during the repair of spontaneously occurring replication fork arrest. Recently, it was also demonstrated that Pol eta takes part in 3'-end extension during the strand invasion in homologous recombination. In this study, we indicated three results. First, the TLS pathway by RAD30, TLS pathway by $R E V 3$ and HR pathway by $R A D 52$ compete during repair of spontaneous DNA lesions. Second, yeast RAD30 is involved in RAD52-dependent HR. Third, there is RAD30-independent extension of the 3 ' end during homologous recombination. 
2E URIO, Masahiro ${ }^{1}$, SUZUKI, Keiichiro ${ }^{1}$, KAWABATA -03 Tsuyoshi ${ }^{1}$, INOUE, Hirokazu ${ }^{1}\left({ }^{1}\right.$ Lab. Genetics, Dept. Regulation Biol., Univ. Saitama)

A role of POL32 homologue in translesion DNA synthesis in Neurospora crassa

Translesion DNA synthesis (TLS) is a system to bypass damaged DNA templates. In repair of DNA damage after UV irradiation, ncpol32, a homologue of S.cerevisiae POL32, was epistatic to N. crassa REV3 homologue. Ncpol32 mutant showed both an increasing spontaneous mutation rate and a decreasing mutation frequency by UV irradiation in dose dependent manner. Mutation spectrum of ncpol32 mutant indicated a substantial increase in the ratio of deletions and a decrease in base substitution. Then data indicate that ncpol32 has an important role in maintenance of genome stability and TLS.
2E OHNO, Mizuki ${ }^{1}$, SAKUMI, Kunihiko $^{1}$, NAKABEPPU, -05 Yusaku ${ }^{1}\left({ }^{1}\right.$ Div. Neurofunctional Genomics, Med. Inst. Bioregulation, Kyushu Univ.)

Accumulation of 8-oxoguanine, an oxidized base, in genome promotes chromosome recombination

Recently, we reported that 8-oxoguanine (8-oxoG), an oxidized guanine base, is unevenly distributed in human genome and that the distribution pattern is conserved among different individuals. Moreover, we found that regions with a high frequency of recombination and single nucleotide polymorphisms are preferentially located within chromosomal regions with a high density of 8-oxoG. Our findings suggest that 8-oxoG is one of main causes for the genomic diversity in human. In the present study, we found that both frequencies of mitotic and meiotic recombination are increased in 8-oxoG-related repair deficient mice with increased accumulation of 8-oxoG in their genome, in comparison to wild type.
2E YAMADA, Masami ${ }^{1}$, HIDAKA, Katsuhiko ${ }^{1,2}$, -04 KAMIYA, Hiroyuki ${ }^{3}$, MASUTANI, Chikahide ${ }^{4}$, HARASHIMA, Hideyoshi ${ }^{3}$, HANAOKA, Fumio ${ }^{4}$, NOHMI, Takehiko ${ }^{1}\left({ }^{1}\right.$ Div. Genet. and Mutagenesis, National Inst. Health Sci., ${ }^{2}$ Grad. Sch. Global Env. Stud., Kyoto Univ., ${ }^{3}$ Grad. Sch. Pharm. Sci., Hokkaido Univ., ${ }^{4}$ Grad. Sch. Front. BioSci., Osaka Univ.)

Mutation spectra induced by incorporation of oxidized dNTPs into DNA by human DNA polymerase eta

Oxidation of DNA precursors, i.e., dNTPs, as well as DNA is a major cause of genome instability. Here, we report that human DNA polymerase $\eta$ (h Pol $\eta$ ) incorporates oxidized dNTPs, which was present at a concentration equal to those of the four normal dNTPs in the reaction mixture, in an erroneous and efficient manner, thereby inducting various types of mutations during in vitro gap-filling DNA synthesis. The analysis of mutation spectra suggests that $\mathrm{h}$ Pol $\eta$ incorporates 2-OH-dATP opposite template $\mathrm{G}$ and incorporates 8-OH-dGTP opposite template A and slightly opposite template $\mathrm{C}$ during DNA synthesis. Besides base substitutions, incorporation of 8-OH-dGTP by $\mathrm{h}$ Pol $\eta$ enhanced the frequency of single-base frameshifts and deletions with the size of more than 100 base pairs. In addition, it enhanced mutant frequencies significantly even when the concentration of $8-\mathrm{OH}-$ dGTP was decreased to the level of $1 / 1000$ of that of the four normal dNTPs. Since h Pol $\eta$ is usually present in replication foci, we suggest that $\mathrm{h}$ Pol $\eta$ may be involved in induction of various types of mutations through the erroneous and efficient incorporation of oxidized dNTPs into DNA in human cells.

\section{E NAKATSU, Yoshimichi ${ }^{1}$, ISODA, Takuro ${ }^{1}$, PIAO, -06 Jingshu ${ }^{1}$, NAKABEPPU, Yusaku ${ }^{2}$, TSUZUKI, Teruhisa ${ }^{1}$ ( ${ }^{1}$ Dept. Med. Biophysics and Radiation Biol., Faclt. Med. Sci., Kyushu Univ., ${ }^{2}$ Div. Neurofunctional Genomics, Dept. Immunobiology and NeuroSci., Med. Inst. Bioregulation, Kyushu Univ.)}

Mutation analysis of tumor-associated genes in oxidative stress-induced tumors in the small intestine of Mutyhdeficient mice

MUTYH is a DNA glycosylase that excises 2-OH-A incorporated opposite guanine as well as adenine incorporated opposite 8oxoG, thus considered to prevent G:C to T:A transversions in mammalian cells. The Mutyh-deficient mice showed a marked predisposition to spontaneous tumorigenesis in various tissues when examined at the age of 18 months. The incidence of adenoma/carcinoma in the intestine significantly increased in Mutyh-deficient mice, as compared with wild-type mice. This high susceptibility of the mutant mice to intestinal tumordevelopment was well correlated with the condition observed in MAP (MUTYH-associated polyposis) patients. We performed mutation analysis of the tumor-associated genes amplified from the intestinal tumors of four mutant mice that had been treated with $\mathrm{KBrO}_{3}$. These tumors had G:C to T:A transversions in either $A p c$ or Ctnnb1; no tumor had simultaneous mutations in the both genes. No mutations were found in either $k$-ras (exon 2) or p53 (exon 5-8). Thus, the aberrations in the Wnt signal transduction pathway could be causatively associated with oxidative stressinduced tumor-development in the small intestines of the Mutyhdeficient mice. 
2E HIDAKA, Masumi ${ }^{1}$, KOMORI, Kayoko ${ }^{2}$, TAKAGI, -07 Yasumitsu $^{3}$, NAKATU, Yoshimichi ${ }^{1}$, TSUZUKI, Teruhisa $^{1}$, SEKIGUCHI, Mutsuo ${ }^{3}\left({ }^{1}\right.$ Faclt. Med. Sci., Kyushu Univ., ${ }^{2}$ Tokushima Bunri Univ., ${ }^{3}$ Front. Res. Cent., Fukuoka Dental College)

A novel gene involved in apoptosis induced by alkylated DNA damage

$\mathrm{O}^{6}$-Methylguanines $\left(\mathrm{O}^{6}\right.$-meG), produced in DNA by the action of alkylating agents, induces apoptosis in mismatch repair proteinsdependent manner when they are not repaired. Mice defective in both Mgmt and Mlh1 genes, the former being involved in DNA repair while the latter in mismatch recognition, predispose to a large number of tumors, indicating the anti-carcinogenic roles of these gene products. To understand the molecular mechanism of $\mathrm{O}^{6}$-meG-induced apoptosis, we isolated MNU-resistant cells from MNU-sensitive $\mathrm{Mgmt}^{-/}$cells by using a gene trap method. One of the mutants isolated is unable to activate caspase-3, a hallmark for the induction of apoptosis. The gene defective in the mutant was identified as a novel gene. When expression of the gene was inhibited by siRNA, induction of apoptosis was partially suppressed. Furthermore, the mutant cells exhibited an increased mutant frequency after treatment with MNU as compared to that of control cells, implying that the gene product may play an important role in maintenance of genetic stability through an induction of apoptosis.

2E KODAMA, Ken-ichi ${ }^{1}$, HORIUCHI, Takashi ${ }^{1}\left({ }^{1}\right.$ Division -08 of Genome Dynamics, National Institute for Basic Biology, Okazaki, Japan)

Micro-evolution of $E$. coli strains able to utilize xylitol as a carbon source

Generally, E. coli cannot utilize xylitol (Xyl), a sugar alcohol, as a carbon source. This characteristic of the K12 strain, for example, cannot be changed by any mutagenic treatments. However, the same treatment of the $\mathrm{C}$ strain generates clones able to catabolize Xyl. Unlike the K12 strain, the C strain possesses a set of genes the products of which can catabolize the two structure-isomeric sugar alcohols, Ribitol and Arabitol. One of these enzymes, Ribitol Dehydrogenase (RDH), also has dehydrogenase activity for Xyl, albeit at a very low level. Thus, when the RDH gene is amplified or mutated, the $\mathrm{C}$ strain acquires the ability to grow in xylitol medium. Here, using C and K12 with a set of the genes able to catabolize Ribitol and Arabitol, we investigated the relationship between the ability to catabolize Xyl and genomic changes. We found that RDH gene amplification conferred the ability to utilize Xyl on the K12 strain, whereas two successive spontaneous mutations, an IS insertional mutation and a basechange mutation, enable the $\mathrm{C}$ strain to catabolize Xyl.
2E OTSUJI, Tomomi ${ }^{1}$, MATSUMURA, Hiroyuki ${ }^{2}$, -09 SUZUKI, Tatsuya ${ }^{2}$, NAKATSUJI, Norio ${ }^{3}$, TADA Takashi $^{2}$, TADA, Masako ${ }^{1,3}\left({ }^{1}\right.$ ReproCELL Inc., ${ }^{2}$ Stem Cell Eng., Inst. Front. Med. Sci., Kyoto Univ., ${ }^{3}$ Dev. Diff., Inst. Front. Med. Sci., Kyoto Univ.)

Cre-inverted loxP system rapidly induces chromosome elimination and intrachromosomal recombination in mouse ES hybrid cells

The Cre-loxP system contributes to create a new chromosome composition. Especially, two loxP sites existing in opposite directions induce chromosomal elimination through sister-chromatid recombination at the loxP sites. We have developed plasmid vectors (CEC) that efficiently induce the elimination of tagged ES chromosomes in the hybrid cells between mouse embryonic stem (ES) cells and somatic cells. Here we showed that Cre-induced recombination products were detected within one day in $4 \mathrm{~N}$ ES hybrid cells at high frequencies, resulting in the rapid elimination of a set of chromosomes. Cre also increased the rate of mitotic recombination around the CEC-tagged region on the same DNA strands. We demonstrated that various simple sequence repeats became the targets of mitotic recombination leading to loss of heterozygosity.

2E IWAMA, Hisakazu ${ }^{1}$, HORI, Yukio ${ }^{2}{ }^{1}$ Life Sci. Res -10 Cent., Kagawa Univ., ${ }^{2}$ Inform. Tech. Cent., Kagawa Univ.)

Evaluation of Noncoding Sequence Alignment Procedures by Species-Specific Insertion Sequences

To investigate the features of noncoding sequence alignment procedures in quantitative manners, we focused on speciesspecific insertion sequences (SSISs). Since the SSISs have been inserted into the genomes after the divergence of the distinct species from their common ancestor, if the SSISs are aligned to any regions, they are reasoned as falsely aligned sites. Thus, we have used SSISs as negative control probes and estimated specificity and robustness of five aligners using 8-kb upstream sequences of 1,490 human-mouse-rat ortholog trios. As a result, REALIGNER showed the highest specificity relative to BLASTZ, LAGAN, MAVID and AVID. Furthermore REALIGNER held its high specificity for insertion-rich sequences, suggesting potential availability to detect regulatory elements embedded in insertion sequences. 
3E TSUCHIDA, Masashi ${ }^{1}$, NASUDA, Shuhei ${ }^{1}$, ENDO, -01 Takashi R. ${ }^{1}{ }^{1}$ Grad. Sch. Agri., Kyoto Univ.)

PCR-based identification of dissected rye $1 R$ chromosomes in common wheat

Rye chromosome $1 \mathrm{R}$ contains many agronomically useful genes. Common wheat lines carrying dissected segments of $1 \mathrm{R}$ are useful in mapping 1R-specific DNA markers and in assembling DNA clones into a contig map. In the 78th Annual Meeting of the Genetic Society of Japan, we reported the process of developing common wheat lines carrying dissected $1 \mathrm{R}$ chromosomes using the gametocidal system. So far, we have established $57 \mathrm{lR}$ dissection lines. However, most of which are hemizygous for dissected $1 \mathrm{R}$ segments, and, when we use them, we need to select plants carrying the $1 \mathrm{R}$ segments in the progeny. We developed PCR-based 1R-specific EST markers and made it possible to identify $1 R$ segments with specific breakpoints by PCR analysis. In this meeting we report the details of the $1 \mathrm{R}$ dissection lines and a strategy for identifying critical plants from the progeny of hemizygous $1 \mathrm{R}$ dissection lines.
3E YOKOTA, Etsuko ${ }^{1}$, MURATA, Minoru ${ }^{1}\left({ }^{1}\right.$ Res. Inst. -03 Biores., Okayama Univ.)

Meiotic behavior of a ring chromosome in Arabidopsis thaliana

The minichromosome 2S-D found in a transgenic Arabidopsis plant is a dicentric ring chromosome, and has no telomere DNA. Despite this dicentric and ring form, 2S-D was transmitted to the next generations, which suggests that the telomeres are not required for stable transmission through meiosis. However, the telomeres are known to play an important role in starting chromosome synapsis at prophase I of meiosis. In this study, therefore, we investigated whether chromosome pairing occur between the two 2S-D chromosomes. For pachytene to metaphase I, two 2S-D chromosomes were sometimes observed to associate each other. This association seemed to result from the chromosome pairing. Immunolabeling with anti-ZYP1 antibody as a probe, clearly visualized the circular synaptonemal-complex structure between two 2S-D chromosomes at pachytene stage. This result indicates that the telomere DNA sequences are not necessary for chromosome pairing when the homologous chromosomes are close enough each other. Recombinations were thought to have occurred between the two 2S-D chromosomes, because smaller ring chromosomes than 2S-D appeared in the next generation.
3E KOMEDA, Norio ${ }^{1,2}$, NONOMURA, Kenichi ${ }^{1}$, -02 KURATA, Nori ${ }^{1}$ ( ${ }^{1}$ The Dept. Plant Genet., Natl. Inst. Genet., ${ }^{2}$ The Grad. Sch. Life Sci., Grad. Univ. Adv. Stud.)

Isolation and characterization of OsPot1, the rice homologue of yeast Pot 1 gene

Telomeres are the essential DNA-protein complexes to protect chromosomal termini from degradation and end-to-end fusion. Pot1 (protection of telomeres) is a single strand telomeric DNA binding protein thought to function in telomere maintenance by protecting chromosome end from being misrecognized by DNA repair machineries and by regulating telomerase accessibility to the telomere. In this study, we identified and characterized the rice homologue of fission yeast Pot 1 gene. We found single Pot 1 orthologue in the rice genome by database search, and named as OsPot1. Two kinds of splice variants were obtained by RT-PCR. OsPot1 was expressed in all tissues examined, leaf, root, callus, and panicle. To examine cellular localization of OsPot1, we raised a polyclonal antibody against recombinant OsPot1. In immunostaining study, OsPot1 signals were detected as punctated foci in the interphase nuclei. Furthermore, we observed OsPot1 at the end of pachytene chromosomes, confirming the telomere localization of OsPot1. In the presentation, we will report the results of more detailed cytological observations.

\author{
3E NAGAKI, Kiyotaka ${ }^{1}$, KASHIHARA, Kazunari ${ }^{1}$, \\ -04 MURATA, Minoru ${ }^{1}$ ( ${ }^{1}$ Res. Inst. Biores., Okayama \\ Univ.)
}

Analysis of centromere-specific histone H3 homologues from tobacco

Centromeres have an important role to segregate chromatids into daughter cells at mitosis and meiosis. The centromeric DNA assembles specific proteins for the role. In the proteins, centromere-specific histone H3 (CENH3) locates only on active centromeres among investigated species. We attempted to isolate CENH3 from tobacco to characterize centromeres of the species. As a result, we found a CENH3 homolog in a tobacco-EST database. Based on the sequence, we made a set of PCR primers, and used the primers for PCR. The PCR amplified two possible candidates. Sequencing of the PCR products revealed the sizes of the homologues, NtCENH3-1 (468 bp, $156 \mathrm{aa}$, and $17.6 \mathrm{kDa}$ ) and NtCENH3-2 (471 bp, $147 \mathrm{aa}$, and $17.8 \mathrm{kDa}$ ). Similarities of those two NtCENH3s are 97.9\% (in DNA) and 98.7\% (in amino acid). Since the N-terminal sequences were identical, we raised a polyclonal antibody using a synthetic peptide from the region. The antibody showed an 18-kDa band in an immunoblotting with extract from tobacco leaves. In immunostaining using the antibody, signals appeared preferentially on the centromeres of tobacco. Thus, the antibody will be a powerful tool to characterize the centromeres of tobacco. 
3E MATSUNAGA, Eiko ${ }^{1}$, ASIDA, Yasuyo ${ }^{1}$, ENDO, -05 Takashi R. ${ }^{1}$, NASUDA, Syuhei ${ }^{1}$ ( ${ }^{1}$ Grad. Sch. Agri., Kyoto Univ.)

Immunological identification of the microtubule-attachment region on barley chromosome $7 \mathrm{H}$ supports the hypothesis that the centromeres of chromosomes $7 \mathrm{HS}^{*}$ and $7 \mathrm{HS}^{* * *}$ are neocentromeres.

We identified telocentric chromosomes $7 \mathrm{HS}^{*}$ and $7 \mathrm{HS}^{* * *}$ with aberrations in the centromeric region of barley chromosome $7 \mathrm{H}$. Although the $7 \mathrm{HS}^{*}$ and $7 \mathrm{HS}^{* *}$ chromosomes lacked the centromere-specific repeatitive sequences, they transmit normally though mitotic and meiotic divisions, indicating that centromeres were functional. On the origin of the functional centromeres of the aberrant chromosomes, two hypotheses were proposed; (1) the functional centromere of normal chromosome $7 \mathrm{H}$ locates not in the primary constriction but in the region distal to the C-band missing in the aberrant chromosome $7 \mathrm{HS}^{* * *}$. Thus, $7 \mathrm{HS}^{*}$ and $7 \mathrm{HS}^{* *}$ utilizes the same centromere sequence as normal chromosome $7 \mathrm{H}$. (2) Loss of functional centromeric sequences caused the formation of new centromeres (neocentromeres) in abberant chromosomes. To test these hypotheses, we analyzed the position of microtubule attachment and localization of the proteins (CENH3 and MAD2) specific to functional centromeres on the barley chromosome $7 \mathrm{H}$. We found that microtubule attached to the primary constriction of chromosome $7 \mathrm{H}$ where CENH3 and MAD2 localized, indicate that formation of neocentromeres in $7 \mathrm{HS}^{*}$ and $7 \mathrm{HS}^{* * *}$ are more plausible.

3E SAKAI, Kazuhiko ${ }^{1}$, ENDO, Takashi R. ${ }^{1}$, NASUDA, -06 Shuhei ${ }^{1}\left({ }^{1}\right.$ Grad. Sch. Agri., Kyoto Univ.)

Structures of barley telocentric chromosomes $7 \mathrm{HS}^{*}$ and $7 \mathrm{HS}^{* *}$ that do not carry centromere-specific repetitive sequences

We induced structural aberrations in the centromeric region of barley chromosome $7 \mathrm{H}$ using the gametocidal system, and identified two telocentric chromosomes (7HS" and $\left.7 \mathrm{HS}^{* * *}\right)$. Our early study revealed that the $7 \mathrm{HS}^{*}$ and $7 \mathrm{HS}^{* *}$ chromosomes showed normal mitotic and meiotic transmission although they lacked the centromere-specific repetitive sequences. The structures of the aberrant chromosomes were only analyzed by $\mathrm{C}$ banding, therefore the details of their breakpoints were obscure. The objective of this study is to identify the breakpoints of the $7 \mathrm{HS}^{*}$ and $7 \mathrm{HS}^{* *}$ chromosomes with respective to the saturated genetic map consisted of barley EST markers. We employed 15 newly identified telocentric and acrocentric chromosomes of chromosome $7 \mathrm{H}$ to allocate EST markers into physical intervals in the pericentromeric region of chromosome $7 \mathrm{H}$. As a result, we found one EST marker that was present in two acrocentric chromosomes of $7 \mathrm{HL}$ but not in the chromosomes $7 \mathrm{HS}^{*}$ and $7 \mathrm{HS}^{* *}$. Thus, the breakpoints of the chromosome $7 \mathrm{HS}^{*}$ and $7 \mathrm{HS}^{* * *}$ were deduced to be in the interval between the most proximal marker and the one adjacent to it.
3E KURIHARA, Daisuke ${ }^{1}$, NODA, Masanori ${ }^{1}$, KAWABE, -07 Akira $^{1}$, FUJIMOTO, Satoru ${ }^{1}$, UCHIYAMA, Susumu ${ }^{1}$, MATSUNAGA, Sachihiro ${ }^{1}$, FUKUI, Kiichi ${ }^{1}\left({ }^{1}\right.$ Dept. BioTech., Grad. Sch. Eng., Osaka Univ.)

Aurora kinase is required for chromosome segregation in plants

Post-translational modifications of core histone tails play crucial roles in chromatin structure and function. Although phosphorylation of Ser10 and Ser28 of histone H3 (H3S10ph and H3S28ph) are ubiquitous among eukaryotes, the phosphorylation mechanism during the cell cycle remains unclear. In the present study, H3S10ph and H3S28ph in tobacco BY-2 cells were observed in the pericentromeric regions during mitosis. GFPtagged AtAUR3 (Arabidopsis thaliana Aurora kinase 3) shows similar localization of H3S10ph and H3S28ph in BY-2 cells. Moreover, the Aurora kinase inhibitor Hesperadin inhibited the kinase activity of AtAUR3 in phosphorylating both H3S10 and H3S28 in vitro. Consistently, Hesperadin inhibited both H3S10ph and H3S28ph during mitosis in BY-2 cells. Hesperadin treatment increased the ratio of metaphase cells, micronuclei was frequently observed, and lagging chromosomes, caused by the delay and failure of sister chromatid separation, were observed at anaphase and telophase in Hesperadin-treated BY-2 cells. The data obtained here suggest that plant Aurora kinases play a role in chromosome segregation.

3E MATSUNAGA, Sachihiro $^{1}$, TAKATA, Hideaki $^{2}$, -08 MORIMOTO, Akihiro ${ }^{1}$, MA, Nan ${ }^{1}$, KURIHARA, Daisuke $^{1}$, ONO-MANIWA, Rika ${ }^{1}$, UCHIYAMA, Susumu ${ }^{1}$, FUKUI, Kiichi ${ }^{1}$ ( ${ }^{1}$ Dept. BioTech., Grad. Sch. Eng., Osaka Univ., ${ }^{2}$ Natl. Inst. Genet.)

A novel cascade to regulate chromosome cohesion during mitosis

Cohesion between sister chromatids is essential for proper chromosome segregation in mitosis. In vertebrate mitotic cells, most cohesin is removed from the chromosome arms, but centromeric cohesin is protected by shugoshin until the onset of anaphase. However, the mechanism of this protection of centromeric cohesion is not well understood. We report that prohibitin2 (PHB2) is involved in the regulation of sister chromatid cohesion during mitosis in HeLa cells. PHB2 was previously identified as a novel chromosome protein in proteome analyses using isolated human metaphase chromosomes. EGFPPHB2 was mainly localized in the cytoplasm and prophase chromosomes. We demonstrate that depletion of PHB2 by RNA interference causes premature sister chromatid separation. In the absence of PHB2, cohesin is dissociated from centromeres during early mitosis, although the centromeric localization of shugoshin is preserved. Thus, our findings suggest that, in addition to the shugoshin, PHB2 is also required to protect the centromeric cohesion during early mitosis and that its function is essential for proper mitotic progression. 
$3 \mathrm{E}$

JOHZUKA, Katsuki ${ }^{1,2}$, HORIUCHI, Takashi ${ }^{1,3}\left({ }^{1}\right.$ Natl. Inst. Basic Biol., ${ }^{2}$ School of Life Science, Graduate University for Advanced Studies (SOKENDAI), ${ }^{3}$ School of Advanced Science, Graduate University for Advanced Studies (SOKENDAI))

Association of condensin with the replication fork barrier sequence within the rDNA cluster in Saccharomyces cerevisiae

Condensin is a central player for condensation and segregation of chromosomes. To know the recognition of chromosomal sites and the association mechanism of condensin are important to understand the condensation of chromosomes. In Saccharomyces cerevisiae, it has been known that condensin is mainly localized at the nucleolus. Previously we reported the association of condensin with the replication fork barrier (RFB) site within the ribosomal RNA gene (rDNA) cluster. Replication fork blocking protein, Fob1p, is required for condensin association with the RFB site. Here, we found that condensin was bound to the short DNA fragment containing RFB sequences inserted at the ectopic chromosomal site (outside of the rDNA cluster) in a FOB1dependent fashion. We intend to discuss the mechanism of condensin association with the RFB site.
3E GUO, Shiguang ${ }^{1}$, NAKAMA, Jyunya ${ }^{2,3}$, TAKAMOTO, -11 Akimi ${ }^{2,4}$, OGURA, Hisakazu ${ }^{1,2}$ ( ${ }^{1}$ Lab. Biol., Grad. Sch. Education, Okayama Univ., ${ }^{2}$ Lab. Biol., Faclt. Education, Okayama Univ., ${ }^{3}$ Fujitsu Business Systems, ${ }^{4}$ Kotoura Junior High School)

Number of active and inactive NORs in three kinds of polyploids in Allium grayi (Liliaceae)

Allium grayi Regel comprises tetraploid $(2 \mathrm{n}=4 \mathrm{x}=32)$, pentaploid $(2 \mathrm{n}=5 \mathrm{x}=40)$ and hexaploid $(2 \mathrm{n}=6 \mathrm{x}=48)$ plants, however basic chromosome complements $(x=8)$ of the species have not yet been cleared. It is known that fluorescence in situ hybridization (FISH) method can detect all the NORs as fluorescence signals and AgNOR staining method make possible to detect only transcriptionally active NORs as AgNOR signals. The FISH experiment using $18 \mathrm{SrDNA}$ probe revealed ten signals in tetraploids, 12 in pentaploids and 14 in hexaploids, respectively. The results of AgNOR staining indicated that six signals in tetraploids, seven in pentaploids and eight in hexaploids. The results showed that the number of active NORs and inactive NORs in tetraploids of the species were found to be six and four, those in pentaploids seven and five, and those in hexaploids eight and six, in each, for the first time. It is estimated that the basic chromosome complement $(x=8)$ of the species contains one or two active NORs and one inactive NORs.

3E S-GARMAROODI, Hamid ${ }^{1}$, TAGA, Masatoki ${ }^{1}\left({ }^{1}\right.$ Div -12 Biomolecular Sci., Grad. Sch. Natural Sci. Tech., Okayama Univ.)

Dosage effects of fungal B chromosome: a case for the conditionally dispensable chromosome (CDC) in a plantpathogenic ascomycete Nectria haematococca MPVI

Certain strains of a plant-pathogenic ascomycete $N$. haematococca MPVI are known to contain B chromosome called CDC in the genome. In order to analyze the dosage effects of B chromosome in fungi, we chose this fungus as a model and attempted to artificially accumulate B chromosome (CDC) by protoplast fusion. Two transformants that contained the same CDC and were marked by hygromycin B and geneticin resistant genes, respectively, were fused under the selection by both antibiotics. Most of the obtained fusants were shown to have two copies of CDCs by PCR, PFGE-Southern, and FISH. Then, two fusants with two CDCs were further marked by different auxotrophic mutations and subjected to protoplast fusion. The finally obtained one prototrophic fusant had four CDCs. Chromosome counting and PFGE analysis suggested that those fusants had the same chromosome complements as the fusion parents except the additional CDCs. In the phenotype analysis, accumulation of CDC did not affect the vegetative morphology but elevated virulence to host pea plant. It also caused sexual sterility manifested by barren perithecia in the matings even for the fusants with two CDCs. 
3E M-MAHMOUD, Ahmed ${ }^{1}$, TAGA, Masatoki ${ }^{1}$ ( ${ }^{1}$ Div. -13 BioSci., Grad. Sch. Natural Sci. Tech., Okayama Univ.)

450-kb B Chromosome in the Filamentous Ascomycetes Nectria haematococca mating population I (anamoph, Fusarium solani f. sp. cucurbitae)

Pulsed field gel electrophoresis and Southern blotting analysis on $N$. haematococca mating population I (MPI) showed that a certain strain has a ca. 450-kb extra DNA band with TTAGGG telomere sequences in its genome. Subsequent cytological observation on mitotic metaphase revealed this DNA band to represent a minute $\mathrm{B}$ chromosome of almost 0.4-0.6um in length and occur as a single copy in the genomes of somatic nuclei. Chromosome painting FISH using total DNA of $450-\mathrm{kb}$ band as probe suggested that this chromosome was not the derivative of A chromosomes. In the crossing experiments performed between the strain harboring that chromosome and another strain without any B chromosomes, tetrad and random ascospore analyses showed that this chromosome was transmitted to the progenies through meiosis in a regular Mendelian manner, which seems peculiar compared with other B chromosomes found in different organisms. Because of its small size, this $450-\mathrm{kb}$ B chromosome is though to be easy to manipulate with genetic engineering techniques, and therefore, may be a promising candidate for constructing artificial chromosome in filamentous fungi.

3E SATO, Hajime ${ }^{1}$, MATSUDA, Muneo ${ }^{1}\left({ }^{1}\right.$ Dept. Biol., -14 Sch. Med., Kyorin Univ.)

A Recombination Hotspot in Both Sexes of Drosophila ananassae

$\mathrm{F}_{1}$ males between the $E P$ and the $O m(2 C) \operatorname{Arc}$ strains of Drosophila ananassae exhibit enhancement of recombination in the proximal region of the 2nd chromosome. This rate of enhancement is 40-50 times as high that at the standard map units $(0.4 \mathrm{cM})$. Using molecular markers, we found that more than $80 \%$ of the recombination in the $\mathrm{Om}(2 \mathrm{C})$-Arc region occurred between the $45 \mathrm{C}$ and $46 \mathrm{C}$ bands of the proximal region of the right arm of the $2 \mathrm{nd}$ chromosome within about $1 \mathrm{Mb}$. A similar enhancement of recombination, 10-20 times as high that at the standard map units, was also observed in females heterozygous for $E P$ and $O m(2 C) A r c$ strains, the female recombination hotspot was also located within the same interval as the male recombination hotspot. We next demonstrated that recombination occurred in high frequency at the same location in both the males and females. Interestingly, a high percentage of the recombinant chromosomes in the hotspot region were found to be recessive lethals $(7 \%)$. Based on these results, we discuss the mechanisms of enhancement of recombination in both sexes of $D$. ananassae. 